\title{
Abstracts from the 17th Annual Scientific Conference of Montenegrin Sports Academy "Sport, Physical Activity and Health: Contemporary Perspectives": Cavtat, Dubrovnik, Croatia. 2-5 April 2020
}

\author{
Edited by Dusko Bjelica', Stevo Popovic', Selcuk Akpinar²
}

Affiliations: 'University of Montenegro, Faculty for Sport and Physical Education, Niksic, Montenegro, ${ }^{2}$ Nevşehir Hacı Bektaş Veli University, Department of Physical Education and Sports, Nevşehir, Turkey

Correspondence: D. Bjelica, University of Montenegro, Faculty for Sport and Physical Education, Narodne omladine bb, Niksic, Montenegro, E-mail:dbjelica@ucg.ac.me

@MJSSMontenegro

MEETING ABSTRACTS FROM MSA DUBROVNIK 2020 CONFERENCE

http://mjssm.me/?sekcija $=$ article\&artid $=500$

\section{Invited speakers}

\section{S1}

PREVALENCE OF PHYSICAL ACTIVITY AMONG ADOLESCENTS FROM 105 COUNTRIES

Adilson Marques'

'University of Lisbon, Faculty of Human Kinetics, CIPER, Lisbon, Portugal Correspondence: Adilson Marques (adncmpt@gmail.com)

Physical activity (PA) is a beneficial health behaviour. To present the worldwide, regional, and national prevalence of PA participation in adolescents. The study was based on surveys of adolescents' population from several countries worldwide. The sample comprised 520,533 adolescents (251,788 boys, 268,745 girls), from 105 countries and regions. Most adolescents engaged in PA up to 3 times/week (57.1\%). The prevalence of engaging in PA every day decreases over the age from $28.2 \%$ at age of $11-12$ years (95\% CI: 27.4, 29.0) to $21.2 \%$ at age of $16-17$ years (95\% CI: $20.3,22.0)$ among boys, and from $19.4 \%$ (95\% CI: $18.5,20.2)$ to $11.1 \%$ (95\% CI: 10.1, 12.0) among girls. For boys and girls who engaged in PA 5-6 times/day, the prevalence increases from countries with the lowest human development index to countries with the highest. Cambodia $(7.3 \%, 95 \%$ CI: 3.8, 10.8), Philippines $(7.7 \%, 95 \%$ CI: 5.6, 9.7), Sudan (8.8\%, 95\% CI: 4.7, 12.9), Timor-Leste (8.9\%, 95\% CI: $5.5,12.3)$, and Afghanistan (10.1\%, 95\% CI: 6.1, 14.1) were the countries with the lowest prevalence of sufficient PA. National, regional and worldwide data on the prevalence of PA in adolescents highlights the importance of improving the global levels of PA, especially in girls.

\section{S2}

\section{FOOTBALL REFEREES - THE THIRD TEAM}

Goran Gabrilo

'University of Split, Faculty of Kinesiology, Split, Croatia

\section{Correspondence: Goran Gabrilo (goran.gabrilo@kifst.hr)}

Football game is getting faster every day and players' skills and abilities are improving with every new generation of players. Therefore, physical fitness is very important for football referees. Referees need to be in good physical shape to keep up with a modern football pace. The physiological aspects and movement patterns of football referees during football game are a well-researched topic during last decade. Also, importance of regular training in football referees is well emphasized in scientific publications, so training sessions are monitored by national football federations and UEFA/FIFA. High physical load of the game, and the stress it generates on the cardio-vascular and musculoskeletal systems can increase a risk of injury. Accordingly, appropriate medical status and low injury occurrence are one of the most important aspects of successful refereeing. Medical status, risk factors, type and frequency of injuries among football referees are recent research areas. Psychological and emotional aspects of refereeing are also very important. Being a football referee is not just being close to the ball. Coping skills (dealing with game stress, stress of making mistake, influence of the referee's decision on players, coach staff or public) are very important. Decision-making process in football referees is intertwined with high level of interaction with players, high physical demands and lot of cues during football match. Some of these aspects are discussed in this paper.

\section{S3 NO CHILD'S LAND: SHRINKING OF CHILDREN'S ROAMING SPACE AND ITS IMPLICATIONS FOR PHYSICAL ACTIVITY Gregor Starc \\ 'University of Ljubljana, Faculty of Sport, Ljubljana, Slovenia Correspondence: Gregor Starc (Gregor.Starc@fsp.uni-lj.si)}


Diminishing of children's physical activity has been identified as one of the largest public health challenges of the 21st century. Although the search for the culprit of children's growingly sedentary lifestyles often ends up with time displacement caused by modern communication technology, physical activity is not reduced only by the prolonged duration of screen time but also by the lack of space that used to support children's independent mobility in its various forms. Ethnographic research, carried out on a large sample of families in Slovenia, provides vivid evidence that from WWII onwards children's roaming space has shrunk with every generation and resulted in a virtually bigger but spatially smaller environment in which contemporary children can still independently move.

\section{S4}

\section{DEVELOPING TALENTED FOOTBALL PLAYERS - GENES OR ENVIRONMENT?}

Hugo Sarmento ${ }^{1}$

'University of Coimbra, Faculty of Sport Sciences and Physical Education, Research Unit for Sport and Physical Activity (CIDAF), Coimbra, Portugal

\section{Correspondence: Hugo Sarmento (hg.sarmento@gmail.com)}

The specificities of how expertise is achieved in Association Football, are being repeatedly investigated by many researchers through a variety of approaches and scientific disciplines (Sarmento et al., 2018). The classic 'nature' vs 'nurture' or in this instance 'gene - environment' debate has long received debate in the scientific community pertaining to the study of sporting and athletic performance. The purpose of this communication was to discuss the most significant scientific evidence in the context of football talent identification and development. The reviewed studies identified the most frequently addressed topics in this area of research: (1) specificity and volume of practice; (2) psychological factors; (3) technical and tactical skills; (4) anthropometric and physiological factors; (5) relative age effect; (6) performance-related genes, (7) injury-related genes, (8) body composition-related genes, and; (9) cardiac adaptations. The aforementioned research can assist scouting and coaching networks at football clubs in identifying and developing talented young players, which may hold successful implications and increase financial return.

\section{S5}

\section{INCLUSIVE PHYSICAL EDUCATION - UNIVERSAL CONCEPT AND DIVERSE IMPLEMENTATIONS}

\section{Sandra Heck ${ }^{1}$}

${ }^{1}$ University of Luxembourg, Faculty of Humanities, Education and Social Sciences, Luxembourg, Luxembourg

Correspondence: Sandra Heck (sandra.heck@uni.lu)

Inclusive (Physical) Education is a central target of educational policies worldwide. While the concept of inclusion in schools is generally based on the same idea that all children shall have the chance to participate equally, the implementation differs significantly and the number of demands for changes in the existing practices increasingly grows. The goal of this study is to provide an overview of the global situation of inclusive physical education and to highlight cross-cultural supportive measures. A meta-synthesis of thematically related studies combined with a qualitative comparative approach allows providing insights into the different existing socio-cultural conditions and demands for inclusive physical education. As a result, it is underlined that the universal concept of inclusive physical education meets on the national ground diverse levels and forms of implementation. Still, despite those differences, common demands to overcome exclusive traditions can be figured out and used to di- rect into supportive measures. The findings more generally prove that a universally accepted concept alone does not make a change when it is not followed by concrete practical support for those being asked to put it into practice.

\section{S6}

EQUINE ASSISTED ACTIVITIES \& THERAPIES PHYSIOLOGICAL, MOTOR, AND PSYCHOLOGICAL EFFECTS

Selcuk Akpinar ${ }^{1}$

${ }^{1}$ Nevsehir Haci Bektas Veli University, Department of Physical Education and Sport, Nevsehir, Turkey

Correspondence: Selcuk Akpinar (sakpinar@nevsehir.edu.tr)

Although the technology can be a key to solve medical problems, people try to find alternative and complementary methods of treatment. One of the methods that can be considered is Equine Assisted Activities \& Therapies (EAAT). Whereas EAAT seem to relatively a new alternative method to treat people with special needs (including different types of disabilities), some sources point out that this method of treatment goes back to the Ancient Greek. Nowadays, the number of professionals undergoing EAAT rises up annually, thus, the scientific studies are also increasing in this area. The goal of this study is to review available literature on research related to EAAT. Specific key words "equine assisted activities", "hippotherapy", "equine assisted therapy", were used to search relevant electronic databases. EAAT is a general term to describe activities and therapies performed by the professionals and with the horses. Equine Assisted Activities include Adaptive Riding and Equine Assisted Learning. On the other hand, Equine Assisted Therapies include Equine Assisted Therapy, Hippotherapy, Equine Facilitated Psychotherapy, and Adaptive (Remedial) Vaulting. Many studies were found in the aforementioned disciplines. The results of the scientific studies provide evidence for beneficial effects of EAAT in physiological, motor, psychological, and social aspects. The possible explanations of those effects can be identified in terms of the neurological and motor adaptations, stimulus - response characteristics of the horses, being in the nature with an animal, environment in the multi stimuli effects, the nature of the horse and the empty that the horses have.

\section{Oral presentations}

01

\section{DIFFERENCES IN SUBJECTIVE QUALITY OF LIFE BETWEEN DEAF AND HARD OF HEARING PEOPLE AND PEOPLE WITH PHYSICAL DISABILITIES WITH DIFFERENT SPORT PARTICIPATION LEVEL}

Dagmar Nemcek' (dagmar.nemcek@uniba.sk)

${ }^{1}$ Comenius University in Bratislava, Faculty of Physical Education and Sports, Bratislava, Slovakia

Correspondence: Dagmar Nemcek (dagmar.nemcek@uniba.sk)

Participation in varieties of sport offers one of the significant opportunities to people with disabilities to help them not only to overcome psychological and physical problems, but also to help them increase a subjective quality of life (S-QOL) level. The objective of the study was to analyse S-QOL in people who are deaf and hard of hearing $(\mathrm{D} / \mathrm{HH})$ and people with physical disabilities (PD) with different level of sport participation. (1) People with $\mathrm{PD}(\mathrm{n}=263)$ and $(2) \mathrm{D} / \mathrm{HH}$ people $(\mathrm{n}=164)$ categorised by the level of sport participation were recruited for the study: (1) elite and competitive athletes (ECA), (2) recreational athletes (RA) and (3) non-athletes (NA). A standardized questionnaires S.QUA.L.A. and WHOQOL was used as a primary research methods. D/HH ECA show significantly higher satisfaction with general health, psycho- 
logical health and spirituality and social relations compare ECA with $\mathrm{PD}$. RA who are $\mathrm{D} / \mathrm{HH}$ are significantly more satisfied with general health than RA with PD. D/HH NA reporting significantly higher satisfaction in their lives with general health, psychological health and spirituality and environment compare NA people with PD. D/HH ECA and NA present significantly higher level of S-QOL through OQOL than ACA and NA with PD. The findings suggest significantly higher S-QOL in the group of people who are $\mathrm{D} / \mathrm{HH}$ compare the S-QOL in people with PD mainly groups of ECA and NA.

\section{$\mathrm{O} 2$}

\section{HAND GRIP FORCE AND RATE OF FORCE DEVELOPMENT ASYMMETRY IN YOUTHS WITH INTELLECTUAL DISABILITY} Gulcan Bayindirli', Selcuk Akpinar', Kursat Ozcan

${ }^{1}$ Nevsehir Haci Bektas Veli University, Faculty of Education, Department of Physical Education and Sport, Nevsehir, Turkey

Correspondence: Gulcan Bayindirli (glcnbyndrl@gmail.com)

Application of quick forces at various magnitudes and weights is important for various daily tasks not only for healthy population but also for people with intellectual disability (ID). Thus, the aim of this study was test hand grip force and rate of force development asymmetry in youths with intellectual disability (ID). 41 youth participants with IDs and 41 healthy youth participants voluntarily joined the study. Force transducer was used to measure maximum hand grip force and maximum hand grip rate of force development (RFD) with a visual biofeedback about their performance from the computer screen. For maximum grip force measurement, the task was to squeeze the apparatus as strong as possible for 5 to $6 \mathrm{sec}-$ onds. For max grip force RFD, the task was to squeeze the apparatus as fast and as strong as possible. After a familiarization trial, participants made 3 trials for each dependent variable and highest value was included in the statistical analysis. The order of the hand presentation was counterbalanced. There was significant asymmetry between hands in maximum hand grip force for both groups. For maximum hand grip RFD, healthy youths showed a significant asymmetry, on the contrary, youths with ID did not show an asymmetry. Youths with ID had symmetrical neurological pathways to produce max force for both hands.

\section{O3}

IMPACT OF TIME-OUT ON EFFICIENCY OF MAN-UP IN WATER POLO: AN ANALYSIS OF THE DIFFERENCES BETWEEN THE THREE LEVELS OF WATER POLO PLAYERS

Mladen Hraste', Igor Jelaska' ${ }^{2}$, Cain C.T. Clark ${ }^{3}$

${ }^{1}$ University of Split, Faculty of Science, Split, Croatia, ${ }^{2}$ University of Split, Faculty of Kinesiology, Split, Croatia, ${ }^{3}$ Coventry University, Faculty Centre for Sport, Exercise, and Life Sciences, Coventry, United Kingdom

Correspondence: Mladen Hraste (mhraste@pmfst.hr)

In water polo, time-outs last one minute and only a team in possession of the ball can request it; although there are divided opinions whether a time-out is advantageous for the team in possession. The aims of this study were, firstly, to investigate the impact of time-out on efficiency of man-up in water polo, and secondly, to investigate the differences in efficiency of man-up in water polo between three qualitative levels of players. The sample consisted of 132 matches of the Adriatic Water Polo League, which were observed for indicators of man-up efficiency. There was no statistically significant difference between man-up efficiency played after time-out and man-up efficiency played without time-out. Additionally, Kruskal-Wallis test partially confirmed the existence of significant differences between three qualitative levels of water polo players. There is a reasonable possibility that the differences between levels are generated by the differences in the tactical knowledge, motor ability, and scoring ability. The results of this study can be applied by trainers for the selection of the adequate tactical solutions and the optimization of training processes among elite and sub-elite, water polo players. Additionally, results can be base for researches dealing with exploring the dynamics of water polo game, observed through recent changes of water polo rules.

\section{4}

\section{RELATIONSHIP BETWEEN BODY HEIGHT AND HAND LENGTH MEASUREMENTS OF BOTH GENDER ADOLESCENTS FROM REGION OF GJAKOVA IN KOSOVO}

Fitim Arifi',2, Fadil, Luta', Valbona Uka', Milazim Kamberi'1,2

'Universi College, Faculty of Physical Culture Sport and Recreation, Prishtina, Kosovo, ${ }^{2}$ University of Tetova, Faculty of Physical Education, Tetovo, North Macedonia

Correspondence: Fitim Arifi (fitim.arifi@kolegjiuniversi-edu.net)

This study was based on measurements from Gjakova region adolescents. The aim of this study was to examine the Body Height of adolescents from Gjakova region of Kosovo as well relationship between Length of Hand and Body Height in both genders adolescents. A total measured subject participated in this research was 207 out of which (101 female and 106 male), females average of age is $18.23 \pm 0.42$ years old (range 18-20 years) and for male 18.29 \pm 0.48 years old (range 18-20 years). Relationship between Body Height and Length of Hand has been analyzed by the simple correlation coefficient at a $95 \%$ confidence interval. The linear regression analysis was carried out to examine extent to which Length of Hand can reliably predict of Body Height. Statistical importance was placed at level $\mathrm{p}<0.05$. As a result anthropometric measurements for both sexes showed that the average of Body Height for male adolescents from Gjakova region are $179.32 \pm 6.10$ centimeters and have the Length of Hand average of $19.19 \pm 0.91$ centimeters, while female from Gjakova region $166.08 \pm 4.93$ centimeters tall, and have the Length of Hand average of $17.47 \pm 0.76$ centimeters. This study also confirms the necessity for developing separate height models for each region in Kosovo.

\section{5}

\section{STATURE AND ITS ESTIMATION UTILIZING LENGTH OF HAND MEASUREMENTS OF BOTH GENDER ADOLESCENTS FROM DISTRICT OF PEJA IN KOSOVO}

Shpresa Memishi', Vullnet Ameti ${ }^{1}$, Fitim Arifi', ${ }^{1}$, Atli Koleci', Metin Dalip ${ }^{1}$ 'University of Tetova, Faculty for Sport and Physical Education, Tetova, North Macedonia, ${ }^{2}$ Universi College, Department of Physical Culture, Sport and Recreation, Prishtina, Kosovo

Correspondence: Shpresa Memishi (shpresa.memishi@unite.edu.mk)

Purpose of this study was to examine the stature of adolescents from district of Peja western region of Kosovo, as well relationship between the length of the hand and standing height from both gender adolescents. The subject participated in this research was 457 students from high school graduates (232 boys and 225 girls) boys average of age is $18.26 \pm 0.46$ years old (range 18-20 years) and for girls average of age is $18.21 \pm 0.41$ years old (range 18-20 years). Measurements of stature and the length of the hand were performed with reference to the ISAK protocol (Marfell-Jones, Olds, Steele \& Carter, 2006). The results for standing height and length of the hand were analyzed by means of the arithmetic mean (SD) and a simple correlation coefficient, while T-test analysis was used for differences between the two genders and linear regressive analysis assessed standing height based on length of hand measurements, Statistical 
importance was placed at level $\mathrm{p}<0.05$. The results obtained in this paper have shown that standing height can be estimated from the length of the hand, which reliably predicts standing height for both genders.

\section{O6}

\section{RELATIONSHIPS BETWEEN KINEMATIC CHARACTERISTICS AND DISTANCE ACHIEVED IN SHOT PUT}

Ahmed Abdellatif ${ }^{1}$

'University of Sultan Qaboos, College of Education, Physical Education and Sport Sciences Department, Muscat, Oman

Correspondence: Ahmed Abdellatif (tifa@squ.edu.om)

Three factors determine trajectory, including horizontal displacement of a projectile: release velocity, release angle and release height. To achieve the greatest possible flight distance, the athlete must project the shot with the optimum combination of release velocity, release angle and release height. The goal of this study was to identify the relationships between kinematic characteristics of the release phase and distance achieved in shot put. The sample of this study consisted of twenty one students from Department of Physical Education at Sultan Qaboos University. The video was observed on kinematical characteristics of the release phase of shot put. The analysis on each shot put trail was done using Kinovea Motion Analysis software. The collected data were analyzed using the statistical package SPSS and the descriptive statistics were expressed as mean (SD) for each variable. The analysis of the data indicates that the distance achieved in shot put was significantly correlated with release resultant velocity, release vertical velocity, and release horizontal velocity, while the distance achieved in shot put was not significantly correlated with release angle and release height. The findings suggest that the increase in the release velocity will increase the distance of the throw, and the results of this study may help the coaches and teachers in systematizing and modifying their training programs.

\section{7}

\section{EXTERNAL VALIDITY OF FORCE-VELOCITY RELATIONSHIP OBTAINED FROM SINGLE AND MULTI-JOINT TASKS}

Predrag Bozic ${ }^{1,2}$

${ }^{1}$ Serbian Institute of Sport and Sports Medicine, Belgrade, Serbia, ${ }^{2}$ University of Montenegro, Faculty for Sport and Physical Education, Niksic, Montenegro

Correspondence: Predrag Bozic (predrag.bozic@rzsport.gov.rs)

The present study explored the external validity of the force-velocity (F-V) modelling approach obtained from isokinetic measurements and maximal sprints on a leg cycle ergometer to predict maximum performance in various functional movement tasks. Moderate active participants were performed evaluation of the knee extensors at velocities between 30 and $180 \%$ as well as maximal sprints on a leg cycle ergometer loaded with $5 \%$ to $12 \%$ of body weight. In addition, they performed various functional movement tasks based on maximal speed, power and force output. The linear regression methods were applied for obtaining the F-V relationship parameters. Obtained finding suggest moderate relationship between functional tasks based on high force and F0 obtained from both, single $(\mathrm{r}=.71)$ and multi-joint tasks $(\mathrm{r}=.50)$, as well as $\mathrm{P} 0$ obtained from multi-joint task $(r=.59)$. In addition, moderate correlation with respect to maximal speed performance were obtained for V0 ( $\mathrm{r}=$ -.55) obtained from multi-joint task, as well as F0 $(\mathrm{r}=-.76)$ and P0 $(\mathrm{r}=-.57)$ obtained from single-joint task showed. Finally, moderate correlation obtained among $\mathrm{P} 0$ obtained from multi-joint task and functional movement tasks based on maximal power $(r=.69$
- .78). Application of F-V modelling approach on single and multijoint tasks provide parameters that could selectively represent performance of different functional movement tasks. While, F0 could explain performance based on high force output, V0 and P0 could be represents of functional tasks based on high speed and power, respectively.

\section{8}

\section{THE KINEMATICS OF TWO VARIANTS OF THE UCHI MATA TECHNIQUE IN THE JUDO SPORT TO AN ELITE ATHLETE} Fadil Rexhepi ${ }^{1}$

'University of Tetova, Faculty of Physical Education, Tetovo, North Macedonia

Correspondence: Fadil Rexhepi (fadil.rexhepi@unite.edu.mk)

Uchi mata is a throw that often brings a victory with maximum points (ippon). The main purpose of this study is to determine the main kinematic indicators of the athlete's body position and the velocity of performance in its two most commonly used variants: classic uchi mata and so-called leg uchi mata. The throwing technique is performed by a qualitative judoist who has achieved high international successes (A.GJ.). The performance was filmed with three digital cameras, then the material was processed with the APAS (Ariel Performance Analysis System). For both variants of the technique greater displacement of the offensive leg and the center of gravity during the opponent's imbalance phase (kuzushi) and during the second throwing phase (tsukuri) is achieved in the anteroposterior direction. The minimum angle on the knee of the supporting leg during the tsukuri phase in the classical variant is $115^{\circ}$, while in the leg uchi mata variant the knee angle is $113^{\circ}$. The maximum velocity of the attacking leg in the classic variant is 4.78 $\mathrm{m} / \mathrm{s}$, while in the leg uchi mata variant is $6.89 \mathrm{~m} / \mathrm{s}$. The duration of the technique's performance for both variants is approximately the same. According to the results it can be concluded that during the performance of the so-called leg uchi mata variant the displacement of the attacker's body and the velocity of action of the attacking leg in the mediolateral direction is greater.

\section{9}

\section{THE CONTRIBUTION OF HIGH SCHOOL BASKETBALL TO ADOLESCENT GIRLS' WELLBEING IN NEW ZEALAND}

Richard L Light ${ }^{1}$, Ricardo Pimenta ${ }^{2}$

'University of Canterbury, School of Health Sciences, Christchurch, New Zealand, ${ }^{2}$ Waseda University, Faculty of Exercise and Sport Science, Tokyo, Japan

\section{Correspondence: Richard L Light (richard.light@canterbury.ac.nz)}

Participating in sport and other recreational activities has long been assumed to have a positive influence on the health of young people, and more recently, on wellbeing and is a common rationale for its inclusion in schools. This presentation draws on a recent study conducted on an adolescent girls' basketball team in an independent secondary New Zealand high school that inquired into why the girls chose to play basketball and which identified enjoyment or fun as the main motivation for playing. Using a combined ethnographic and grounded theory methodology provided detailed insight and understanding of the girls' experiences, the meaning basketball had for them and the positive influence it had on their wellbeing. Data analysis developed three major themes that most contributed to the participants' enjoyment of being in the team which were: (1) Positive relationships; (2) How the Team operated as a "Safe Haven" and, (3) Achievement and 'belongingness' in competition. In the development of theoretical concepts during the latter stages of the grounded theory analysis we drew on Seligman's PERMA model 
for happiness and wellbeing. This aligned very well with the substantive themes we had developed. The findings suggest how the PERMA model could be used to enhance the positive contributions sport can make toward wellbeing among young people.

\section{0}

EFFECTS OF DIFFERENT ANGLE REPEATED SPRINT TRAINING (RST) ON PHYSICAL PERFORMANCE AMONG COLLEGE FOOTBALL PLAYERS

Tah Fatt Ong ${ }^{1}$, Shu Feng $\mathrm{Ng}^{1}$

'Tunku Abdul Rahman University College, Faculty of Applied Sciences, Kuala Lumpur, Malaysia

Correspondence: Tah Fatt Ong (ongtf@tarc.edu.my)

Repeated Sprint Training (RST) with Change of Direction (COD) has the potential to produce positive impacts on neuromuscular adaptations that are highly related to physical performance of footballers. The aim of the present study was to investigate the effects of different angle repeated sprint training (RST) on specific aspects of physical performance among college football players. The experimental study was conducted on 27 college football players from TARUC KL. The subjects were randomly assigned into experimental group 1 ( $45^{\circ} \mathrm{RST}$ program), experimental group 2 (90 ${ }^{\circ}$ RST program) and experimental group 3 (180 ${ }^{\circ}$ RST program). All experimental groups had gone through the pre-test, post-test and seven weeks of different angle repeated sprint training. All the three groups showed significant improvement in all the physical tests (speed, agility, power and endurance). Group 3 showed the highest significant improvement in repeated sprint ability mean time (RSAm) $(\mathrm{p}=0.000,4.67 \%)$, vertical jump $(\mathrm{p}=0.002,7.50 \%)$ and aerobic endurance ( $\mathrm{p}=0.002,9.29 \%)$. Group 1 showed the highest significant improvement in agility $(\mathrm{p}=0.009,3.19 \%)$. The finding revealed that different angle training programs are able to bring specific changes to specific fitness components of football players. The findings suggest that coaches can use specific change of angle direction to manipulate and target on specific physical adaptations needed for the players.

\section{1}

\section{TESTING SPONSORSHIP RECALL AND RECOGNITION} AFTER THE GAMES OF THE SMALL STATES OF EUROPE MONTENEGRO 2019

Suncica Rogic', Milena Radonjic', Vladimir Djurisic', Nikola Misnic ${ }^{1}$ 'University of Montenegro, Faculty of Economics, Podgorica, Montenegro

Correspondence: Suncica Rogic (suncica@ucg.ac.me)

In order to explore sponsorship awareness, two approaches are most commonly used - recall and recognition. By researching sponsorship recall, respondents are asked to state the brand name from their memory without any incentive. On the contrary, recognition refers to a consumer's ability to name a brand after being presented with a brand list as an incentive. The aim of this study was to test the sponsorship recall and recognition six months after the Games of the Small States of Europe were held in Montenegro (GSSE 2019). Online survey was distributed to participants of the Games, as well as the volunteers and potential spectators. Survey data was analyzed using descriptive statistics. Our results show that not all companies that invested and sponsored the GSSE2019 were recognized by the respondents. Namely, top of mind sponsors were companies which activated their sponsorship investment using other marketing channels. Other sponsors, whose name was also displayed in official documents and around courts and sport halls, achieved low recall levels. Therefore, we conclude that sponsorship, as an isolated medium, cannot achieve great results. Our findings suggest that the sponsorship investment itself is not sufficient to maximize the potential marketing effects. Companies which engage in sponsorship activation achieve higher sponsorship awareness, which can lead to positive attitudes towards the brand.

\section{2 \\ OUTDOOR GREEN PARKS AS PHYSICAL ACTIVITY PROMOTION TOOLS TO TACKLE NONCOMMUNICABLE DISEASES \\ Romeu Mendes ${ }^{1,2,3}$, Ana Anjos' ${ }^{1}$ David Pires ${ }^{4}$ \\ 'University of Trás-os-Montes e Alto Douro, Vila Real, Portugal, ${ }^{2}$ North- ern Region Health Administration, Porto, Portugal, ${ }^{3}$ EPIUnit-Instituto de Saúde Pública, Universidade do Porto, Porto, Portugal, ${ }^{4}$ Vila Real Mu- nicipality, Vila Real, Portugal}

Correspondence: Romeu Mendes (romeuduartemendes@gmail.com)

This study aimed to analyse the energy expenditure of an outdoor green park walking circuit. We analysed Corgo Park in Vila Real (Portugal). This public outdoor green park has a walking/running circuit of $5 \mathrm{~km}$ on flat terrain. Study participants completed the circuit on brisk walking (self-selected pace). Exercise intensity was controlled by Borg Rating of Perceived Exertion Scale (6-20 points). Energy expenditure $(\mathrm{kcal})$ was assessed through a clinically validated heart rate monitor (Polar RSCX800). Twenty-nine participants completed the study ( 15 women and 14 men; aged $52.38 \pm 3.27$ years). The $5-\mathrm{km}$ circuit took $53.14 \pm 4.16 \mathrm{~min}$ to complete (women $55.10 \pm 3.92 \mathrm{~min}$ vs. men $51.10 \pm 3.43 \mathrm{~min} ; \mathrm{p}=0.007$ ), at a walking speed of $5.68 \pm 0.44 \mathrm{~km} / \mathrm{h}$ (women $5.47 \pm 0.38 \mathrm{~km} / \mathrm{h}$ vs. men $5.90 \pm 0.30 \mathrm{~km} / \mathrm{h} ; \mathrm{p}=0.006$ ), under an ambient temperature of $27 \pm 3{ }^{\circ} \mathrm{C}$. Exercise intensity was perceived as $9.74 \pm 1.26$ points at Borg Scale (light-intensity). Energy expenditure was $4.36 \pm 1.51 \mathrm{kcal} / \mathrm{kg}$ of bodyweight. Per example, for an individual of $70 \mathrm{~kg}$, is expected an energy expenditure of around 305 kcal. The walking circuit of the Corgo Park represents an effective and light-intensity exercise dose than can be prescribed (three-tofour times/week) to accomplish with the physical activity recommendations for noncommunicable diseases control.

\section{3}

\section{THE EFFECTS OF UNILATERAL VERSUS BILATERAL RESISTANCE TRAINING ON PHYSICAL PERFORMANCE AMONG TRAINED MEN}

Ali Md Nadzalan', Nur Ikhwan Mohamad', Asmadi Ishak', Thariq Khan Azizuddin Khan', Ebby Waqqash Mohamad Chan ${ }^{2}$

${ }^{1}$ Sultan Idris Education University, Faculty of Sports Science and Coaching, Perak, Malaysia, ${ }^{2}$ University of Malaya, Centre For Sport and Exercise Sciences, Kuala Lumpur,Malaysia

Correspondence: Ali Md Nadzalan (ali.nadzalan@fsskj.upsi.edu.my)

Currently, many methods of resistance training is evolving that make many fitness practitioners have a lot of ways to train themselves or their clients. This include performing exercise unilaterally or bilaterally. The objectives of this study is to determine the chronic effects of unilateral versus bilateral resistance training on physical performance among trained men. Forty-five trained men were recruited as study participants and were divided into three groups; i) unilateral, ii) bilateral and iii) control group. Participants underwent pre-test consisted of physical performance tests (unilateral and bilateral 1RM test, $30 \mathrm{~m}$ sprint, vertical jump, agility t-test), followed by six weeks of training intervention before been assessed of their physical performance again. Results showed that both unilateral and bilateral group managed to significantly improve all the physical performance parameters during the post-test. Unilateral group managed to obtained significantly greater unilateral 1RM 
score in both squat and bicep curl while bilateral group obtained significantly greater $1 \mathrm{RM}$ strength in bilateral $1 \mathrm{RM}$. No significant differences were found comparing $30 \mathrm{~m}$ sprint, agility t-test and vertical jump between both training groups. Findings suggested that both performing unilateral and bilateral were similarly effective in improving physical performance.

\section{4}

\section{PHYSICAL ASSESMENT OF SECONDARY SCHOOL STUDENTS} AND DETERMINATION OF THE RELATED NORM VALUES Cevdet Tınazcı', Ciler Demırtay', Caner Acıkada ${ }^{2}$

${ }^{1}$ Near East University, Faculty of Sports Sciences, Nicosia, Cyprus, ${ }^{2}$ European University o Lefke, School of Physical Education and Sports, Lefke, Cyprus

\section{Correspondence: Cevdet Tinazci (cevdet.tinazci@neu.edu.tr)}

Understanding and obtaining physical fitness is not only a part of physical education but also general education. Therefore, it is not just physical education teachers who are responsible for physical fitness but also students families, schools and society. This study aims to determine anthropometric and physical differences of adolescent boys and girls. In this study, differences between age groups and genders were analysed by finding out anthropometric and motoric characteristics of male and female students at 12-14 ages. EUROFIT test battery was used to collect data. It was found out that 14 year old male students were different from other ages in terms of height, humerus length, anaerobic power and hand grip power $(\mathrm{p}<0.05)$. 13 and 14 year old female students were different from 12 year old group in terms of height and hand grip power $(\mathrm{p}<0.05)$. Peak anaerobic power values of 12 year old students in both genders were found to be statistically different and bend arm and shuttle running values of 13 year old students in both genders were found to be statistically different. The results of this study suggest according to age and gender, muscle endurance and strength level can varied.

\section{5}

\section{RECREATIONAL EXERCISE MOTIVATION, PERCEIVED HEALTH AND PHYSICAL ACTIVITY APP USE AMONG UNIVERSITY STUDENTS}

Irmak Hürmeriç Altunsöz ${ }^{1}$, Elif Numanoğlu' ${ }^{1}$ Güncem Dilan Karayaprak ${ }^{1}$ ${ }^{1}$ Middle East Technical University, Physical Education and Sports Department, Ankara, Turkey

Correspondence: Irmak Hurmeric Altunsoz (hurmeric@metu.edu.tr)

Physical activity participation is an essential element for maintaining a healthy life. Thus, it is critical to understand the factors that contribute to an active lifestyle. The purpose of this study was to investigate recreational exercise motivation, perceived health, and physical activity app use among university students. A convenience sample of 96 university students (22 women and 76 men, Mage=22.45) from Middle East Technical University participated in this study. The participants filled out a demographic information form, the Recreational Exercise Motivation Scale (REMM), and the International Physical Activity Questionnaire (IPAQ-short form). Results showed that being healthy $(\mathrm{M}=4.17)$ and developing motor skills $(\mathrm{M}=4.03)$ were the primary motivating factors for doing exercise among university students. Their perceived health status was high $(M=4.15)$. This study also found that 76 university students did not use any physical activity apps, and they thought that activity applications were not useful and not practical to change the physical activity behaviors of individuals. The rest of the participants emphasized that they used the apps for doing physical activity with other people. Besides, the activity level of university students (moderate and high level) did not make any difference in recreational moti- vation factors. Understanding the elements of recreational exercise motivation and physical activity behaviors among students helps us design effective programs that may support a healthy lifestyle on university campuses.

\section{6}

\section{URBAN-RURAL DIFFERENCES OF FEMALE STUDENTS IN INDICATORS OF NUTRITIONAL STATUS AND BODY COMPOSITION, LEVEL OF PHYSICAL ACTIVITY AND INDIVIDUAL SEDENTARY ACTIVITIES AS FACTORS THAT DEFINE OBESITY}

Donata Vidakovic Samarzija'

'University of Zadar, Department of Teacher and Preschool Teacher Education, Zadar, Croatia

Correspondence: Donata Vidakovic Samarzija (dovidak@unizd.hr)

To determine differences in indicators of nutritional status and body composition, level of physical activity and certain sedentary activities towards the place of residence. The study was conducted on a sample of 208 female students aged 10 years (111 students from urban schools and 97 students from rural schools). Based on 7 morphological measures, indicators of nutritional status and body composition were calculated (Body Mass Index, Waist circumference, Waist-to-Hip-Ratio, Subscapular/tricipital skinfolds index and Body fat \%). Overall physical activity level was estimated by PAQ-C questionnaire. The Man- Whitney $U$ test was applied to identify urban-rural differences. In a total sample $76,44 \%$ of female students were normal weight, $17,31 \%$ were overweight, $6,25 \%$ were obese. There were no significant differences by place of residence in Body Mass Index, Waist circumference and Subscapular/tricipital skinfolds index. Significant differences were obtained in the indicators of body mass distribution. Urban students had significantly higher Waist-to-Hip-Ratio and Body fat \% while rural students had a significantly higher overall level of physical activity. No differences were observed in sedentary activities. The results indicate that female students from rural areas are still more physically active, which contributes to a better distribution of body fat and a lower proportion of fat in total body mass.

\section{7}

\section{INJURY PREVENTION STRATEGIES IN SOCCER: A SYSTEMATIC REVIEW}

lason Vasileiadis ${ }^{1}$

${ }^{1}$ Cardiff Metropolitan University, Cardiff, Wales, United Kingdom

Correspondence: lason Vasileiadis (jvasiliadis20@gmail.com)

Soccer is maybe the most physically-demanding sport in the world, as soccer players are obliged to play a great number of games in one season, with recovery breaks being short and most times insufficient. As a consequence, injury rates are high among players and their participation in the games is adversely affected. This in turn adds a great financial and psychological burden for players and clubs alike at all levels (amateur, semi-professional, elite). This study reviews the most efficient contemporary injury prevention strategies in football and the scientific evidence behind them. It also aims to determine the benefits and the applicability of these strategies in youths, men, women at all performance levels. Standard systematic review methodology was modified and adopted for this review and electronic-searching tools were used to locate the papers needed. A total number of 44 studies were analysed. We have isolated 5 injury prevention strategies developed by researchers as the most effective to reduce the number of injuries and even to enhance performance to a certain degree: Fifa 11+, Foam rolling techniques, strength training for injury prevention, pre activation routines and 
finally core training. We evaluated these in relation to their scientific substrate and to their applicability in the training programs introduced by sports scientists as well as strength and conditioning coaches on the pitch. Our present systematic review revealed five main injury prevention strategies as the most effective and popular ones today.

\section{8}

\section{PHYSICAL INTERVENTION AS A MEANS OF INCREASING THE CONDITION OF HAEMATO-ONCOLOGICAL SURVIVORS IN SUBSEQUENT CARE}

Marie Crhová', Kateřina Kapounková', Iva Hrnciř́ková', Ivan Struhár' , Zora Svobodová2, Alexandra Malá2, Andrea Janíková ${ }^{3}$, Markéta Hadrabová ${ }^{3}$ ${ }^{1}$ Masaryk University, Faculty of Sports Studies, Department of Health Promotion, Brno, Czech Republic, ${ }^{2}$ Masaryk University, Faculty of Sport Studies, University Sports Centre, Brno, Czech Republic, ${ }^{3}$ Masaryk University, Faculty of Medicine, Heamatooncological Department, Brno, Czech Republic

Correspondence: Marie Crhová (409415@mail.muni.cz)

The main aim of the interventional motion and respiratory programme is increasing fitness in hemato-oncological patients as well as cessation of their muscle mass loss as a result of their disease and treatment. Hemato-oncological diseases and their treatment bring a range of side effects that are caused by cardiac, neural, and pulmonary toxicity of the treatment, which has influence upon the decreasing quality of the patients' lives. Studies indicate that physical exercise, especially of aerobic character, increase cardio-respiratory fitness, muscle strength, and physical well-being. The motion and respiratory interventional programme took place over a period of 6 months. It was divided into a 3 months respiratory training at home and a directed motion aerobic programme that took place 3 times a week for 60 minutes. The intensity of the exercise was set up individually on the level of the anaerobic threshold of each participant, which was ascertained on the basis of the initial performance test. The research sample were 16 people, mean age value was 53.31 years of age. The results of the performance tests after the motion and respiratory programme of the participants of the study showed improvements in the field of the participants aerobic capacity as well as in the field of sympto-vagal disbalance unfortunately without statistical significance. There is still an open scientific question regarding the most effective types of physical intervention in terms of their influence on the health of surviving hemato-oncological patients.

\section{9 \\ EFFECTS OF A 12-WEEK WALKING FOOTBALL PROGRAM ON COGNITIVE PERFORMANCE IN PATIENTS WITH TYPE 2 DIABETES}

Ana Barbosa', João Brito ${ }^{2}$, Júlio Costa ${ }^{2}$, André Seabra², Pedro Figueiredo ${ }^{2}$, Romeu Mendes ${ }^{1,3}$

${ }^{1}$ Universidade do Porto, EPIUnit-Instituto de Saúde Pública, Porto, Portugal, ${ }^{2}$ Portugal Football School, Portuguese Football Federation, Lisbon, Portugal, ${ }^{3}$ Northern Region Health Administration, Lisbon, Portugal

Correspondence: Ana Barbosa (ana.barbosa.02@gmail.com)

We aimed to analyse the effects of a walking football program in cognitive performance in middle-aged and older patients with type 2 diabetes (T2D). This quasi-experimental study enrolled 31 male participants recruited from primary health care units, diagnosed with T2D, with 50-70 years old, major diabetes complications controlled and with no contraindications to exercise. Participants engaged in 60-min walking football sessions, three times per week, for 12 weeks. Sessions included strength and conditioning exercises, technical skills drills, and small-sided games. Montreal Cognitive Assessment (MoCA) test was used to evaluate cognitive performance before and after the exercise program. 29 participants (64.5 \pm 4.5 years) completed the exercise program: $41.4 \%$ had equal or less than six years of education; $34.4 \%$ between $7-12$ years; and $24.1 \%$ higher than 12 years. The median (P25-P75) score of MoCA at baseline was $26(23-27)$ points, and at the end of program was 26 (24-28) points (Wilcoxon test; $\mathrm{p}=0.041$ ). A 12-week walking football program showed promising effects in the cognitive performance of middle-aged and older men with T2D. FUNDING: FIFA Research Scholarship 2018. TRIAL REGISTRATION: NCT03810846.

\section{O20}

\section{PREDICTORS OF EXERCISE CONSISTENCY AMONG PILATES PROGRAM PARTICIPANTS}

Antonia Mikulandra', Natasa Zenic ${ }^{1}$

${ }^{1}$ University of Split, Faculty of Kinesiology, Split, Croatia

Correspondence: Antonia Mikulandra (antoniacovic@yahoo.com )

Pilates-program continues to enjoy widespread popularity, but there is an evident lack of information about factors that contribute to participants' exercise-consistency (EC). This study aimed to evaluate predictors of EC in Pilates-program. The investigation comprised 107 participants of Pilates-program (91\% females), members of one certified studio. The predictors included anthropometrics, personal health-status, and fitness-status, motives for exercising, history of injuries, stress-level, etc. The dependent variable (criterion) was based on EC in Pilates-program (participated 1-2 months [short-term EC], 3-9 months [middle-term EC], more than one season [long-term EC]). Multinomial logistic regression (with shortterm EC as a reference value) was applied to identify the influence of studied predictors on the criterion, with calculated Odds Ratio (OR) and 95\% Confidence Intervals (CI). The higher EC was found in males (middle-term-EC: OR: 7.00, 95\%CI: 6.95-7.05, long-termEC: OR: 1.98, 95\%CI: 1.96-1.99). The better initial fitness level was related to long-term-EC (OR: 1.88, 95\%CI: 1.38-2.56), and the history of injured spine/back was correlated to middle-term-EC (OR: 8.55, 95\%CI: 1.01-72.6). While EC is crucial for achieving long-term training effects, the knowledge about established relationships can be directly implemented in development of optimal models aimed at an increase of long-term participation in Pilates-program.

\section{1}

\section{THE VALIDITY AND RELIABILITY STUDY OF WHO QUALITY OF LIFE SCALE SHORT FORM (WHOQOL-BREF) IN KAZAKH LANGUAGE}

Baglan Yermakhanov ${ }^{1,2}$, Erdal Zorba ${ }^{2}$, Mutlu Turkmen $^{3}$

${ }^{1}$ Khoja Akhmet Yassawi International Kazakh-Turkish University, Faculty for Sport and Art, Turkistan, Kazakhstan, ${ }^{2}$ Gazi University, Faculty for Sport Science, Ankara, Turkey, ${ }^{3}$ Bayburt University, Physical Education and Sport School, Bayburt, Turkey

Correspondence: Baglan Yermakhanov (baglan0989@gmail.com)

The World Health Organization defines quality of life as an individual's perception of their position in life in the context of their culture and value systems in relation to their goals, expectations, standards and interests. The aim of this study was to verify the validity and reliability of the Kazakhstan version of WHOQOL-BREF. For this purpose, 509 students, 208 men (40.9\%) and 301 women (59.1\%) voluntarily studied on a scale of 26 subjects and 5 subscales (general health, physical health, psychological health, social relations, environment). We used to make the Confirmatory factor analysis. Then Cronbach's alpha analysis was used to analyse the in- 
ternal reliability of inventory design. The index value corresponding to the results of the index coefficient, $\mathrm{x} 2 / \mathrm{sd}(\mathrm{x} 2=936.08, \mathrm{SD}=289)$ $=3.23, \mathrm{GFI}=0.88, \mathrm{CFI}=0.86, \mathrm{NFI}=0.80, \mathrm{AGFI}=0.85, \mathrm{RMSEA}=$ $0.66, \mathrm{SRMR}=0.52, \mathrm{RMR}=0.47$. Internal inventory ratios ranged from 0.60 to 0.90 . We can say as a result, the Kazakh version of the WHOQOL-BREF is a valid and reliable measuring tool.

\section{O22}

\section{PRACTICAL APPLICATION OF AUDIO-VISUAL DEVICES IN SCHOLASTIC SWIMMING EDUCATION}

Zsófia Kovács ${ }^{1,2}$, Máté Katona', István Karsai ${ }^{2}$, Ferenc Tóvári ${ }^{3}$, Gyöngyvér Prisztóka ${ }^{3}$

"University of Pécs, Faculty of Humanities, "Education and Society" Doctoral School of Education, Pécs, Hungary, ${ }^{2}$ University of Pécs, Medical School, Sports Facilities, Pécs, Hungary, ${ }^{3}$ University of Pécs, Faculty of Sciences, Institute of Sport Sciences and Physical Education, Pécs, Hungary

Correspondence: Zsofia Kovacs (muppika@gmail.com)

The perception passages of the "digital indigenous natives" are different, beside their analytic processes their spatial-visual processing pathways are going to be the priority. As PE teachers why couldn't we apply modern digital devices as an extension to our classes just like the other bookish teachers during their lessons? To measure the efficiency of audio-visual devices in the brackets of scholastic swimming education (9-11years old) based on the students' performance. We had been working together for 12 weeks with the students (experimental $n=26$, control $n=26$ ) within the given timeframe they must learn new swimming techniques (freestyle, backstroke) with classical and new methodologies. The requirement was completing 25 meters of distance with the skills acquired. The results will show, that the experimental group within the given timeframe ended up with better results opposing the classical group. For the "digital indigenous native" students alongside of the leadership of a professional, the immediate applications of visual and the auditory experiences can provide a faster and more complex knowledge inside the brackets of scholastic swimming education.

\section{O23}

\section{DIFFERENT SPORTS AND EATING ATTITUDES}

Alemka Saric ${ }^{1}$, Hrvoje Karnincic ${ }^{1}$, Gordan Drasinac ${ }^{2}$

${ }^{1}$ University of Split, Faculty of Kinesiology, Split, Croatia, ${ }^{2}$ University of Split, Department of Professional Studies, Split, Croatia

Correspondence: Alemka Saric (alemka.saric@icloud.com )

Sports rules determine the eating habits of athletes, while in some sports athletes reduce weight, others intensify weight gain. This research was conducted with the aim of determining the difference in eating habits among sports that differ in weight regulation. The sample of 76 athletes was divided into 4 sub-samples ( 1 increase weight, 2 reduce weight, 3 neutral and 4 water sports). A sample of variables is questionnaire score EAT26 (Eating Attitudes Test) and reported oscillations in body mass (current, maximum, minimum and ideal weight). All data were analysed by descriptive statistics. In order to examine the reliability Cronbach's alpha reliability coefficient and interclass correlation was calculated, difference between groups were tested by Kruskal-Walis ANOVA test. The questionnaire on this sample meets the reliability criteria, groups are significantly different in the questionnaire score $(\mathrm{H}=8.95 ; \mathrm{p}=0.03)$. There is a significant difference between bodybuilders and athletes in sport games and recreation $(Z=2.76 ; p=0.03)$. Twelve athletes have a score above 20 and suggest eating disorders, 10 of them come from weight-category sports or bodybuilding. While all athletes think they have two kilograms more bodybuilders think they have two kilograms less.
Bodybuilders and athletes from sports with weight categories are particularly vulnerable groups in developing eating disorders.

\section{O24}

\section{OLYMPIC GAMES AND TOURISM}

Dejan Đurovic', Violeta Siljak ${ }^{2}$

${ }^{1}$ Alfa BK University, Faculty of Management in Sport, Belgrade, Serbia, ${ }^{2}$ UN University for Peace European, Center for Peace and Development, Belgrade, Serbia

Correspondence: Dejan Djurovic (valu@t-com.me)

The Olympics represent the highest form of competition in the sport, thus attracting a great deal of public attention and have an undeniable impact on many other areas, which undoubtedly include tourism. The aim of this paper is to determine the mode and level of influence of the Olympic Games on the development of tourism and economy of the organizing countries. In the paper, the historical method, the theoretical analysis method and the comparative method were applied. The impact of the Olympic Games on the tourism of the host city, apart from the increased number of tourists and new tourist accommodation, can be reflected in the transformation of the type of tourism that is dominant in the host city. In fact, after the Games, there is increasing interest in business and convention tourism in the host city, due to the promotion the city is experiencing thanks to the Olympics. The Olympics, as the biggest sporting event and global phenomenon, and tourism, as a vital industry in the future, are interactively dependent on one another. Although the Olympics are a good driver of many positive changes, they can only be successful if the opportunity to organize is well utilized and a smart strategy is devised that is not universal but specific to each host city.

\section{O25}

\section{THE OLYMPIC GAMES AND THE NEW OPPORTUNITIES FOR SPORTS DEVELOPMENT OF URBAN RESIDENTS}

Adam Omorczyk

'University of Silesia, Katowice, Poland

Correspondence: Adam Omorczyk (aomorczyk@us.edu.pl)

The Olympic Games are not only the sports mega event, a great opportunity to promote the country and the region or city, goodly expenditure for the government or a strong impulse for the city's development. The Olympic Games are also a great opportunity to the progress of sporting activities. The purpose of this work is to draw attention to the impact of the Olympic Games on the chances of developing sports activities, especially in the host-cities. Both data analysis (books, articles, maps, internet, films, recordings, previous researches) and author's field research in some host-cities (among others in Athens or Barcelona) were used. The research shows that the Olympic Games significantly affect the chances of developing sports activity in many areas, primarily due to the new sports and recreation infrastructure as well as the promotion of sport and physical activity during the organization of the Olympics. Residents have more opportunities to play sports, participate in more sports events or competitions and can get to know sports disciplines they have not known before. The Olympic Games are great opportunities for urban residents to develop physically, improve their health and enjoy their free time, thanks to which the city (as a whole, a living and vibrant structure) can function and develop better.

\section{O26 \\ CURRICULUM DEVELOPMENT FOR A SWISS MSC. PROGRAM IN SPORTS PHYSIOTHERAPY}

Ursula Kung ${ }^{1}$, Ron Clijsen ${ }^{1,2,3,4}$, Jan Taeymans ${ }^{3,4}$, Mario Bizzini ${ }^{5}$, Stephan 
Meyer $^{6}$, Nicolas Mathieu ${ }^{5}$, Slavko Rogan ${ }^{3,4}$, Erich Hohenauer ${ }^{1,2}$, Amir Tal$\mathrm{Akabi}^{4}$

${ }^{1}$ International University of Applied Sciences, THIM, Landquart, Switzerland, ${ }^{2}$ University of Applied Sciences and Arts of Southern Switzerland, Landquart, Switzerland, ${ }^{3}$ Vrije Universiteit Brussel, Brussels, Belgium, ${ }^{4}$ Bern University of Applied Sciences, Department of Health Professions, Division of Physiotherapy, Bern, Switzerland, ${ }^{5}$ Swiss Sport Physiotherapy Association, Magglingen, Switzerland, ${ }^{6}$ Swiss Federal Institute of Sport, Magglingen, Switzerland

Correspondence: Ursula Kung (u.kueng@physioschule.ch)

Sports physiotherapists are recognised professionals, involved in prevention and management of sport-injuries. In order to develop advanced skills, knowledge and the ability to integrate evidence-informed practice, a postgraduate level (MSc.) is viewed as the threshold level for specialisation in sports physiotherapy. The goal of this paper is to disseminate the development of an educational curriculum in MSc. in sports physiotherapy at Bern University of Applied Sciences (Switzerland). The curriculum was designed in collaboration with the Swiss Sports Physiotherapy Association, the Swiss Federal Office of Sports and Swiss Olympics. The competencies and standards defined by the International Federation of Sports Physical Therapy were used as guidelines. The curriculum has a modular structure, runs as part-time program over six semesters and is awarded with 90 ECTS. Students enrolled in the program earn 1 credits point per 30 hours study load. The part-time MSc. in sports physiotherapy program, offers a highly student-centred learning approach, enabling the student to focus on continuing professional development and clinical practice.

\section{O27}

\section{THE IMPACT OF GLOBALIZATION ON EDUCATION AND DILEMMAS BETWEEN TRADITIONAL AND MODERN EDUCATION}

Fadil Mamuti ${ }^{1}$

'University of Tetovo, Faculty of Physical Education, Tetovo, North Macedonia

Correspondence: Fadil Mamuti (fadil.mamuti@unite.edu.mk)

This study aims to point out the impact of globalization on education and the dilemmas that appears between traditional and modern education. Globalization is a complex, multifaceted and world-wide phenomenon. It is an unstoppable and irreversible process of international, economic, politic, education and culture integration. Education is the process of facilitating learning, or the acquisition of knowledge, skills, values, beliefs, and habits. As the needs of people are changing, the education system also has change, and this change should be accepted by the people. Education system is a process that needs transformation and changes, it must be reformed and adapted to contemporary education in a globalized world. Modifying the role of teachers from traditional to modern education is a necessary but not an easy process. The experiences in various educational and social systems, age differences and opinions about the educational process, lack of foreign languages, lack of sophisticated conditions as well as lack of information and communication technologies, make this process more difficult. This makes the dilemmas of which type of education is better traditional or modern, especially in underdeveloped and developing countries. Therefore, reforms in the education towards contemporary education, the successful transition from traditional to modern education, youth protection from migration, expanding labour market and social security should be priorities of every educational institution.
028

\section{THE FREQUENCY AND MOTIVATION OF UNIVERSITY AND COLLEGE STUDENTS TO PARTICIPATE IN SPORTS}

Sarolta Fest', Erzsébet Lestyán', Ágota Balogh Szabóné1, Josip Lepes², Szabolcs Halasi ${ }^{3}$

${ }^{1}$ Gál Ferenc College Faculty of Education, Szarvas, Hungary, ${ }^{2}$ Gál Ferenc College, Szeged, Hungary, ${ }^{3}$ University of Novi Sad, Hungarian Language Teacher Training Faculty, Subotica, Serbia

Correspondence: Fest Sarolta (fest.sarolta@pk.gff-szarvas.hu)

The institutional background of higher education can contribute to the social and emotional development of students and their overall health and psychological well-being. The aim of our research is to investigate the frequency and motivation of Hungarian home and cross-border higher education students to participate in sports. In our study we compare the sporting habits, environment and interests of Hungarian and foreign students. Both quantitative and qualitative methods were used in our research. In the quantitative part of the research, 500 students from 5 institutions completed our questionnaires. The qualitative research includes interviews with leaders of sports institutions and teachers of physical education. Based on the results of our research, it was found that sporting habits are greatly influenced by the institutional environment and the availability of equipment as well as the students' timetable. Students' participation in sports is motivated by health promotion and awareness. With all of this in mind, factors undermining student participation in sports are largely lack of time and access to facilities. There is a difference in the frequency and motivation of Hungarian home and cross-border university and college students due differences in the availability of sports facilities, equipment and their location. However, a lack of time was important in both cases. Student motivation was also stimulated where sports trainers were not only managers but also participated in sports activities. This contributed greatly to the students' motivation to learn.

\section{O29 \\ CONNECTION BETWEEN BALANCE AND COORDINATION IN PRESCHOOL CHILDREN}

Jelena Alic ${ }^{1}$, Gordana Ivkovic', Branko Turopoljac ${ }^{1}$

'University of Zadar, Zadar, Croatia

Correspondence: Jelena Alic (jcetinic@unizd.hr)

The aim of the research is to determine if there is a correlation between balance and coordination in children of preschool age. The study was conducted on appropriate sample of 92 preschool children, of whom 49 boys and 43 girls. The results indicate that there is a correlation between balance and coordination achieved in all the tests except in the test of standing on the bench with two legs one in front of the other and in the test of walking on all fours. Differences by gender and by additional sports activity are significant only in the test of running between stands. Boys have better coordination than girls. Children who do additional sports activities have better coordination than children who do not participate in additional sports activities. Considering the results obtained, it can be concluded that the balance is related to the coordination, so the use of kinesiological operators for the development of balance could indirectly affect better results in tests for evaluation of coordination and vice versa.

\section{O30}

\section{STRATEGIES AND PSYCHOLOGICAL SKILLS TRAINING EXPERIENCE IN MALAYSIA NATIONAL RUGBY TEAM DURING THE COMPETITIONS OF THE ASIA RUGBY CHAMPIONSHIP 2018} Thariq Khan Azizuddin Khan', Ahmad Fadzlee Ahmad Idriss', Zulakbal Abd Karim ${ }^{1}$ 
${ }^{1}$ Sultan Idris Education University, Faculty of Sport Science and Coaching, Perak, Malaysia

Correspondence: Thariq Khan Azizuddin Khan (thariq@fsskj.upsi.edu. my)

The purpose of this study is to examine the application, experiences, and perceptions of the psychological skills training (PST) among Malaysian national rugby 15 's players during the Asian Rugby Championship (ARC). In this study the mixed method research design (Exploratory Sequential Mix-Method) using questionnaire (quantitative) and interview (qualitative) methods were employed. Firstly, the Test of Performance Strategies (TOPS) questionnaire was administered with all 25 players. Using the MANOVA statistical analysis the study findings showed that there were only significant differences in the two aspects of strategy namely automacity and goal setting $(\mathrm{p}<0.017)$ out of nine psychological performance strategies. In terms of psychological strategy based on player position and experience, there were significant differences only in each aspect of the strategy encompasses goal setting and automacity only ( $\mathrm{p}<0.017$ ). Secondly, semi structured interviews were conducted with 10 key players, the results indicated that 70 percent of players were unable to provide accurate information and limited experience on the use of psychological strategies during competition. The implications of this combined analysis indicate that there is no difference in the use of sports psychology strategies overall or in terms of player position and experience. Malaysia rugby players' also have limited experience on comprehensive psychological skill training due to lack of consistent psychological skills training.

\section{O31}

\section{COGNITIVE FUNCTION AND SPORT ACTIVITY OF MALE OLDER ADULTS}

Petra Pacesová', Pavel Smela', Branislav Antala', Dagmar Nemcek ${ }^{1}$ ${ }^{1}$ Comenius University, Faculty of Physical Education and Sport Correspondence: Petra Pacesova (petra.pacesova@uniba.sk)

The aim of the study is to expand the knowledge in the area of the cognitive function and sport activity. We assume that some kind of sport activity (open skill sports) can help increase the level of cognitive functions. The research sample comprised of 65 male in older adulthood ( $55.45 \pm 6.10$ years). Men were divided into three groups: males engaged in open-skill sports $(n=13)$, in closed-skill sports $(n=24)$ and not engaged in any sport activity $(n=28)$. We used standardized S-test to determine the level of cognitive functions. To obtain the results we used Kruskall-Wallis test and Mann-Whitney $\mathrm{U}$ test. To determine the relationship between age and the level of cognitive function, we used Spearman Rho coefficient. Males engaged in open-skill sports have shown higher level of cognitive functions than male engaged in closed-skill sports $(\mathrm{p}=0.001)$ and also as non-athletes $(\mathrm{p}=0.001)$. There was also difference between male engaged in closed-skill sports and non-athletes $(\mathrm{p}=0.04)$. Correlation analysis also showed a strong negative relationship between the level of cognitive function and age. Our study confirmed theoretical and research background that sport activity can help increase the level of cognitive function and, at the same, that the level of cognitive function decreases with age. We could not confirm the theory of different involvement of cognitive functions regarding different types of sport disciplines.

\section{O32}

PERSONALITY TRAITS AS A PREREQUISITE FOR PROPER ACCESS TO YOUNG ROWERS

Mladen Marinovic', Ana Kokan ${ }^{2}$

${ }^{1}$ University of Split, Faculty of Kinesiology, Split, Croatia, ${ }^{2}$ Institut of Ki- nesiology and Sport, Split, Croatia

Correspondence: Mladen Marinovic (marin@kifst.hr)

In this paper, the authors emphasize the characteristics of mental well-being, for which it is essential to know the psychological characteristics of the participants in the sport. During last 25 years authors have applied three test in area of motivation and personality traits with purpose to analyze characteristics of competitive rowers. The tests are: General achievement motivation questionnaire (GAM), Sport achievement questionnaire (SAM) and Eysenck's personality questionnaire (EPQ). The research included 63 male rowers, members of rowing club Neptun (Dubrovnik, Croatia), who competed at National Championships in junior and senior category. Using statistical package 13 (TIBCO Software Inc. (2017)), scatterplot was obtained between two personality traits: neuroticism $(\mathrm{N})$ and extraversion-introversion (E). In such scatterplot, the lower score limits were interpolated at E 14 and N 10 (Eysenck \& Eysenck, 1994) and using the Galen-Kant-Wundt scheme a four temperament picture was presented. In the quadrant of sanguine (stable extraverts (ES)) 17 young rowers were projected. Choleric (extrinsic neurotic (EN)) is 15 as well as phlegmatic (introverted stable (IS)) and 16 melancholic (introvert neurotic (IN)). Every child has the right to have a positive effect on the sport in order to create physical fitness and mental well-being. That is why it is very important for those who manage the sporting process to have valid information on the physical and psychological status of the individual.

\section{O33}

\section{PRE-COMPETITIVE ANXIETY DIFFERENCES BETWEEN YOUTH FEMALE AND MALE KARATE ATHLETES}

Sasa Krstulovic', Jurica Matanovic', Marko Erceg' ${ }^{1}$, Goran Kuvacic ${ }^{1}$

${ }^{1}$ University of Split, Faculty of Kinesiology, Split, Croatia

Correspondence: Sasa Krstulovic (sasa@kifst.hr)

Emotions in sports competitions play a significant role and have been the subject of interest in many studies so far. Anxiety usually has a negative connotation and is presented as something bad for sports success. Therefore, the aims of this investigation were: 1) to determine the severity of pre-competitive anxiety in young karate athletes and 2) to identify possible differences in the degree of pre-competition anxiety between female and male karate athletes. The sample of subjects comprised of 20 female and 20 male karate competitors (mean $\pm \mathrm{SD}$ : age $=17.2 \pm 0.69$ years). To determine the level of pre-competitive anxiety, subjects completed the CSAI2 questionnaire one hour before the national competition. Most of the subjects had moderate levels of somatic and cognitive anxiety and moderated to high levels of self-esteem. T-test for independent samples did not identify statistically significant differences between females and males in the variables of pre-competitive anxiety. Since these are not elite athletes, a high value of pre-competitive anxiety is expected. Additionally, no gender differences in perceptions of competition are in line with previous research. Future research should link the degree of pre-competitive anxiety and situational performance in the same competition.

\section{4}

\section{OVERVIEW OF MUSCULOSKELETAL MECHANOBIOLOGY: INTERPRETATION OF MUSCLE ADAPTATION BEHAVIOR AFTER MUSCLE STRENGTH TRAINING}

Slavko Rogan', Jan Taeymans ${ }^{1}$, Roger Hilfiker ${ }^{2}$, Heiner Baur ${ }^{1}$ ${ }^{1}$ Bern University of Applied Sciences, Department of Health Professions, Bern, Switzerland, ${ }^{2}$ University of Applied Sciences and Arts Western Switzerland Valais, School of Health Sciences, HES-SO Valais-Wallis, Leukerbad, Switzerland 


\section{Correspondence: Slavko Rogan (slavko.rogan@bfh.ch)}

Controversy exists regarding training load for optimal muscle adaptation in humans. Knowledge from mechanobiology could assist in clarifying the training load parameters for effective gain in muscle mass. Human cells have mechanosensors that detect bending forces and osmotic pressure changes. Mechanical stimuli are converted into intracellular biochemical signals that control gene expression and cellular function. Muscle strength training can be seen as a pacemaker that produces mechanically stimuli on the muscle cell. The following protein synthesis is regulated by the 'mammalian Target of Rapamycin' protein (mTOR). This overview work aimed to summarise the physiological reactions to muscle strength training on hormone markers, intramuscular signalling and skeletal muscle mass adaptation through the mTOR pathway. Two independent reviewers performed a systematic search in PubMed. Characteristics describing physiological muscle cell reactions, muscle tissue reactions and parameter of training load were extracted. Twenty-three articles investigated hormone marker and intramuscular signalling while four studies evaluated muscle tissue reaction and training regimes after muscle strength training. Recommendation for muscle strength training regimes to increase muscle mass in humans may consist of the following: $>70 \%$ of one-repetition maximum, $>6$ sets $\mathrm{x} 8$ to 10 repetitions with a rest of $<2$ minutes.

\section{O35}

TRADITIONAL GAMES AND INTERGENERATIONAL STRATEGIES - RELEVANT SELF-REPORTED HEALTH DOMAINS IN "PLAYERS" WITH PARKINSON'S DISEASE

Marlene Rosa ${ }^{1,2}$, Carina Forte', Raul Antunes ${ }^{3,4}$, Tânia Maurício ${ }^{5}$ ${ }^{1}$ Polytechnic of Leiria, Health Sciences School, Leiria, Portugal, ${ }^{2}$ Polytechnic of Leiria, Center for Innovative Care and Health Technology, Leiria, Portugal, ${ }^{3}$ Polytechnic of Leiria, Education School, Leiria, Portugal, ${ }^{4}$ Polytecnhic of Leiria, Center of Quality of Life, Leiria, Portugal, ${ }^{5}$ Portuguese Association of Parkinson Disease, Lisbon, Portugal

Correspondence: Marlene Rosa (marlene.rosa@ipleiria.pt)

Games have been increasingly used as a rehabilitation strategy because of their potential to integrate the multidimensional health domains affected by Parkinson's disease (PD). To describe the most relevant patients' self-reported health domains after a program with traditional games, including intergenerational dynamics. Three sessions were held with adapted traditional games, including nine elderly people with Parkinson Disease. Additionally, a session with intergenerational dynamics was also organized. Feedback from participants with PD was collected, using a structured interview based on questions about personal feelings and perceptions during games' sessions. The analysis of this interview involved codification of health-related domains using the International Classification of Functioning, Disability and Health (ICF). Throughout the three sessions, 125 relevant health-related domains were self-reported: $52 \%$ were activity and participation related domains (e.g., d920, participation in recreation and leisure activities; d7502, relationship building skills), $40 \%$ were body structures and functions domains (e.g., b1522, emotion) and $8 \%$ were contextual factors domains (e.g., b440, demonstration of positive attitudes towards the disease). This program demonstrated to be potentially important for people with Parkinson disease as it positively affected patients' perception of their health in several domains.

\section{O36}

\section{USING AN ORIGINAL QUIZ GAME FOR LEARNING ABOUT FALLS RISK AND COGNITIVE-MOTOR EXERCISE IN DEMENTIA - AN ICF HEALTH-APPROACH}

Mónica Costa ${ }^{1,2}$, Marlene Rosa ${ }^{1,2}$, Catarina Tomás ${ }^{1,2}$, Inês Lopes ${ }^{1}$, Susana Arranhado ${ }^{1,3}$, Marta Duarte ${ }^{4}$

${ }^{1}$ Polytechnic of Leiria, Health Sciences School, Leiria, Portugal, 'Polytechnic of Leiria, Center for Innovative Care and Health Technology, Leiria, Portugal, ${ }^{3}$ Center for Health Technology and Services Research, Porto, Portugal, ${ }^{4}$ Alzheimer Portugal Foundation, Lisbon, Portugal Correspondence: Monica Costa (marlene.rosa@ipleiria.pt)

Dementia caregivers' education is a key intervention with a significant impact on moderating burden-related factors, including on the exercise management and falls prevention. To implement an original QUIZ game as a literacy session for dementia caregiver's about fall risk and cognitive-motor exercise. The QUIZ, addressing fall risk and cognitive-motor exercise importance, was implemented in a group of 3 caregivers of people with dementia. The session was video recorded and verbal interactions were transcribed. The International Classification of Functioning, Disability and Health (ICF) was used for coding health-related domains shared between caregivers. Thirty-three different ICF codes were discussed during the QUIZ implementation: 13 about body functions and structures (e.g., psychomotor control b1470, memory b144, form of thought b1601, emotion b1522, etc.); 16 about activities and participation (e.g., handling crisis d2402, handling stress, d2401, maintaining one's health $\mathrm{d} 5702$, recreation and leisure $\mathrm{d} 920$, etc.); 4 about environmental factors (e.g., general products and technology for personal use). Using a QUIZ to understand the risk of falling and the importance of exercise for people with dementia seems to be an efficient literacy tool, as it generates a multidimensional health discussion between caregivers.

\section{O37}

\section{CREATING A BRAND ON THE IDENTITY OF A SPORTS CLUB}

Nenad Bulovic', Neven Seric ${ }^{1}$

'University of Split, Faculty of Economics, Business and Tourism, Split, Croatia

Correspondence: Nenad Bulovic (nenad.bulovic@inet.hr)

Creating a sports club brand is important strategic marketing activity. The quality of the content of sports club brand can be communicated effectively by promoting its key features. The identity of a sports club is important marketing feature that significantly contributes to differentiation on the market. Although communication of the brand image through its identity is increasingly encouraged in recent scientific literature, it is not yet common practice in sports. There are no clear links between the brand image and the sports club identity. The aim of the paper is to argue the importance of implementing the identity of sports club in its brand image. The research has conducted by qualitative and quantitative methods through different sport case studies. The identity of sports club is recognized in terms of its existence, social significance, activities and development to date. The sports brand identity should communicate the core values of the sports club identity. A differentiated brand of sports club is an imperative for desirable positioning on the market. The identity of a sports club is valuable marketing and strategic perspective of its brand. The distinctiveness of sports club brand significantly depends on the implementation of its identity in its image.

\section{O38 \\ SPORTS COMPETITIONS AND FREE MOVEMENT OF WORKERS IN EU: THE BOSMAN RULING AND BEYOND Nikola Dozic', Vladimir Savkovic', Aneta Spaic ${ }^{1}$ \\ 'University of Montenegro, Faculty of Law, Podgorica, Montenegro \\ Correspondence: Nikola Dozic (nikolad@ucg.ac.me)}

The purpose of this article is to establish the influence that the free 
movement of workers in the EU internal market (i.e. Article 45 of the Treaty on the Functioning of the European Union - TFEU) has had historically on the organization of sport competitions in Europe, particularly so since the famous Bosman ruling. To that end, firstly, a brief retrospective was made of the specific and privileged position of Union of European Football Associations (UEFA) in the decades before the aforementioned crucial decision rendered by the Court of Justice of the European Union (CJEU). Secondly, a detailed examination of the relevant circumstances in the Bosman case was undertaken in order to establish which (impermissible) restrictions to free movement of workers in EU were eliminated and which, if any, remained. Thirdly, further developments of the CJEU case law regarding the implementation of Article 45 TFEU on European sports organizations were examined as well. Finally, based on the findings coming from the undertaken analyses, a conclusion is offered that in spite of some significant developments in recent decades, the rules of European sports associations are still somewhat controversial in terms of their concordance with one of the four freedoms of the EU internal market.

\section{O39}

\section{MANAGING PUBLIC MONEY FOR SPORTS ACTIVITIES IN KOSOVO}

Iber Alaj', ${ }^{1}$, Enver Tahiraj', Fadil Luta', Sami Sermaxhaj'

${ }^{1}$ Universi College, Faculty of Physical Culture Sport and Recreation, Prishtina, Kosovo, ${ }^{2}$ European University Kallos, Faculty of Health Science, Tuzla, Bosnia and Herzegovina

Correspondence: Iber Alaj (iberalaj@yahoo.com)

Sport in the country is supported through program policies relying on its development with the difficulties that our society has gone through and the sports activity of the country itself. The purpose of this study presents the money management in sports organizations, infrastructure and other stakeholders. Structured analysis of reflected expenses was used based on the period of 2018. The results have shown the budget allocation for federations, clubs, sports infrastructure, etc., that money management for sport has been executed for some 35 sports federations with around 867 clubs, with a total of approximately 81.041 athletes participating in activities, of which 67.583 are men and 13,458 women and the amount that was spent was about $14,247,919$ euro out of 18.489 .005 euro in revenue from the government of the country. If appropriate measures are taken to increase the budget by involving serious investors in public infrastructure in public-private partnerships, which then would subsequently affect the increase of sports facilities and their rational management. Sports organizations should be supported in functioning fiscal facilities available to companies that are assisting clubs and federations in developing and improving the sport and its conditions for the progress of sports activities.

\section{O40}

RELATIONSHIP BETWEEN BODY HEIGHT AND HAND LENGTH IMPACT OF TRAINING PROGRAM FOR THE DEVELOPMENT OF EXPLOSIVE FORCE ON SOME SPECIFIC MOTOR SKILLS IN 14-YEAR OLD STUDENTS

Astrit Iseni', Vullnet Ameti', Shpresa Memishi', Blerim Sulejmani ${ }^{1}$

'University of Tetova, Faculty of Physical Education, Tetovo, North Macedonia

Correspondence: Astrit Iseni (astrit.iseni@unite.edu.mk)

The purpose of this research is to confirm the impact of the training model for the development of explosive force on some specific motor skills. The research was conducted on a sample of 170 male testers aged 14 years \pm 6 months, students of primary schools "Naim-
Frashëri" and "BajramShabani" - Kumanovo. A total of 9 specific motor variables were used in this research, of which: 6 variables for the evaluation of explosive force and 3 variables for evaluating sprinting. In order to verify the differences between the control and experimental groups in the initial and final measurements, univariate and multivariate analysis of variance and covariance was used. From this research we can conclude that variables for assessing specific motor abilities have statistically significant differences with probability 0.000 between the control and experimental group in the initial measurements, in only 4 variables out of 9 motor-specific variables, while after Applying the experimental model, in the final measurements, we can observe that all motor-specific variables have statistically significant differences with probability of 0.000 between the control and experimental groups. Thus we can prove that this training model has a significant influence on the development of explosive force, as well as other motor skills such as speed and agility, and the same pattern can be used in top sportspersons.

\section{O41 \\ THE INFLUENCE OF SPECIFIC-MOTOR ABILITIES ON ANTHROPOMETRIC CHARACTERISTICS AT 13 YEAR OLD STUDENTS \\ Vullnet Ameti ${ }^{1}$, Astrit Iseni', Shpresa Memishi', Haki Ismaili ${ }^{1}$}

'University of Tetova, Faculty of Physical Education, Tetovo, North Macedonia

Correspondence: Vullnet Ameti (vullnet.ameti@unite.edu.mk)

This paper explores the influence of specific - motor abilities on latent anthropometric dimensions of the body. The purpose of this research is to establish connection between specific - motor abilities as prediction system and latent anthropometric dimension as parameters criteria. The research has been conducted with 60 male aged $13 \pm 6$ months, in primary school "BajramShabani" - Kumanovo. The study used 30 variables of which 13 variables for assessment of specific - motor compartment, and 17 variables for assessment of Anthropometric characteristics. With the application of factor analysis, it is determined the structure of specific motor variables and Anthropometric variables in latent space, and the extracted factors are presented as a system of prediction variables and using regression analysis is determined the influence of criteria variables. Based on the analysis of the results, it can be concluded the following: variables of specific motor abilities (such prediction system) have a statistically significant impact on Anthropometric variables (such criteria variables). The variables of specific motor skills (such prediction system) have statistically significant variables AFAK1 (first anthropometric factor) and AFAK2 (second anthropometric factor), on significance level of 0.045 or 0.027 . This means that with the application of these specific-motor tests, we can expect a proper development of functional and motor abilities among students, as well as, it has a positive influence in the development of the whole anthropological status.

\section{2 \\ ACTIVITY PROFILE IN AMATEUR BOXING: DIFFERENCES BETWEEN THE 1984 AND 2017 WORLD CHAMPIONSHIPS Goran Kuvacic', Roko Cule', Sasa Krstulovic', Marko Erceg ${ }^{1}$ 'University of Split, Faculty of Kinesiology, Split, Croatia Correspondence: Goran Kuvacic (gorkuv@kifst.hr)}

Activity analysis means identifying and describing the elements of a particular sport and evaluating them in contributing to overall success. Therefore, the main aim of this investigation was to identify differences in some tactical parameters of elite amateur boxers over a period of 33 years. For this investigation, five final matches from 
the 1984 World Championship in Los Angeles and the 2017 Amateur Boxing World Championship in Hamburg were analyzed. Ten situational parameters in 5 weight categories were analyzed: lightweight $(-60 \mathrm{~kg})$, light welterweight $(-64 \mathrm{~kg})$, welterweight $(-69 \mathrm{~kg})$, light heavyweight $(-81 \mathrm{~kg})$ and super heavyweight $(+91 \mathrm{~kg})$. Three boxing experts collected data via video analysis of five finals in each competition. T-test and Mann-Whitney U test revealed statistically significant differences between the two competitions in all observed situational variables. In modern boxing, fighters have a greater tendency to initiate a clinch. Activity intensity is at the highest level in the second round, slightly lower in the first round, and probably due to fatigue the lowest in the third round. The total number of punches follows the same pattern. On the other hand, thirty years ago, the intensity and the total number of punches increased progressively through the rounds. The straight hand punch is the most frequent in both competitions. Olympic boxing has evolved significantly over the last 30 years. Based on the results obtained, one can predict the direction of future changes in the structural and situational parameters of Olympic boxing.

\section{3}

\section{ACCURACY OF VO2MAX PREDICTION USING GARMIN} PHOENIX 5, 6 GPS WATCH

Jan Hnízdil', Stefan Balkó', Martin Skopek'

'Jan Evangelista Purkyně University in Ústí nad Labem, Ústí nad Labem, Czech Republic

Correspondence: Jan Hnizdil (jan.hnizdil@ujep.cz)

The goal of this study is to validate the Garmin VO2max test using a Garmin watch (Phoenix 5 and 6) against VO2max measurement, using golden standard - incremental treadmill test with Oxycon Delta open circuit spirometry. Forty healthy subjects, recreational runners, (27 men, 13 women) between the ages of 22 and 45 (age $=33.7 \pm 3.9$ years) followed instructions how to obtain a VO2max score according Garmin procedure (VO2G). One week after Garmin test, VO2max was measured with an incremental test on the treadmill using modified Conconi test. VO2max was detected using Oxycon Delta open circuit spirometry (VO2O). Using Garmin formula, averaged VO2max was $52.89+/-4.26$ ml.kg- 1 . min-1. Result from direct spirometry was $52.34+/-4.02$ ml.kg-1. min-1. Descriptive statistic, t test value $(0.75, \mathrm{p}=0.47)$, Person correlation coefficient (0.85) effect size ?2 (-0.01) and visual inspection of Bland Altman plot indicate there are no significant difference between direct (VO2O) and indirect (VO2G) VO2max assignment. The findings suggest that there is strong validity and reliability of VO2max assignment using the Garmin Phoenix 5 and 6 GPS and heart monitors. This may provide alternative, less expensive and easier way to establish $\mathrm{VO} 2 \mathrm{max}$ value.

\section{O44}

\section{EXPERIENCE MARKETING OF SPORT'S TOURISM IN MONTENEGRO}

Radmila Janicic ${ }^{1}$

${ }^{1}$ University of Belgrade, Faculty of Organizational Sciences, Belgrade, Serbia

Correspondence: Radmila Janicic (radmila.janicic@gmail.com)

The paper present theoretical and practical aspects of experience marketing in sport's tourism in Montenegro. Focus of the paper is developing theoretical aspects of experience marketing in sport's tourism in Montenegro. The goal of the paper is to analyse both theoretical and practical aspects of experience marketing in sport's tourism. Also, in empirical research of the paper will be present results about segmentation of target groups of sport's events and their experience. The research will be prepared by questioner and proceed by modern quantitative tools, which present results in appropriate ways, useful for further strategic planning of experience marketing in sport's tourism. The results of experiences of audiences will be useful for further developing of sport's tourism in Montenegro. The results of empirical research will lead to further theoretical and practical analysis of experience marketing in sport's tourism. The theoretical improvement of experience marketing is important, as new concept of marketing approach. It is very important for tourists to be in touch with sports, adventure, outdoor activities, like natural, minimalism nomads, whose love to experience simple, minimalism life, in contact with nature, in camp's communities. Tourists experience deep contact with nature, through sport's activities. The empirical research, in the paper, will show all aspects of experience marketing in sport's tourism in Montenegro.

\section{5 \\ SPORT'S JOURNALISM IN DEVELOPMENT OF MONTENEGRO TOURISM \\ Svetozar Janicic ${ }^{1}$ \\ ${ }^{1}$ Sport Club, Belgrade, Serbia \\ Correspondence: Svetozar Janicic (radmila.janicic@gmail.com)}

The paper present theoretical and practical aspects of sport's journalism in development of Montenegro tourism. Focus of the paper is developing theoretical and practical aspects of sport's journalism in development of Montenegro tourism. The goal of the paper is to analyse both theoretical and practical aspects of sport's journalism in development of Montenegro tourism. Also, in empirical research of the paper will be present results about segmentation of target groups of sport's clubs, sport's events, sport's players, sport's organizations, sport's institutions and sport's educational institutions. The research will be prepared by questioner and proceed by modern quantitative tools, which present results in appropriate ways, useful for further strategic planning of Montenegro sport's tourism. The results of research will be useful for further developing of Montenegro sport's tourism. The results of empirical research will lead to further theoretical and practical analysis of sport's journalism in development of Montenegro tourism. The theoretical improvement of sport's journalism in development of Montenegro tourism is based on new concept of holistic marketing approach. The empirical research, in the paper, will show all aspects of sport's journalism in development of Montenegro tourism. Sports and sport's events connect people in the world. Sport is human need and cosmopolitan approach to world's globalization. The paper will present impact of sport's journalism in development of globalization.

\section{6}

\section{MODEL FOR DEVELOPMENT OF NEW SPECIALIZED TOURISTIC PRODUCT BASED ON THE SPORT PLATFORM} Neven Seric ${ }^{1}$, Anđela Jaksic-Stojanovic ${ }^{2}$

'University of Split, Faculty of Economics, Business and Tourism, Split, Croatia, ${ }^{2}$ University Mediterranean, Podgorica, Montenegro

Correspondence: Neven Seric (nevseric@inet.hr)

This study presents the model for the development of new specialized touristic products based on the sport platform. Focus of the paper is to introduce new scientific model for that purpose. The goal of the paper is to present new scientific concept for the development of the new sport's touristic product. Through empirical research will be present results of one case study from Croatia's sport - touristic practice. The research has conducted by qualitative research. The result of the research will be present through appropriate way, 
useful for testing of the new model for development of new specialized sport - touristic product. The presented model will be the challenge for new research in this area of original touristic products. The presentation of the new model testing. New specialized tourism products are often developed by inertia nowadays. It is usually doing without scientific approach, by combining different contents. Sub-segmentation on the global tourism market implies a higher level of specialization of new tourism products. Especially those based on sports in countries whose athletes and their international successes are a distinctive receptive country's feature on the global touristic market.

\section{O47}

\section{SPORT AND RECREATIONAL ACTIVITIES IN RURAL TOURISM IN COUNTY OF ZAGREB - ANALYSIS AND POSSIBILITIES}

Romana Caput-Jogunica', Tara Glaser ${ }^{2}$, Sanja Curkovic ${ }^{1}$

'University of Zagreb, Faculty of Agriculture, Department for Physical Education and Sport, Zagreb, Croatia, ${ }^{2}$ University of Zagreb, Faculty of Agriculture, Zagreb, Croatia

Correspondence: Romana Caput-Jogunica (rcaput@agr.hr)

According to the Croatian Institute of tourism, the main tourist' motives to spend holidays in Croatia are: to achieve a new experience, to get to know better nature sights and traditional habits as well as sport and recreation. The purpose of this paper is to determine the role and current situation regarding the offer of sport, recreational activities and old sports and games in the rural tourism of the County of Zagreb. The second goal is to recommend further development according to the opportunities and particularity those of unused localities. Development possibilities of sports recreational activities in rural tourism are adduce with SWOT analysis. Comparison of current situation of rural tourism in county of Zagreb is made with good examples from Croatia and other European countries. According to the SWOT analysis the main opportunities for further development are: all-year attractive offer; unused potential of excursion and recreational tourism; increasing demands for outdoor trips and activities and excursion as well as possibilities for educational, sport and recreational activities and promotion of the County' particularities in Europe. One of the preconditions for the development of rural tourism in the County of Zagreb has to be based on the profile of tourist. Except the attractive sport and recreational activities like cycling, horseback riding, walking and climbing tours, orienteering, running, golf, old sports and games etc., it is important to provide promotional activities and to secure trained staff and high standards of infrastructure.

\section{8}

\section{THE ROLE OF RECREATIONAL PROGRAM ATTRIBUTES IN PREDICTING TOURIST REVISIT INTENTION}

Sanja Pekovic', Milica Bojbasa', Djurdjica Perovic ${ }^{1}$

'University of Montenegro, Faculty of Tourism and Hotel Management, Kotor, Montenegro

Correspondence: Sanja Pekovic (psanja@ucg.ac.me)

Recreational programs have great importance in creating a tourist offer. In fact, their main role is to meet the needs of contemporary tourists what could be reflected positively on tourist revisit intention. Accordingly, Western European destinations invest in the development of tourist offer through creation of recreational programs. However, satisfaction with recreational programs depends on various attributes such as diversity, quality, price, frequency, etc. Therefore, if recreational programs are adequately implemented in a way that tourists are satisfied with these attributes then it could be expected that probability of tourist revisit intention increases.
Taking into account the importance of recreational programs, the aim of this paper is to empirically identify which attributes of recreational programs positively influence tourist revisit intention using data on tourists that visited Montenegro during 2019. The findings indicate that certain attributes of recreation programs have positive impact on tourist revisit intention. Based on obtained findings, it is necessary to improve those attributes of recreational programs that did not adequately meet the tourist expectations.

\section{O49 \\ DIFFERENCES BETWEEN FEMALES AND MALES AFTER MUSCLE-DAMAGE AND CRYOTHERAPY}

Erich Hohenauer ${ }^{1,2,3}$, Joseph T. Costello ${ }^{3}$, Tom Deliens ${ }^{4}$, Peter Clarys ${ }^{4}$, Ursula M. Küng ${ }^{2}$, Rahel Stoop ${ }^{1,4}$, Ron Clijsen ${ }^{1,2,4}$

'University of Applied Sciences and Arts of Southern Switzerland, Landquart, Switzerland, ${ }^{2}$ University of Applied Sciences "Thim van der Laan", Landquart, Switzerland, ${ }^{3}$ University of Portsmouth, Portsmouth, United Kingdom, ${ }^{4}$ Vrije Universiteit Brussel, Brussels, Belgium Correspondence: Erich Hohenauer (erich.hohenauer@supsi.ch)

The aim of this studies were to investigate and compare the physiological differences and effects on recovery between females $(n=20)$ and males ( $\mathrm{n}=19)$ after muscle-damage (5x20 drop jumps), followed by cold-water immersion (CWI) and partial-body cryotherapy (PBC). The physiological variables were measured by means of cutaneous vascular conductance (CVC), muscle oxygen saturation (SmO2), mean arterial pressure (MAP) and skin temperature which were measured up to $60 \mathrm{~min}$ after CWI and PBC. Recovery variables were delayed-onset of muscle soreness (DOMS), maximum voluntary contraction (MVC), vertical-jump performance (VJP) and muscle swelling. $\mathrm{CVC}$ and $\mathrm{SmO} 2$ reductions after CWI were larger in the males vs. the females compared to PBC. CWI led to lower skin temperature values in both females and males compared to PBC. There were no main differences on recovery outcomes observed between females and males during the $72 \mathrm{~h}$ recovery period. These results highlight the differences and commonalities between females and males after muscle damage and cryotherapy. In an attempt to explain these differences between females and males, this study might help to better understand the mechanisms of cryotherapy between these two groups.

\section{O50}

\section{ASSESSMENT OF THE KNOWLEDGE OF AMATEUR ATHLETES FROM MONTENEGRO ABOUT THE IMPORTANCE OF} MOUTHGUARDS IN THE PREVENTION OF DENTAL INJURIES

Mirko Mikic ${ }^{1}$, Miroslav Kezunovic', Erol Vrevic ${ }^{1}$

'University of Montenegro, Faculty for Sport and Physical Education, Niksic, Montenegro

Correspondence: Mirko Mikic (mirko.mikic@t-com.me)

The most common type of orofacial injuries while taking part in sports activities are dental injuries. The aim of this study was to evaluate the knowledge of amateur athletes about importance of mouthguard in the prevention of orofacial injuries. This cross sectional study covered 110 amateur athletes of both sexes, ages 15-30. The research instrument was a closed type questionnaire. Statistical data analysis was performed using commercial statistical software SPSS 17.0. The research had a share of $90.10 \%$ of male participants. When asked whether they suffered a dental injury during training or during a game, $15.45 \%$ responded positively. $100 \%$ of participants heard about mouthguards, while only $2.72 \%$ used them. A total of $90.10 \%$ of participants consider that mouthguards are purchased only in sports equipment stores, while $9.9 \%$ of them think that they are custom made by dentists. A total of $64.5 \%$ of participants believe 
that mouthguards are recommended only in combat sports, $33.6 \%$ think that they should be only used in contact sports, $1.8 \%$ in all sports. As much as $98.18 \%$ of participants believe that additional education on the prevention of sports injuries would be beneficial for athletes. The results of this research indicate that there is a low level of knowledge about the importance and ways of preventing orofacial injuries and that in future it is necessary to do more research and education in this field.

\section{1 \\ EFFECTS OF GENDER ON MUSCLE OXYGEN SATURATION OF THIGH MUSCLES DURING MAXIMAL TREADMILL EXERCISE TESTING}

María-José Paredes-Ruiz', María Jódar-Reverte', Ignacio Martinez-González -Moro', Vicente Ferrer-López ${ }^{1}$

${ }^{1}$ University of Murcia, University Institute for Researching in Aging, Research Group: Physical Exercise and Human Performance, Murcia, Spain

Correspondence: María Jose Paredes (mariajoseparedesruiz@gmail.com)

Currently muscle activity can be assessed by oxygen muscle saturation (SmO2) measured by Near-infrared Spectroscopy (NIRS). It is a non-invasive technique that can be used in training planning and control, but we need to know more about it. Analyze gender differences in $\mathrm{SmO} 2$ of quadriceps and hamstrings, in several phases of a maximum stress test. 20 subjects, with an average age of 21 years (10 males and 10 females), performed a maximal treadmill exercise testing. We obtained maximum oxygen consumption (Metalyzer 3B) and monitored the electrocardiogram continuously. In addition, we measure $\mathrm{SmO} 2$ of quadriceps and hamstrings in rest (R), start decline (D) and maximum effort (M), with two Humon Hex device one placed the anterior side of the thigh and another on the back. Quadriceps SmO2 in males: $\mathrm{R}=59.4+11.5 \% ; \mathrm{D}=48.3+19.1 \% ; \mathrm{M}=52.5+13 \%$. Quadriceps SmO2 in women: $\mathrm{R}=51+11.5 \% ; \mathrm{D}=48.5+9.4 \% ; \mathrm{M}=43.1+6.9 \%$. Hamstrings $\mathrm{SmO} 2$ in males: $\mathrm{R}=56,2+13.1 \%$; $\mathrm{D}=62.9+9.1 \%$; $\mathrm{M}=57.5+13.9 \%$. Hamstrings $\mathrm{SmO} 2$ in women $\mathrm{R}=56.9+18.9 \%$; $\mathrm{D}=49.7+7.4 \% ; \mathrm{M}=38.2+14.6 \%$. There are no significant differences between muscles. There are only significant differences in $M$ in hamstrings (p-0.009). SmO2 during treadmill exercise is similar in both sexes but the overall decrease with maximum exercise is greater in women's hamstrings.

\section{O52}

MODEL OF DIFFERENTIATED TRAINING OF RUNNERSMARATHONES ON DEVELOPMENT OF TEMPO AND SPEED ENDURANCE BASED ON TAKING INTO ACCOUNT TYPES OF ENERGY METABOLISM

Vladislav Bakayev', Alexander Bolotin ${ }^{1}$

${ }^{1}$ Saint-Petersburg Polytechnic University, Institute of Physical Education, Sport and Tourism, Saint-Petersburg, Russia

Correspondence: Vladislav Bakayev (vlad.bakaev@gmail.com)

Studies have shown that the adaptation of the body of marathon runners of different types of energy metabolism to competitive loads, as well as to the development of pace and speed endurance is not the same. The process of adaptation of the functional systems of their body, characterizing the pace and speed endurance, occurs mainly due to the differentiation of the use of tools and methods corresponding to the type of their energy metabolism. This allows not only more efficiently expanding the capabilities of the cardio-respiratory system of athletes, but also bringing them to a higher quality level of development of tempo and speed endurance. As a result of the study, it was found that for athletes of the aerobic type of ener- gy metabolism, pace endurance should be developed using the standard-continuous exercise method, and speed endurance should be developed using the repeated training method. For marathon runners of the anaerobic type of energy metabolism, pace endurance should be developed by the method of interval exercise, and speed endurance by the method of unsaturated effort with a normalized number of repetitions of distance segments. For marathon runners of a mixed type of energy metabolism, pace endurance should be developed by the variable training method, and speed endurance should be developed by combining the repetitive method with the method of unsaturated effort with a fixed number of repetitions of overcoming distance runs.

\section{3}

\section{COMPARISON OF DYNAMIC AND STATIC STRETCHING TO THE LEVEL OF EXPLOSIVE STRENGTH OF IN PRIMARY AND SECONDARY SCHOOL PUPILS LOWER LIMBS}

Hana Kabesová', Jitka Vaněcková', Martin Bahník'

'Jan Evangelista Purkyně University in Ústí nad Labem, Ústí nad Labem, Czech Republic

Correspondence: Hana Kabesova (hana.kabesova@ujep.cz)

The issue and the inclusion of static and dynamic stretching in warming-up in the training unit solves many authors. Research also suggests that in the context of flexibility development, it is necessary to concentrate on other motor skills. The goal of this study is to evaluate the influence of static and dynamic stretching in the introductory parts, during warm-up, at the level of the explosive lower abilities in limbs aged 16 to 18 years. It was used the questioning method to record the measured data (raw score) and for this it was used a record sheet. As another methods were chosen standardized tests, which were used for diagnostics explosive forces of lower limbs - long jump from the snoop and vertical jump. A static stretch method was used, based on the fact that long and static durations cause a negative effect on performance. Another method was the use of dynamic warm-ups, when higher forces are expected to be generated due to increased activation of motor units. The latest testing was done without the application of any stretch. The demonstrable result is that dynamic stretching has the most efficient influence on the explosive force of the lower limbs and is the most appropriate type of warm-up before sporting performance.

\section{4}

INTERNAL AND EXTERNAL TRAINING LOAD OF YOUNG TEAM HANDBALL PLAYER'S DURING THE COMPETITION

Dora Maric ${ }^{1,2}$, Barbara Gilic ${ }^{1,3}$, Nikola Foretic ${ }^{1}$

${ }^{1}$ University of Split, Faculty of Sport, Split, Croatia, ${ }^{2}$ University of Palermo, PhD Program in Health Promotion and Cognitive Sciences, Palermo, Italy, ${ }^{3}$ University of Zagreb, Faculty of Kinesiology, Zagreb, Croatia Correspondence: Dora Maric (do.maric@gmail.com)

The aim of study was to examine the internal- and external-training-load (ETL and ITL, respectively) during the match of young handball players. Field testing included heart-rate-monitoring (Memory belt, Suunto) as a marker of ITL and accelerometry (motion-biosensor, Actical Respironcis, Philips) as a marker of ETL. Time motion analysis data was obtained through recording player's game activities and later analysed with a software package (Matlab). T-test and Pearson-product-moment correlation coefficient was used to examine the differences and the relationship between variables collected in the study. T-test analysis did not show significant differences between the total distance covered (2216.42-2135.42 meters), steps conducted (1829.25-1829.83 steps), steps per minute (91.46-91.49 steps/min), energy expendi- 
ture (92.24-90.87 mets), time spent in higher intensity zones calculated by motion biosensor (13.08-12.75 minutes), training-load calculated by Edwards TRIMP method (91.54-88.56 scores) in the first- and in the second-half of the match. Physical activity variables show no significant correlations with the data assessed by heart rate monitors. Similar results in monitored training-load variables in first and second half is connected with game intensity that was consistent during whole match. Lack of correlations between ITL and ETL variables points that accelerometry is not suitable for assessment of metabolic training-load in intermittent activities such as handball.

\section{O55}

\section{RELATIONS BETWEEN EXTERNAL TRAINING LOAD INDICATORS AND RUNNING PERFORMANCE IN ELITE SOCCER}

Toni Modric ${ }^{1,2}$, Sime Versic ${ }^{1,2}$, Damir Sekulic ${ }^{1}$

${ }^{1}$ University of Split, Faculty of Kinesiology, Split, Croatia, ${ }^{2}$ NK Hajduk, Split, Croatia

Correspondence: Toni Modric (toni.modric@yahoo.com)

Relationship between weekly external training load, and running performances in soccer matches is still unknown. The main goal of this study was to: (i) evaluate running performances in matches and weekly external training load, and (ii) to evidence possible associations which may exist between these two sets variables. Running performances in matches of Croatian first division and external training load in the week that precede each match were analysed by Global Positioning System throughout 78 items. The average weekly total distance covered, total weekly number of acceleration and deceleration are 1.81 times greater in trainings than in matches. The greatest distance covered in high intensity running is done by forwards, both in matches and weekly trainings $(894 \mathrm{~m}$ and $657 \mathrm{~m}$ in average, respectively). The lowest distance covered in high intensity running is evidenced for central defenders in matches (averagely $402 \mathrm{~m}$ ) and for central midfielders in weekly trainings (averagely $431 \mathrm{~m}$ ). Higher weekly amount of medium and high intensity activities (distance covered in running, high speed running, sprinting and number of high intensity accelerations and decelerations) positively reflects in the matches $(\mathrm{p}<0.05)$. Results from this study indicate that running demands differ depending on playing positions both on trainings and matches. These findings should be applied in creating position specific training plans and programs.

\section{6}

ASSOCIATION OF MOTOR ABILITIES AND MORPHOLOGICAL CHARACTERISTICS WITH RESULTS ON A ROWING

\section{ERGOMETER}

Tomislav Sablic ${ }^{1}$, Ognjen Uljevic', Sime Versic

'University of Split, Faculty of Kinesiology, Split, Croatia

Correspondence: Tomislav Sablic (t_sablic@hotmail.com)

The main aim of this study was to determine the influence of morphological characteristics and motor abilities on the results achieved on the rowing ergometer. The participants were XY students of Faculty of Kinesiology in Split, Croatia (XY males, XY females). The sample of variables consisted of a total of 22 variables: 11 variables measuring morphological characteristics, 10 motor abilities (predictors), and the result on a rowing ergometer. The ergometer variable represented the test result achieved on a rowing ergometer at a distance of 2.000 meters. The correlation between predictors and criterion were evidenced by Pearson's product moment correlation. Significant correlation was found between rowing $2000 \mathrm{~m}$ on ergometer and wall squat, stand and reach, body height, foot-tap- ping and calf skinfold for men; and body height and mass, calf- and mid-upper-arm-circumference, biceps-, triceps-, subscapular- and calf-skinfold, medicine ball throw and wall squat test, for women. Success in rowing is directly dependent on the morphological characteristics and motor abilities. For more detailed analysis, partial influences of each individual factor, psychophysical characteristics, technical and tactical abilities and external influence should be taken into consideration.

\section{7}

\section{SPORT SPECIFIC VERTICAL JUMPS IN VOLLEYBALL}

Suncica Pocek', Dusko Cvijovic', Zoran Milosevic', Patrik Drid'

'University of Novi Sad, Faculty for Sport and Physical Education, Novi Sad, Serbia

\section{Correspondence: Suncica Pocek (suncicapocekfsfv@gmail.com)}

Vertical jump is fundamental part of the spike, block and serve. Jump is also used when setting, because it reduces the flight time of the ball and speeds up the attack. We hypothesized that players from various sport activities can have similar values of general jumping performance, while at the same time different specific volleyball jumping performance. One hundred male college athletes (age: $19.8 \pm 0.7$ yrs.; training experience: $6.73 \pm 3.9$; body height: $185.8 \pm 7.5$; body mass: $81.32 \pm 9.37 \mathrm{~kg}$ ) have participated in this study. Subject sample have been composed of physically active non players, volleyball, football, basketball, handball, combat, track and field and water polo players. Subjects performed spike and block vertical jumps and standing broad jump. Athletes were familiarized with testing protocol during 12 weeks of their training sessions. Differences were determined using the MANOVA with a LSD post hoc test ( $\mathrm{p}$ $\leq 0.05$ ). The differences in jumping abilities reached statistical significance for the block jump, relative block jump, spike jump and standing broad jump. Volleyball players had the highest jumps, even though basketball players had higher values of body height (spike jump $57.31 \pm 10.09$ vs $49.47 \pm 8.42 \mathrm{~cm}$, body height $190.00 \pm 7.27$ vs $194.43 \pm 4.35 \mathrm{~cm}$ ). In order to excel, players should master the technique of basic skills so they could use their motor abilities in the most efficient way.

\section{8}

\section{DEVELOPMENT AND TESTING OF AN INSTRUMENT FOR ASSESSING THE COORDINATION OF PRESCHOOL AND EARLY SCHOOL AGE CHILDREN}

Nenad Rogulj', Kajo Tukic ${ }^{2}$, Sonja Marie-Buotic ${ }^{3}$, Marijana Cavala'

'University of Split, Faculty of Kinesiology, Split, Croatia, 'Primary School "Knez Trpimir", Kastel Gomilica, Croatia, ${ }^{3}$ Kindergarten "Marina”, Marina, Croatia

Correspondence: Nenad Rogulj (nrogulj@kifst.hr)

The aim of research was to establish metrical characteristics of three newly constructed tests for assessing coordination abilities in preschool children and in younger pupils. The research was done on the total sample of 101 respondents; 62 boys and girls in lower school grades, aged 7-8 in addition to 39 preschool boys and girls, aged 5-6. Three motor tests for assessing coordination abilities were measured. Significant correlations between three measurement items in all three tests as well as high values of Cronbach alpha coefficients indicate good reliability. The sensitivity of the tests was analysed after the condensation of results with a rough arithmetic medium. Pragmatic validity was tested using the variance analysis method. Factor analysis was used to determine the factor validity of newly constructed tests. For the purpose of research, we constructed three new measuring instruments for assessing coordination. The tests are simple, easily implementable and do not require particular material-tech- 
nical or infrastructure conditions. We established very good sensitivity, homogeneity, reliability and pragmatic and factor efficiency in all three analysed measuring instruments. Apart from diagnostic purposes and with certain adjustments, these tests may be used as training operators in developing general coordination.

\section{O59 \\ DIFFERENCES IN BALANCE WITH EYES CLOSED, EYES OPENED AND VIRTUAL REALITY ENVIRONMENT \\ Miodrag Spasic', Marin Barisic', Josip Lukac ${ }^{1}$ \\ 'University of Split, Faculty of Kinesiology, Split, Croatia \\ Correspondence: Miodrag Spasic (mspasic@kifst.hr)}

Many studies have examined differences between maintaining balance with open and closed eyes. In this research virtual reality technology is included as special type of visual input for creating static and dynamic virtual environment. The purpose of this paper was to determine whether there is a differences between balance tests on Biodex Balance System (BBS) with different visual input. Participants in the study were young, healthy and active males average age of $21.25 \pm 1.14$ years, body mass $82.57 \pm 8.37 \mathrm{~kg}$ and average body height $185.42 \pm 5.18 \mathrm{~cm}$. Six balance tests were applied on BBS, four in real world and two in virtual environment. Duration and instability level of the BBS platform were same for all tests. None of the participants finished the test in dynamic virtual environment so that test was excluded from further statistical analysis. Factor analysis revealed two main factors (latent dimensions). First factor is characterized with open eyes tests while extremely high projection on second factor can only be seen in a case of test done with the eyes closed. The findings of this study suggest that maintaining balance on BBS with open eyes is different ability than maintaining balance on BBS with eyes closed. Participants cannot maintain balance on BBS if they are immersed in dynamic virtual environment because they obviously rely on visual input.

\section{O60}

\section{FUNDAMENTAL MOTOR SKILLS IN IDENTIFYING DIFFERENCES IN PERFORMANCE LEVELS BETWEEN} STUDENTS AND ATHLETES AGED 10-12 YEARS IN ALBANIA Rovena Elmazi ${ }^{1}$

${ }^{1}$ Sports University of Tirana, Faculty of Physical Activity and Recreation, Tirana, Albania

Correspondence: Rovena Elmazi (rd.elmazi@gmail.com)

Fundamental motor skills developed during childhood are considered building blocks for sport-specific movement patterns and are typically the focus of physical development programs for children, to develop basic motor skills from early childhood. It has been shown that within a sport-specific environment, fundamental motor skills can separate children with potential for sport success. The study aimed to assess fundamental motor skills in identifying differences in performance levels between students and athletes aged 10-12 years living in Albania, and further examine the indicators obtained to study how these two groups compare. The data gathered are indispensable in revealing obesity level, physical and technical capacities and identifying talented athletes. 641 students from primary and secondary schools and 410 athletes were subjected to standard anthropometric measurements, standard physical fitness tests and technical measurements. It can be observed that athletes demonstrate a growth in body mass, even the physical fitness and technical indicators speak for a bigger development. Testing procedures should be expanded from only subjective measurements to objective assessments of technical capacities connected to motor skills. This could be used to select talented children in basketball at a very early age.

\section{O61}

\section{EFFECTS OF PROGRAM OF INTENSIVE TRAINING OF ALPINE SKIING TECHNIQUES ON SOME MOTOR ABILITIES}

\section{Mijo Curic ${ }^{1}$}

'Josip Juraj Strossmayer University of Osijek, Faculty of Education, Department of Kinesiology, Osijek, Croatia

Correspondence: Mijo Curic (micuric@gmail.com)

Skiing activity especially in the conditions of initial learning of alpine skiing technique, is quite tense and takes place over a longer period of time during the day, with physical and psychological loads, caused by adaptation to new equipment and external tough conditions. The aim of this research was to determine the effects of experimental short-term program of intensive training of alpine skiing techniques to particular motor abilities of students. The sample is divided into an experimental group beginners who were on skis for the first time and control group. The results of ANCOVA within variables for the evaluation of motor abilities show statistically significant effects of the applying experimental program in three out of eight variables. The contribution to these effects is seen in the agility assessment test Hexagon test $\mathrm{p}=.001$, and in static force leg evaluation tests endurance of squat on left leg $p=.017$ and endurance of squat on right leg $\mathrm{p}=.013$. From the mean value results (M) it is obvious that the experimental group achieved better results compared to the identical tests applied to the control group. The data obtained in this research are of great importance to everyone responsible for the transfer of knowledge and positive developmental effects of physical exercise.

\section{O62}

THE EFFECT OF AN IN-SEASON 8-WEEK PLYOMETRIC TRAINING PROGRAMME FOLLOWED BY A DETRAINING PERIOD ON EXPLOSIVE SKILLS IN COMPETITIVE JUNIOR SOCCER PLAYERS

Luis Branquinho', Ricardo Ferraz ${ }^{1,2,3}$, Pedro Mendes ${ }^{4,5}$, João Petricia ${ }^{4,5}$, João Serrano ${ }^{4,5}$, Mário C. Marques ${ }^{1,2}$

'University of Beira Interior, Department of Sport Sciences, Covilhã, Portugal, ${ }^{2}$ Research Centre in Sports, Health and Human Development, Vila Real, Portugal, ${ }^{3}$ Football Association of Castelo Branco, Castelo Branco, Portugal, ${ }^{4}$ Polytechnic Institute of Castelo Branco, Department of Sport and Well Being, Castelo Branco, Portugal, ${ }^{5}$ Polytechnic Institute of Castelo Branco, Sport, Health \& Exercise Research Unit, Castelo Branco, Portugal;

Correspondence: Luis Branquinho (brankinho_07@hotmail.com)

Based on importance of the explosive efforts in soccer, strength training is crucial in order to make players physically prepared for competition. The aim of this study was to examine the effect of a plyometric training and resistance programme, on motor abilities, kicking speeds, and individual techniques in junior soccer players. A training programme was applied for eight weeks and was composed of countermovement jump, countermovement onto a box, sprints, and sprints with change of direction. The players were evaluated before and after the application of the training programme, and after four weeks of detraining. The applied tests were: countermovement jump, speed dribbling, sprint, kicking speed, and Yo-Yo test. The results showed statistically significant differences $(p<0.05)$ and indicate that general performance may not be sensitive to four weeks of detraining. The findings demonstrate that the combination of soccer drills and specific power training with no additional training optimizes some general and soccer-specific performance. 
P1

\section{PHYSICAL ACTIVITY OF GRADUATES IN MONTENEGRO IN RELATION TO GENDER}

Gorica Zoric ${ }^{1}$, Milena Mitrovic', Katarina Dragutinovic ${ }^{2}$

'University of Montenegro, Faculty for Sport and Physical Education, Niksic, Montenegro, ${ }^{2}$ Primary School "Vuk Karadzic", Podgorica, Montenegro

Correspondence: Gorica Zoric (goricazoric27@gmail.com)

Physical activity of young people in Montenegro is a topical issue. The rate of overweight and obese young people is increasing, with water-preventing activities reflecting, first of all, the first healthy lifestyles, quality nutrition and adequate physical activity. The main goal of this research was to determine the differences in the level of physical activity of graduates in Montenegro in relation to gender. The survey was carried out on a sample of 574 male and female respondents aged 18-19 years old. A standardized international questionnaire on the physical activity of IPAQ, in order to determine the differences between the tested groups a T-test. At the overall level, showed that there is a statistically significant difference in the level of physical activity of graduates in Montenegro in relation to gender, in favor of the graduate group. When it comes to individual domains of physical activity, a significant difference was obtained in riding bicycles for the purpose of transportation, hard work in the household and home, total activities in household and home, hard activities during free time, moderate activity during free time, total free time activities, total moderate activity and total physical activity in favor of a group of graduates. Well-known positive effect of physical activity on health has been scientifically confirmed nowadays.

\section{P2}

\section{MODERN DANCE TRAINING POSITIVE IMPACT ON THE IMPROVEMENT OF MOTOR COMPETENCE IN YOUNG GIRLS} Aleksandra Belic', Dragan Marinkovic ${ }^{1}$

'University of Novi Sad, Faculty of Sport and Physical Education, Novi Sad, Serbia

Correspondence: Aleksandra Belic (play.dance.studio@gmail.com)

Physical inactivity among children in our society has been increasing at an alarming rate over the past two decades. Development of motor competence is important in its own way, by either encouraging or discouraging individuals' physical activity levels. With a broader repertoire of physical skills, children will have a greater chance of finding activities that they can do well and enjoy. The purpose of this study was to examine is there a positive influence of modern dance training on improvement motor competence in young girls. The sample consist 120 girls aged 7 to 9 years, divided into 2 groups: 64 respondents who are engaged in modern dance, and 56 respondents that do not deal with this type of physical activity. For measuring motor competence Körperkoordinationstest für Kinder (KTK) was applied. The results of univariate analysis ANOVA showed that there are differences between divided groups, on the level of statistical significance of $\mathrm{P}=0.00$, in all four KTK subtest: walking backwards, moving sideways, hopping for height and jumping sideways. According to the results of this research, we can conclude that modern dance training is physical activity that positively impact improvement motor competence in young girls. Further research is needed to clarify strong relationship between motor competence and physical activity and how they are related to better health outcomes in children.
P3

\section{DIFFERENCES IN ANTHROPOMETRIC CHARACTERISTICS BETWEEN ELITE HANDBALL AND VOLLEYBALL PLAYERS FROM SERBIA}

Bojan Masanovic' ${ }^{1}$ Zoran Milosevic ${ }^{2}$, Marko Aleksandrovic ${ }^{3}$, Dragan Krivokapic', Marin Corluka ${ }^{4}$

'University of Montenegro, Faculty for Sport and Physical Education, Niksic, Montenegro, ${ }^{2}$ University of Novi Sad, Faculty of Sport and Physical Education, Novi Sad, Serbia, ${ }^{3}$ University of Nis, Faculty of Sport and Physical Education, Nis, Serbia, ${ }^{4}$ University of Mostar, Faculty of Science and Education, Mostar, Bosnia and Herzegovina

Correspondence: Bojan Masanovic (bojanma@ucg.ac.me)

Some previous studies suggest that a specific body structure is necessary if the athlete wants to be competitive at the professional level. The purpose of this study was to describe anthropometric characteristics of elite handball and volleyball players as well as to make a comparison between them. In this study were enrolled 60 male athletes, divided into three groups: 15 handball players, 14 volleyball players and 31 healthy sedentary subjects. The variables sample included 20 anthropometric measures that defined longitudinal and transversal dimensionality of skeleton, volume and body mass, and subcutaneous fat. The descriptive statistics were expressed for each variable, while the ANOVA and the LSD Post Hoc tests were carried out to detect differences between groups. The results showed that a significant difference was found in 13 variables, while that no significant difference was found in the remaining 7 variables. Therefore, these findings may give coaches better working knowledge about the characteristics of top handball and volleyball players, and suggest them on which variables to focus their attention during the process of talent identification.

\section{P4}

\section{WATER POLO PLAYERS (U15) OF NATIONAL TEAMS OF MONTENEGRO AND CROATIA AND THEIR BODY COMPOSITION}

Jovan Gardasevic', Dusko Bjelica', Ivan Vasiljevic ${ }^{1}$

'University of Montenegro, Faculty for Sport and Physical Education, Niksic, Montenegro

Correspondence: Jovan Gardasevic (jovan@ucg.ac.me)

The aim of this research was to determine the differences between the water polo players (U15) of national teams of Montenegro and Croatia in the body composition and anthropometric characteristics. A battery of 11 variables evaluated body composition and anthropometric characteristics: body height, body weight, triceps skinfold, biceps skinfold, skinfold of the back, abdominal skinfold, upper leg skinfold, lower leg skinfold, body mass index, fat percentage and muscle mass. It was found that there are statistically significant differences in five variables, in three variables at $\mathrm{p}<0.01$ (body height, triceps skinfold and biceps skinfold), and in two variables at $\mathrm{p}<0.05$ (upper leg skinfold and muscle mass). It can be stated that the water polo players of Montenegro have statistically significantly higher triceps skinfold, biceps skinfold and upper leg skinfold, and statistically significantly lower body height and muscle mass than the water polo players of Croatia.

\section{P5}

\section{ANTHROPOMETRIC CHARACTERISTICS AND BODY COMPOSITION DIFFERENCES BETWEEN RUGBY PLAYERS ACCORDING TO THEIR SPECIFIC PLAYING POSITION} Dragan Bacovic', Pavle Malovic'

'University of Montenegro, Faculty for Sport and Physical Education, Niksic, Montenegro 


\section{Correspondence: Dragan Bacovic (dragibacovic1@gmail.com)}

The rugby team is divided into two units, forwards and backs. Forwards have an obligation to gain space through hard physical contact, while backs aim to pass the ball through the defense of the opposing team with fast and agile play. PURPOSE: This research aimed to assess differences in anthropometric characteristics and body composition of national team of Montenegro and Bulgaria, regarding the positions they play in the team. METHODS: All respondents were divided into four sub-samples. The first two sub-samples consisted of 7 backs of Montenegro and Bulgaria, while the remaining two sub-samples consisted of 8 forwards of Montenegro and Bulgaria. Differences in all variables were determined using a t-test, with a statistical significance of $p<0.05$. RESULTS: It can be concluded that Bulgarian forwards had significantly higher values in the variables that estimate the level of subcutaneous adipose tissue than the backs of Bulgaria, while in the Montenegrin team is an opposite situation. In terms of muscle mass, backs of Bulgaria have significantly higher values than Bulgarian forwards, as well as of all Montenegro players. CONCLUSION: According to results, it can be more precisely assumed why Montenegro team lost the match against Bulgaria team with a score of 57-0. One of the reasons can be an inadequate selection of Montenegrin backs, as well as the dominance of the Bulgarian backs.

\section{P6}

\section{MULTIPLE REGRESSION ANALYSIS IN CMJ AND SJ JUMP} TESTS ON 10 -14 YEARS OLD PLAYERS OF TIRANA FOOTBALL CLUB

\section{Aida Bendo}

'Sports University of Tirana, Faculty of Physical Activity and Recreation, Tirana, Albania

Correspondence: Aida Bendo (bendoaida@yahoo.com)

In vertical jump performance, the goal of the task is simply to jump as high as possible. In many sports, the height at which an athlete can jump is often of critical importance, as well as the maximal force applied during the vertical jump. In the absence of resistance to air and other external forces, the projection of the center of gravity COG of the whole body is completely determined by the vertical velocity at the moment of take-off and the acceleration due to gravity. This study aims to use the use the multiple regression method in both CMJ and SJ vertical jump tests, to understand whether vertical jump parameters, can be predicted based on anthropometric variables such as: age, height, and body mass, as well as biomechanical variables such as: vmax, F.tot.rel, EFI and efficiency. Multiple regression method allows to determine the overall fit of the model and the relative contribution of each of predictor to the total variance explained. In each of CMJ and SJ tests, was found how much of the variation in the test performance of the depended variable can be explained by anthropometric and biomechanical parameters, but also the relative contribution of each independent variable in explaining the variance. Multiple equations of regression for this team emerged these parameters as the best predictor of the main variables for each test: for Hmax in CMJ test: vmax and body mass; and for Fmax in SJ test: body mass and Pmax $/ \mathrm{kg}$.

\section{P7}

\section{BIOMECHANICS ANALYSIS OF GOLF SWING DURING FLAT, FRONT FOOT HIGHER THAN BACK FOOT AND BACK FOOT HIGHER THAN FRONT FOOT}

Rachnavy Pornthep ${ }^{1}$, Khaothin Thawichai', Pojprapai Soodkhet ${ }^{2}$, Jongpinit Watcharin ${ }^{2}$

${ }^{1}$ Suranaree University of Technology, School of Sports Science, Nakhon
Ratchasima, Thailand, ${ }^{2}$ Suranaree University of Technology, School of Ceramic Engineering, Nakhon Ratchasima, Thailand Correspondence: Rachnavy Pornthep (rachnavy@sut.ac.th)

The purpose of the study was to investigate movement in the center of pressure during the golf swing with flat, a front foot higher than a back foot and back foot higher than the front foot. Five male single-handicap golfers hit balls with a five-iron from the flat and $20 \mathrm{~cm}$ step high. During the golf swing Qualysys ${ }^{\mathrm{sm}}$ motion analysis system $(120 \mathrm{~Hz})$ and Kistler ${ }^{\mathrm{rm}}$ ground reaction force $(600 \mathrm{~Hz})$ were collected. The result showed that there was a significant difference in knee joint angle, ground reaction force and the center of pressure movement during the swing with flat, a front foot higher than a back foot and back foot higher than the front foot. There was no significant difference in club head speed. Golfers attempted to adjust the stance by flex the knee for balance and transfer the body weight to the lower foot at the start of the swing and shifted the weight during the backswing and downswing resulting in the center of pressure movement backward during backswing and movement towards during downswing. However, golfers attempt to maintain tempo with the same club head speed.

\section{P8}

\section{CONTACT VS NON-CONTACT SPORTS: DIFFERENCES IN POSTURAL STABILITY}

Dragan Marinkovic ${ }^{1}$, Ana Marijanac', Borislav Obradovic', Jovan Vukovic', Aleksandra Belic', Aleksandra Ivancic ${ }^{2}$

'University of Novi Sad, Faculty of Sport and Physical Education, Novi Sad, Serbia, ${ }^{2}$ University of Novi Sad, Faculty of Medicine, Novi Sad, Serbia

Correspondence: Dragan Marinkovic (marinkovic@uns.ac.rs)

It has been demonstrated that characteristic of sport could influences postural stability ability, however, the amount of physical contact involved has not been taken into account. To compare static postural stability among contact and non-contact sports. Twenty athletes (age 24.0Â \pm 3.1 years; BMI 19.2 $\hat{\mathrm{A}} \pm 2.8 \mathrm{~kg} / \mathrm{m} 2$ ) were allocated to either the Contact-group (CG; $\mathrm{n}=10$ ) or the Non-contact group (NCG; $\mathrm{n}=10$ ). The following stability parameters were used in the research: Double leg sway distance (SWAY); Right leg sway distance (RSWAY); Left leg sway distance (LSWAY); Sitting sway distance (SSWAY). ANOVA shows that NCG had significantly greater (ES = $1.00 ; \mathrm{p}=0.01$ ) Double leg sway distance (SWAY) compared with the CG. This study also indicates that athletes from NCG demonstrated significantly larger oscillation of postural sway on right leg (ES = $1.27 ; \mathrm{p}=0.00)$, and left leg ( $\mathrm{ES}=0.82 ; \mathrm{p}=0.03)$. No differences were found in Sitting sway distance (SSWAY) between two groups $(E S=0.12 ; p=0.73)$. Significant differences on general level for all stability parameters were found $(\mathrm{P}=0.00)$. The findings suggest that contact sports may lead to increased postural stability through enhanced use of proprioceptive and vestibular information.

\section{P9}

\section{DECREASING THE EFFECTIVENESS FOR SHOOTING THE BASKET - BASIC PROBLEM FOR THE EUROPEAN WOMEN BASKETBALL}

Mariana Borukova ${ }^{9}$

'National Sports Academy “Vassil Levski”, Sofia, Bulgaria

Correspondence: Mariana Borukova (marianaborukova@gmail.com)

The view of women basketball great experts in Europe is that during the last years the effectiveness of shooting the basket is becoming a dying art and is gradually lacking in women basketball which impacts negatively the game. The purpose of our research is to effect studies related to the effectiveness of shooting the basket in women 
basketball for various age groups - U16, U18 and U20. To realize the research we have studied specialized literature and analyzed game effectiveness statistic data from Genius Sport official system for registering the game indicators of the European Basketball Federation (FIBA) The initial data are processed mathematically-statistically by: variation analysis, relative share for establishing shooting the basket effectiveness from various distances and comparative analysis. We have researched shooting effectiveness data from the last European championships for the three age groups. The results show a decrease of the competitors' skills for effecting baskets by the growth of age. Women basketball is dynamic sport having many elements but the effectiveness of shooting the basket is its heart that many people forget. The coaches working on every level should use at least $30 \%$ of the studying and training process for specific shooting the basket exercises. That is the minimum, which could stop that process so that basketball game would not fall in crises.

\section{P10}

BUISNESS MODELS AND STRATEGIE WHICH CAN BE APPLIED TO MAKE JJIF JU JUTSU MORE FINANCIALY VIABLE

\section{Olivera Simovic', Djurdjica Perovic', Toni Janovic ${ }^{2}$}

'University of Montenegro, Faculty of Tourism and Hotel Management, Kotor, Montenegro, ${ }^{2} \mathrm{BJJ}$ and JJIF Ju Jutsu, Kotor, Montenegro

Correspondence: Olivera Simovic (oki-keti@t-com.me)

This study is focused on the participants from JJIF Ju Jutsu and the possibility to make profit from their skill and knowledge which they accumulated in a lifetime of practicing the sport. The end goal is to identify potential ways how to make Ju Jutsu (JJIF) more commercially successful by using methods from another martial art, Brazilan Jiu Jitsu. The study shows that DVDs, Online instructional web sites, competitions with prize money, use of social media could increase the visibility and financial success of Ju Jutsu by attracting more participants and providing income to gym owners. A questionnaire was used as well as comparative analysis of existing ways to commercialize the martial art. Experts identified big events with media coverage as a way to improve the financial viability of Ju Jutsu. As well that most ways to increase income from Brazilian Ju Jutsu directly translate to JJIF Ju Jutsu. Moreover the study also identified which of the methods from Brazlian Ju Jutsu were underused in JJIF Ju Jutsu. There are many ways to make JJIF Ju Jutsu more financially viable that already exist in another martial art which is fairly similar.

\section{P11}

\section{INFLUENCE OF AEROBIC TRAINING ON SELECTED MOTOR FITNESS VARIABLES AMONG UNTRAINED MALES} Abdulhameed Al Ameer ${ }^{1}$

${ }^{1}$ King Fahd University of Petroleum \& Minerals, Dhahran, Saudi Arabia Correspondence: Abdulhameed Al Ameer (alameer@kfupm.edu.sa )

Aerobics is a medicine and prevents from many diseases. The purpose of this study was to find out the influence of twelve weeks aerobic training on selected motor fitness variables among untrained males. Thirty subjects selected from different classes from the PE101, weight control course, 18 to 22 years of age. The selected participants randomly assigned into two equal groups of 15 each, such as experimental and control group. The experimental group participated in the aerobic training for 12 weeks, training twice in a week for 40 minutes each session. The selected variables such as speed and cardio-vascular endurance measured by $50 \mathrm{M}$ sprint and $12 \mathrm{~min}$ run / walk test. The collected data were analysed statistically through (ANCOVA). The analysis of data revealed significant performance i.e. Speed: The post-test scores analysis proved that there was significant difference between the groups as the obtained $\mathrm{F}$ value at 14.07 was greater than the required $\mathrm{F}$ value at 3.34. Cardio-vascular endurance: Post-test scores analysis proved that there was significant difference between the groups as the obtained $\mathrm{F}$ value at 12.01 was greater than the required $\mathrm{F}$ value at 3.34. The differences between the post-test mean were significant. It is concluded that the aerobic training had shown improved performance in the selected motor fitness variables among the untrained males.

\section{P12}

\section{LEISURE-TIME PHYSICAL ACTIVITY OF THE CITY OF ZAGREB RESIDENTS}

Hrvoje Radasevic ${ }^{1}$, Jelena Cvrljak', Mirna Andrijasevic ${ }^{2}$

${ }^{1}$ Andrija Stampar Teaching Institute of Public Health, Zagreb, Croatia, ${ }^{2}$ University of Zagreb, Faculty of Kinesiology, Zagreb, Croatia Correspondence: Hrvoje Radasevic (hrvoje.radasevic@stampar.hr)

There is an increasing number of studies indicating the importance of exercising and leisure physical activities (PA) for the purpose of improving health, as well as for reducing the risk of certain chronic diseases. The aim of this research is to determine the extent to which the Zagreb residents engage in leisure PA compared to current WHO recommendations and guidelines. The aim is also to determine whether there are differences, depending on gender and age, in the conducting of different types of leisure PA. The sample of the study consisted 446 Zagreb residents. Data were collected using a standardized survey questionnaire used in the second cycle of the European Health Interview Survey. Leisure PA consisted certain variables: 1. recreational aerobic PA; 2. Resistance training; 3. Walking, 4. Cycling. The results showed that $76.2 \%$ of citizens don't conduct recreational aerobic PA, and $89.9 \%$ don't conduct resistance training even once a week. Men were more physically active than women in recreational aerobic $\mathrm{PA}$, walking and cycling $(\mathrm{P}<0.01)$. Results in variables of walking, cycling and resistance training were higher among residents aged $<60$ years $(\mathrm{P}<0.001)$. The findings suggest an insufficient leisure PA level of the City of Zagreb residents. There is a need for more quality, science-based interventions to promote physical activity in leisure time.

\section{P13}

\section{INTERNET ADDICTION AND LEVEL OF PHYSICAL ACTIVITY OF STUDENTS FROM BULGARIAN UNIVERSITIES}

\section{Milena Kuleva'}

\section{'National Sports Academy “Vassil Levski”, Sofia, Bulgaria}

Correspondence: Milena Kuleva (mil3na@gmail.com)

In this scientific study the problem of Internet addiction (IA) and the physical activity (PA) of students will be observed. The growing problem of increasing internet addiction and decreasing physical activity is becoming more apparent. The purpose of this study is to test whether physical activity is affected by internet addiction and vice versa. METHODS: We used a self-assessment Internet Addiction Test (IAT) and the International Physical Activity Questionnaire (IPAQ). The tests were distributed to 133 students from 3 Bulgarian universities - National Sports Academy "Vassil Levski”, Veliko Turnovo University and GS Rakovski Military Academy. We used Descriptive, Frequencies and Pearson Chi-Square analysis. The level of Internet Addiction at all three universities studied is Mild, but the level of Physical Activity is different at all three universities. The highest addiction is observed among students from the NSA, and the lowest among students from the Military Academy. The general weekly Physical Activity is highest among NSA students and lowest in Military Academy students. The same is with the moderate weekly PA. The relatively higher Internet Addiction of NSA students do not affect their physical activity. The lower Internet 
Addiction of students at the Military Academy does not manifest in more Physical Activity, but on the contrary - much smaller. The level of physical activity is rather irrelevant to how much time we spend on the Internet.

\section{P14}

INDOOR ROWING EXERCISE ON BALANCE, FLEXIBILITY, REACTION TIME AND MUSCLE STRENGTH IN OLDER ADULTS

Khaothin Thawichai', Rachanavy Pornthep ${ }^{1}$

${ }^{1}$ Suranaree University of Technology, School of Sports Science, Nakhon Ratchasima, Thailand

Correspondence: Khaothin Thawichai (thawichai.khaothin@gmail. com)

There are very few studies that focus on indoor rowing exercise on fitness components related to falling such as balance, flexibility, reaction time, and muscle strength in older adults. To determine the effect of indoor rowing exercise on balance, flexibility, reaction time and muscle strength in older adults. Thirty healthy older adults volunteer from Phoklang Nursing Home, Muang, Nakhon Ratchasima, Thailand. All participants were randomly assigned to two groups an indoor rowing exercise group and a control group. The exercise group $(\mathrm{n}=15)$ participated in an 8 -week indoor rowing exercise and the control group $(n=15)$ did not participate in indoor rowing exercise. Both groups were tested on balance, flexibility, reaction times, and muscular strength before and after 8-weeks indoor rowing exercise. The rowing ergometer was set up 5 days a week; each session included a 10-minute warm-up, a 20-minute rowing exercise, and a 10-minute cooling-down period. Exercise intensity was 40\%-50\% of $1 \mathrm{RM}$ during the 2 -week adaptation period and $50 \%-60 \%$ during the next 6-weeks. Data of the study show that the participants of the training group perform significantly difference higher on balance, flexibility, reaction time and muscle strength than the participants in the control group. This study suggested that indoor rowing exercise can use improve balance, flexibility, reaction time and muscle strength in older adults.

\section{P15}

\section{GENDER DIFFERENCES IN GROSS MOTOR COORDINATION IN 6-7 YEAR OLD CHILDREN}

Boris K. Popovic', Brigita Banjac ${ }^{1}$, Aleksandra Belic', Danilo Radanovic', Drazenka Macak', Jovan Vukovic'

'University of Novi Sad, Faculty of Sport and Physical Education, Novi Sad, Serbia

Correspondence: Boris Popovic (borispopovic0803@gmail.com)

Motor coordination in childhood plays a very important role in the physical and psychological health in childhood. Across the childhood, gender differences have been reported in performance for many motor tasks. The goal of this study was to examine the difference in the level of gross motor coordination between preschool boys and girls. A total of 345 preschool children (186 boys and 159 girls) aged 6 to 7 years $(6.5 \pm 0.29)$, were assessed for the gross motor coordination using Körperkoordinationstest für Kinder (KTK): walking backwards (WB), moving sideways (MS), hopping for height $(\mathrm{HH})$ and jumping sideways (JS). The results of T-test for independent variables and Man- Whitney test indicate that raw scores revealed boys and girls scoring similarly in our study. According to motor quotients, boys have a higher level of Total MQKTK score than girls. The general conclusion about the level of motor coordination is that today's children are much inferior in relation to results of the former children. These differences might be explained by specific leisure activities of "new-age" children. With respect to gender differences, the boys have better gross motor coordination comparing to the girls pairs mostly because of better physical fitness, especially of explosive strength, endurance and agility.

\section{P16 \\ INVESTIGATION OF PHYSICAL FITNESS ACCORDING TO GENDER AMONG OLDER ADULTS WITH SIMILAR PHYSICAL ACTIVITY LEVELS \\ Gulsah Sahin', Ali Coskun², \\ ${ }^{1}$ Canakkale Onsekiz Mart University, Sport Science Faculty, Canak- kale, Turkey, ${ }^{2}$ Canakkale Onsekiz Mart University, Bayramiç Vocational School, Canakkale, Turkey \\ Correspondence: Gulsah Sahin (nazgulsah@hotmail.com)}

The aim of this research was to investigate physical fitness of older adults with similar physical activity levels according to gender. A totally of 112 individuals ( 74 women, 38 men) over 65 years participated to the research or 99 young-old and 13 older adults participated to the research. Participants were reached in the life center which serves for individuals over 65 years in the Canakkale. The physical activity scale for the Elderly (PASE) Turkish version was used to assess their physical activity levels, and the Senior Fitness test was used to measure physical fitness based on performance. The Mann Whitney U test was used to compare the nonparametric data between the gender and the t-test was used for the parametric data. As a result, no significant difference was found in age, height and weight between older women and older men $(p>0.05)$. There was a significant difference in the chair stand test, arm curl test, get-up and go test and 2 min step test between older women and older men $(p<0.05)$. There was no significant difference in back scratch and chair sit and reach test between older women and men $(p>0.05)$. There is a gender-related difference between physical fitness components of men and women with similar levels of physical activity, except flexibility. Older men had stronger arms and legs, better dynamic balance, and better agility and aerobic capacities compared to older women in this research.

\section{P17}

\section{BODY MASS INDEX AS AN INDICATOR OF OBESITY IN MALE} ADOLESCENTS IN MONTENEGRO

Ivan Vasiljevic', Dusko Bjelica', Jovan Gardasevic ${ }^{1}$

'University of Montenegro, Faculty for Sport and Physical Education, Niksic, Montenegro

Correspondence: Ivan Vasiljevic (vasiljevic.ivan301@gmail.com)

Obesity today is a common chronic health problem that lowers quality of life and significantly affects morbidity and overall mortality. According to the World Health Organization, increasing obesity in children and adolescents is becoming a global health problem in both developed and developing countries. The aim of the study is to determine the level of nutrition by body mass index in male adolescents in Montenegro. The population in this study consisted of adolescents aged 15 to 18 years resident in the territory of Montenegro. The total sample of respondents is 678 male adolescents from secondary schools in Montenegro. Overweight is most prevalent in 17 -year-olds. When it comes to obesity, it is most prevalent in 15 -year-olds and lowest in 18-year-olds. Overweight in male adolescents in Montenegro is increasingly present and is being identified with other countries in Europe.

\section{P18}

\section{CARDIORESPIRATORY FITNESS AMONG HIGH SCHOOL STUDENTS IN SERBIA}

Lidija Markovic', Nebojsa Trajkovic', Milorad Jaksic', Spela Bogataj ${ }^{2}$ 
'University of Novi Sad, Faculty of Sport and Physical Education, Novi Sad, Serbia, ${ }^{2}$ University of Ljubljana, Faculty of Sport, Ljubljana, Slovenia

\section{Correspondence: Lidija Markovic (markoviclidija169@gmail.com)}

Based on the increase in obesity and a decrease in PA, a decline in cardiorespiratory fitness of adolescents can be anticipated. The purpose of this study was to compare the cardiorespiratory fitness in gender and in different age groups in Serbian adolescents. A total of 579 healthy adolescents, regardless of the PA level, between 1419 years (285 males, 294 females) participated in this study, and the oxygen consumption was measured indirectly by the formula. The subjects of both sexes were divided into 5 age groups. The results showed a main effect of $\operatorname{sex}(F(1)=219.34, \mathrm{P}<0.01, \mathrm{ES}=0.278)$ for the distance covered in the shuttle run test. Boys scored significantly higher $(\mathrm{p}<0.05)$ on both, the total laps in the shuttle run test and VO2 max compared with girls in all age categories. Regardless, there was no significant difference for the score in the shuttle run test with age in boys $(p>0.05)$. The results for the girls in all parameters of cardiorespiratory fitness are similar, with no statistically significant differences between age groups ( $p>0.05)$. It can be concluded that boys had, as expected a significantly higher performance outcome in the shuttle run test. Furthermore, in both genders, the changes in shuttle run test results with age were only not significant in both genders.

\section{P19}

\section{BONE DENSITY AND MINERALIZATION AMONG} ADOLESCENT SWIMMERS: A SYSTEMATIC REVIEW

Milorad Jaksic', Lidija Markovic', Goran Dimitric ${ }^{1}$

'University of Novi Sad, Faculty for Sport and Physical Education, Novi Sad, Serbia

Correspondence: Milorad Jaksic (lormida90@gmail.com)

Adolescence is the most important period of bone development. During this time bone growth reaches $90 \%$ of total growth and is notably affected by increasing level of physical activity. The purpose of this study is to review the state of bone density and bone mineralization between swimmers and non-athletes. Different age categories of adolescents were analyzed concerning gender. Specific keywords such as "swimmers", "bone health", "bone tissue", "bone mineral density", "bone mineral contents" and "bone mass" were used for searching the relevant electronic database, Web of Science. The research was conducted with PRISMA guidelines. The results of the study indicated that there were statistically significant differences between athletes and non-athletes in the state of bone mineralization. Nevertheless, there was decreased mineralization in all regions of swimmers' body (spine, hips, hamstrings) compared to athletes engaged in collective sports on dry ground. Physical activity is extremely important in bone acquisition during childhood and adolescence and also could be an important factor in bone mineral formation in pre-puberty. Swimmers are advised to increase the number of training with weights because sport might cause bone building during the long-term program.

\section{P20}

\section{DETERMINING FACTORS OF PHYSICAL PERFORMANCE IN A EXERCISE STRESS TEST IN WOMEN PRACTICING NORDIC WALKING}

María Jódar', María José Paredes', Vicente Ferrer', Ignacio MartínezGonzález-Moro'

'University of Murcia, University Institute for Researching in Aging, Research Group: Physical Exercise and Human Performance, Murcia, Spain

Correspondence: María Jodar (mariajodarreverte@gmail.com)
Currently, Nordic Walking (NW) is an emerging activity, it is considered an easy, safe and healthy aerobic endurance sport. Analyze the influence of age, experience and relative fat mass (RFM) on physical performance in women practicing Nordic Walking during maximal treadmill exercise testing. The population was formed by 20 women, who underwent a maximum stress test with continuous electrocardiographic recording. The Bruce protocol on the ramp was modified with progressive increases in speed and incline. In addition, we measured their height, weight and waist. The study of exhaled gases was carried out. Our population has an average RFM of $39.8 \pm 2.9$. Veterans reach higher levels of intensity during the exercise, with a variable speed of $6.4 \pm 0.9 \mathrm{Km} / \mathrm{h}$, compared to novels $5.6 \pm 0.7 \mathrm{Km} / \mathrm{h}(\mathrm{p}<0.05)$. We observe that a higher RFM, higher body mass index (BMI) and waist size index there is a lower oxygen consumption (VO2) and metabolic equivalent (METS) $(\mathrm{p}<0.05)$. Likewise, a longer time increases both VO2 and METS $(p<0.05)$. The results suggest that the indexes and anthropometric relationships RFM, BMI and WSI influence performance in women practicing Nordic Walking. In addition, previous experience in this discipline is also an influential factor on the intensity of the exercise.

\section{P21}

\section{CORRELATIONS BETWEEN PROCESS- AND PRODUCT- ORIENTED ASSESSMENT OF LOCOMOTOR SKILLS IN PRE- SCHOOL CHILDREN}

Danilo Radanovic', Drazenka Macak', Nebojsa Trajkovic', Boris Popovic', Marko Gusic', Dejan Madic'

'University of Novi Sad, Faculty of Sport and Physical Education, Novi Sad, Serbia

Correspondence: Danilo Radanovic (radanilo17@yahoo.com)

Preschool years are a very important period for a child's development and improvement of motor competence (MC). Comparisons of assessment outcomes may provide different types of information relating to MC. The aim of this study is to examine the correlations between two different types of assessment outcomes for the same locomotor skills in pre-school children. Sample consisted of 119 preschool children ( 81 boys; age $5.90 \pm 0.53$ years). They were recruited from a kindergarten in Novi Sad, Serbia and only healthy children with signed parent approval were tested. Three locomotor skills (run, hop and horizontal jump) were assessed using Test of Gross Motor Development, second edition (TGMD-2). Also, the same three moving patterns were tested with 20 meters dash, hop on one leg from Körperkoordinationstest für Kinder (KTK) testing battery and standing long jump. Descriptive statistics were calculated for all variables and correlations between two types of assessment of locomotor variables were estimated by Spearman's rho correlations. All correlations were statistically significant at the 0.01 level. According to Cohen, the strength of correlations was strong between run and 20 meters dash $(r=0.50)$, hop and hop on one leg $(r=0.58)$ and moderate between horizontal jump and standing long jump $(r=0.46)$. Both types of assessments help researchers to better understand how MC relates to other variables, especially to health outcomes.

\section{P22}

MOTOR LEARNING EFFICACY OF SWIMMING TECHNIQUES THROUGH IMPLEMENTATION OF TIME CONCENTRATED AND TIME DEPLOYED MODEL OF LEARNING

Dragan Krivokapic', Danilo Bojanic', Milovan LJubojevic

'University of Montenegro, Faculty for Sport and Physical Education, Niksic, Montenegro

Correspondence: Dragan Krivokapic (dr.agan@t-com.me) 
The issue discussed in this paper refers to motor learning efficacy of basic swimming techniques through implementation of time concentrated and time deployed model of learning. By study year 2016/17 students of the third year of the Physical Culture Department of the Faculty of Sports and Physical Education of the University of Montenegro realized practical lessons in subjects Swimming and Water polo 2 in Igalo, at the swimming pool of the Institute "Dr Simo Milosevic" according to the model of time concentrated learning, and since the above mentioned year, practical lessons in those subjects have been realized at renovated swimming pool of the sports centre in Niksic, according to the model of time deployed learning. Two models of learning basic swimming techniques have been realized on four generation of students of the third year. On the base of the given results, it can be concluded that there were not any significant differences in average evaluations of the subsamples as indicators of successfully learned basic swimming techniques. Starting from the goal of this research which was an attempt to compare efficacy of influence of two different models of motor learning of basic swimming techniques it can be stated that both models can be recommended as equally efficient in learning basic swimming techniques.

\section{P23}

PREVALENCE OF OVERWEIGHT AND OBESITY AMONG PRIMARY SCHOOL-AGE CHILDREN IN REPUBLIC OF SRPSKA: A CASE STUDY

Adriana Ljubojevic', Igor Vuckovic', Zeljko Vukic', Goran Pasic', Sasa Markovic' ${ }^{1}$ Zeljko Sekulic ${ }^{1}$

${ }^{1}$ University of Banjaluka, Faculty of Physical Education and Sport, Banjaluka, Bosnia and Herzegovina

Correspondence: Adriana Ljubojevic (adriana.ljubojevic@ffvs.unibl. org)

The rise in childhood obesity in European Region over the past decade and a half has been dramatic and represent the most serious health challenges of the early 21 st century. The aim of this research was to collect data about prevalence of overweight and obesity among primary school-age children from Republic of Srpska. The study included 2039 children (ages 6-8) from 11 schools from Banja Luka region. The children were measured for body height, weight, and body mass index (BMI) using references developed by World Health organization (WHO). The results shows that prevalence rates of overweight and obesity vary across different age groups, with the lowest overweight (5\%) and obesity $(2,9 \%)$ reported in 6 -year-old, while the highest overweight $(15,2 \%)$ and obesity $(7,1 \%)$ prevalence rates were observed in a 8 -year-old. The overall prevalence of overweight $(10,5 \%)$ and obesity $(5,2 \%)$ in primary schoolage children from Republic of Srpska seem to be slightly lower than results reported in other European countries. However, the trend of overweight and obesity is increasing with age. The surveillance system of nutritional status is of considerable importance to reverse pandemic trend of childhood obesity, especially for creating national health strategies that have to provide a better environment for healthy growing up.

\section{P24}

\section{AFFECT OF A SINGLE DOSE OF CHOCOLATE ON HEART RATE VARIABILITY}

Aleksandar Klasnja', Nebojsa Janjic', Borislav Tapavicki', Djurdja Cvjetkovic', Vedrana Karan', Otto Barak', Miodrag Drapsin' 'University of Novi Sad, Faculty of Medicine, Novi Sad, Serbia

Correspondence: Aleksandar Klasnja (aleksandar.klasnja@mf.uns. ac.rs)
Increase in blood pressure and reduction in heart rate variability are associated with several cardiovascular diseases and higher mortality in patients. Different nonpharmacological treatment options that could be used in prevention of cardiovascular diseases are studded lately. The aim of this study was to investigate the acute effect of a single dose of dark and milk chocolate on blood pressure and heart rate variability. Thirty-two healthy subjects (aged 20-25 years; both sexes) were divided into two groups: 14 subjects in the milk chocolate ( $30 \mathrm{~g})$ group and 18 in the dark chocolate $(30 \mathrm{~g})$ group. Blood pressure was determined with sphygmomanometer and the heart rate variability with an electrocardiogram in supine position after 10 minutes rest at baseline and after 60 minutes from consumption. A single dose of dark chocolate significantly reduced systolic blood pressure and significantly increased standard deviation of RR intervals, standard deviation of all NN intervals and high frequency component of heart rate variability parameters. There were no significant changes in any measured cardiovascular parameters in the milk chocolate group. Consumption of $30 \mathrm{~g}$ of dark chocolate decreases systolic blood pressure and triggers a significant increase in parasympathetic modulation suggesting potential health benefit associated with dietary intake of dark chocolate.

\section{P25}

\section{ETHICS AND DOPING IN SPORT}

Milovan Ljubojevic', Nina Đukanovic' ${ }^{1}$, Aldijana Nokic', Ivan Vasiljevic ${ }^{1}$ 'University of Montenegro, Faculty for Sport and Physical Education, Niksic, Montenegro, ${ }^{2}$ High medical school "Milutin Milankovic", Belgrade, Serbia

\section{Correspondence: Milovan Ljubojevic (milovan.lj@ucg.ac.me)}

Aim of this paper was to examine students' attitudes about certain ethical issues related to the use of banned substances. The examination was conducted on 25 students of Faculty for Sports and PE in Nikisic, 2019. Participants completed questionnaires consisting of 18 questions ( 4 of them general type, related to the definition of doping and violations of doping rules and 14 questions to specific ethical doping dilemmas). Among many answers to the questions regarding clear ethical issues and the use of doping are several interesting considerations. So e.g. 8 (32\%) of the respondents believe that if an athlete agrees to the risk of doping, they should be free to decide whether or not to use banned substances. Four (16\%) of the respondents thought that doping would be justified and acceptable if they were sure that it would not endanger the health of the athlete, while two (8\%) students had the opinion that the use of doping is justified and acceptable if they are certain that they will win a medal. Answers related to the questions concerned with ethical dilemmas of using doping in sports indicate that specific, smaller, number of students believe that it is right of each person to independently decide to take or not doping, regardless of whether it is moral or not.

\section{P26}

\section{NUTRITION STATUS OF CHILDRENS 7-8 YEARS OLD IN CENTRAL REGION OF MONTENEGRO}

Milena Mitrovic' ${ }^{1}$, Katarina Dragutinovic ${ }^{2}$, Gorica Zoric ${ }^{1}$

'University of Montenegro, Faculty for Sport and Physical Education, Niksic, ${ }^{2}$ Primary school "Vuk Karadzic", Podgorica, Montenegro

Correspondence: Milena Mitrovic (milenam1054@gmail.com)

Obesity is a chronic disease characterized by an increase in body fat, to the extent that it causes impairment of health and the development of a number of complications. Therefore, the main objective of this study is to measure the morphological characteristics of 7-8 years old children from Podgorica and to determine their level of nutrition. The sample consisted of 180 pupils (7-8 years) of Pri- 
mary school "Milorad Musa Burzan" from Podgorica, divided into 2 sub-samples according to the gender criterion (100 boys and 80 girls). The measured variables were: body height, body weight and waist circumference. Descriptive statistics were applied to the statistical basic data: arithmetic mean and standard deviation. Levels fed were calculated based on BMI indice. Differences between the genders were obtained by applying the Hi square test $(\mathrm{p}<0.05)$. Based on BMI values, $61 \%$ of boys are normally fed, while $20 \%$ are obese. As for girls, $71 \%$ were normally fed, while $8 \%$ were obese. Based on BMI values, girls are less obese than boys, and that difference is statistically significant, the Hi square test showed. These percentages of obesity are not very worrying, though measures should be taken to reduce them and prevent them from spreading, given the detrimental effects and consequences of obesity on health.

\section{P27}

\section{EFFECTS OF A SIX-MONTH PHYSICAL ACTIVITY PROGRAM ON SOCIAL INCLUSION OF MONTENEGRIN ELDERLY PEOPLE}

Dusko Bjelica ${ }^{1,2}$, Stevo Popovic ${ }^{1,2,3}$, Bojan Masanovic ${ }^{1,2}$, Radenko Matic ${ }^{4}$, Marina Vukotic ${ }^{1}$, Selcuk Akpinar ${ }^{5}$

'University of Montenegro, Faculty for Sport and Physical Education, Niksic, Montenegro, ${ }^{2}$ Montenegrin Sports Academy, Podgorica, Montenegro, ${ }^{3}$ Montenegrin Academy of Sciences and Arts, Center of Young Scientists, Podgorica, Montenegro, ${ }^{4}$ University of Novi Sad, Faculty of Sport and Physical Education, Novi Sad, Serbia, ${ }^{5}$ Nevşehir Hacı Bektaş Veli University, Department of Physical Education and Sports, Nevşehir, Turkey;

Correspondence: Dusko Bjelica (sportmont@t-com.me)

It is the fact $11 \%$ of adults are not able to have friendship experience, to perform useful activities in society, and to hope for a better future; this percent is probably higher within elderly people. PURPOSE: The present study aimed to assess the effect of physical activity on social inclusion of elderly people. Forty-five elderly people were randomly assigned to intervention group (15) or observational group (30). Social Inclusion Scale (SIS) was applied, while ANOVA was employed to examine group difference within social isolation, social relations and social acceptance. Organized psychical activities did not influenced social isolation and social acceptance; however, the significant influence were recognized in the case of social relations of elderly people. Therefore, it is concluded the organized physical activities has proved to be useful for improving social relations in elderly people. This research has been done within nation project under the title "Effects of Physical Activity on Social Inclusion of Older People" that was approved by Ministry of Science in Montenegro (No.01- 2587 from 11 December 2017), as well as in line with the COST Action's objectives (CA15122).

\section{P28}

\section{ESTIMATION OF DIFFERENT RESEARCH EXPECTATIONS OF FIRST-YEAR STUDENTS FROM THE SPORT SCIENCE PROGRAMMES AND THEIR TEACHERS FROM VARIOUS STAGES OF THEIR PROFICIENCY}

Stevo Popovic', Radenko Matic ${ }^{2}$, Dusko Bjelica', Nebojsa Maksimovic ${ }^{2}$ 'University of Montenegro, Faculty for Sport and Physical Education, Niksic, Montenegro, ${ }^{2}$ University of Novi Sad, Faculty of Sport and Physical Education, Novi Sad, Serbia;

Correspondence: Stevo Popovic (stevop@ucg.ac.me)

The goal of this study was twofold, the first goal was focused on identifying how first-year students' from the Sport Science programmes and teachers' expectations of student research differ, while the second goal was focused on identifying how teachers' expectations differ based on stages of their proficiency, from novice to expert. A survey of 194 first-year undergraduate students (31\% of females vs. $69 \%$ of males) and 38 professors from University of Novi Sad, Serbia was conducted. Data collection involved two standardized surveys: Student Expectations of the Research Process and Faculty Expectations of Student Research that were modified to satisfy Sport Science students and teachers requirements. The gulf between student and teacher research expectations were found to be considerable, while the gulf among the different stages of teachers' proficiency was recognized in the area of responsibility for firstyear students learning the skills necessary to succeed at carrying out university-level research. In conclusion, it is interested to highlight that the gulf between student and teacher research expectations was found and need to be further analysed in the following stage of our research, while the gap between the different stages of teachers' proficiency is not considerable.

\section{P29}

\section{BEHAVIORAL AND NEURONAL EFFECTS OF CEF AND VAL ON EPILEPSY RAT MODEL}

Ying-Jui Ho', Pin-Jiun Lin', Hsin Tung Jao', Yuan-sheng Fang

${ }^{1}$ Chung Shan Medical University, Department of Psychology, Taichung City, Taiwan, ROC

Correspondence: Ying-Jui Ho (joshuayjho@gmail.com)

Epilepsy is the second most common neurological disorder, which causes not only motor dysfunction, but also cognitive impairments. Excessive glutamate and insufficient of GABA are involved in epilepsy. Val, a GABA inhibitor, is one of the first-line antiepileptic drugs. CEF increases expression of GLT-1 and shows neuroprotections. We measured effects of CEF and Val on seizure, motor, cognitive function, and neuroprotections in epilepsy rats. Male Wistar rats were injected with pentylenetetrazole (PTZ, $35 \mathrm{mg} /$ $\mathrm{kg}$ ) to induce epilepsy model. CEF (10 or $50 \mathrm{mg} / \mathrm{kg}$ ) and Val (50 or $100 \mathrm{mg} / \mathrm{kg}$ ) were administered starting from the 4th PTZ injection for 7 days. The rats were tested in rotarod, object recognition test, and passive avoidance test. The brain was taken for histological examination. Epilepsy rats showed seizure and impairments in motor and cognitive functions. Treatments with CEF and Val dose-dependently reduced seizure and improved motor and cognitive functions. Combination of CEF $(10 \mathrm{mg} / \mathrm{kg})$ and $\mathrm{Val}(50 \mathrm{mg} / \mathrm{kg})$ showed also beneficial effects on behavior. Histologically, epilepsy rats showed lower neuronal density and neurogenesis in the hippocampus but higher apoptosis in the amygdala, which were restored by the treatment with CEF, Val, and combination of CEF and Val. $\mathrm{CEF}$ and combination of CEF and Val showed neuroprotection and improvement in motor and cognitive functions in epilepsy.

\section{P30}

\section{THE IMPACT OF SPORT CLOTHES BRANDS PERSONALITY ON} CUSTOMERS PURCHASE INTENTION

Amir Firoozi', Seyed Mohammad Ali Mirhosseini', Elnaz Gisavi ${ }^{1}$ 'Islamic Azad University of Shiraz, Physical Education Department, Shiraz, Fars, Iran

Correspondence: Amir Firoozi (amir_firoozi373@yahoo.com)

Companies use different factors in the market to compete with more customers. Successful companies use brand personality strategies to shape their customers' behaviors. The goal of this study is to know whether personality components of sport clothes brands influence on customer behavior and their intention or not. The statistical population of this research includes all customers of sports clothes brands that sampled 276 samples in an accessible way and were surveyed by Matzeler et al. (2016) and Lam et al. (2012). Then, the data were analysed using descriptive statistical methods and test 
hypothesis from the Kolmogorov-Smirnov test, multiple regression, and path analysis. Indicate that the accountability component weight of impact $(\beta=0 / 271)$, emotional component weight of impact $(\beta=0 / 234)$ and domination component impact weight of $(\beta$ $=0 / 222)$ of foreign sport clothes brands personality on customers purchase intention has a direct and significant impact. Due to the effective role of the sport clothes brands personality on customers purchase intention, it is suggested that sport clothes brands have an effective brand personality for their brand according to the tastes, cultures and desires of each geographical region Shape. In order to design, produce, sell and guarantee their products, they will leave a proper and vibrant personality. The whole process is coupled with the type of advertising and marketing of brands and manufacturers that shape the brand personality in the minds of customers.

\section{P31}

\section{MUSCULAR STRENGTH AND LUNG FUNCTION IN} PHYSICALLY NON ACTIVE STUDENTS WITH HYPERMOBILITY Nikola Bakic', Aleksandra Popovic', Milan Popovic ${ }^{2}$

'University of Novi Sad, Faculty of Medicine, Department of Physiology, Novi Sad, Serbia, ${ }^{2}$ University of Novi Sad, Faculty of Medicine, Department of Histology and Embryology, Novi Sad, Serbia

Correspondence: Nikola Bakic (bakicnikola44@gmail.com)

Elastin and collagen are the most important components of bones, tendons, skin and lung tissue. In addition, elastic and collagen fibers are integral part of all three proper muscle fascia and allow the force that develops due to contraction of muscle fibers, to be transmitted to the tendons. The goal was to compare values of muscle strength and lung function between students with weak and normal connective tissue. The study included 100 physically non active healthy students (50 female and 50 male) divided into two groups: students with weak and students with normal connective tissue. Diagnosis of hypermobility was confirmed using Brighton score and the Beighton criteria. Muscle strength of upper and lower extremities and lung function were measured. When analyzing average and maximum values of strength of muscle contraction of leg extensors, arm extensors and arm flexors between groups a significant difference was observed. Parameters of lung function were also significantly different between groups regarding to VC ( $\mathrm{p}<0.001)$, FVC ( $\mathrm{p}=$ $0.05)$ and FEV1 $(p=0.25)$. Students with weak connective tissue have significantly lower values of dynamometric parameters and lung function in comparison to students with normal connective tissue.

\section{P32}

\section{INFLUENCE OF ANTHROPOLOGICAL ON THE LEVEL OF ACQUISITION OF BASIC SKI TECHNIQUES}

Marija Bubanja'

${ }^{1}$ University of Montenegro, Faculty for Sport and Physical Education, Niksic, Montenegro

Correspondence: Marija Bubanja (marijabubanja@ymail.com)

The aim of this research is identifying statistically considerable influence of anthropological characteristics (morphological characteristics, body composition indicators and functional-motor skills) on the level of acquisition of basic ski techniques: downhill ski, V turn, basic winding and parallel winding. The research was carried out on a sample of 35 students who attended regularly the course of the Basics of Skiing at the Faculty of Sport and Physical Education, Niksic, Montenegro. Within the morphological characteristics and body composition indicators research, a sample of 8 variables was used to obtain latent anthropometric dimensions. For the evaluation of functional and motor skills research the study included a system of 10 variables, and in accordance with them the effect of the results on the acquisition level of the four basic techniques of Alpine skiing has been explained and predicted. To calculate the effect of predictor variables on the criterion variables, the following were considered: multiple correlation, determination coefficient, level of statistical significance of regression coefficient and partial regression coefficient. According to the obtained results it was determined that the morphological characteristics and body composition indicators did not have a statistically significant effect on the process of adopting the four basic ski techniques. On the other hand, the functional and motor skills had a statistically significant influence on only one criterion variable: the parallel winding. An unverified statistical significance can be the result of some other anthropological factors that are not tested in this study.

\section{P33}

\section{ASSESSMENT OF SPORTS ACTIVITIES OF STUDENTS AT KING FAHD UNIVERSITY OF PETROLEUM AND MINERALS (KFUPM) Moataz Bellah Hassanain'}

'King Fahd University of Petroleum \& Minerals, Dhahran, Saudi Arabia Correspondence: Moataz Bellah Hassanain (mootazbh@kfupm.edu. sa)

The purpose of the study was to evaluate sports Activities of the students, university teams and team coaches at KFUPM. 786 subjects (710) Students - (590) from Undergraduate, (120) from prep Year, (67) from university team and (9) Team coaches. Three separate questionnaires administered to the students, university team and team coaches to elicit their opinion. The results yielded that the main obstacle for student's participation in sports activities is inadequate infra- structure, poor facilities and arrangements. The content of the training program for the difference sports preclude achieving good results and the need to increase the number of training modules and set up training camps at different times. The inter class tournament to be organized over the whole semester for the games and sports instead of knock- out Competition. Besides, a double knock - out system to be introduced to give equal chance to play again even if one loses in first round. In addition, a parallel league tournament for those not selected in the class team, for fairness in participation. The study revealed that the Physical Education Department can open up new additional courses for the elite sports persons to give them a chance to raise their academic performance through these courses. The university should publish a manual of sports Activities as a guide for sports Activities information to the students.

\section{P34}

\section{EFFECTS OF THE WORK OF THE ATHLETIC SCHOOL SECTIONS ON THE DEVELOPMENT OF RUNNING SPEEDS AT 100 AND 300 METERS}

Nikola Radulovic', llona Mihajlovic', Milan Solaja'

'University of Novi Sad, Faculty of Sport and Physical Education, Novi Sad, Serbia

Correspondence: Nikola Radulovic (nikolaradulovicfsfv@gmail.com)

The research was carried out with the aim to identify the effects of a twelve-week training (two 45-minute trainings a week, 24 trainings in total) on the increase of the running speed of young boys pioneers of the athletic school section. The total sample $(\mathrm{N}=31)$ was consisted of pupils of Primary School "Prva Vojvođanska brigada" from Novi Sad, aged 10-12 years (pupils of fifth and sixth grades), an experimental group $(\mathrm{N}=16)$ and pupils who do not do sports $(\mathrm{N}=15)$ coming from the same school and being of the same age. Two tests were applied, $100 \mathrm{~m}$ bullet-start running, and $300 \mathrm{~m}$ bullet-start 
running. To determine the effect of the experimental treatment, the univariate analysis of covariance (ANCOVA) was used. Statistically important differences were identified between the groups in the initial test, with the variables of $100 \mathrm{~m}$ bullet-start running $(\mathrm{p}=0.01)$ and $300 \mathrm{~m}$ bullet-start running $(\mathrm{p}=0.00)$ in favour of the experimental group. The univariate analysis of covariance identified statistically important positive effects of the treatment in the variable $100 \mathrm{~m}$ bullet-start running $(\mathrm{P}=0,00)$ and $300 \mathrm{~m}$ bullet-start running $(\mathrm{P}=0.02)$ in favour of the experimental group. The work of the athletic school section can bring to an increase in the running speed of young pioneer boys aged 10-12 years, as it has been confirmed by this research.

\section{P35}

\section{PHYSICAL ACTIVITY AND SPORTS PREFERENCE STRUCTURE} OF STUDENTS AT LOWER SECONDARY SCHOOLS

Martin Nosek', Jakub Wiedner', Ladislav Valter', Ivana Turkova'

${ }^{1} J a n$ Evangelista Purkyne University, Faculty of Education, Usti nad Labem, Czech Republic

Correspondence: Martin Nosek (martin.nosek@ujep.cz)

The research aimed to find out the amount of physical activity and sports preferences of students at lower secondary schools. A group of 130 students ( 33 female $12.4 \pm 0.4$ years old, 32 male $12.6 \pm 0.6$ years old, 37 female $15.2 \pm 0.3$ years old and 28 male $15.3 \pm 0.6$ years old) participated in this research. The data was collected and analysed through the NAR 2001 (National anthropological research) and INDARES (sports preference structure system) questionnaires. We determined a significant difference between boys and girls in the amount of the physical activity. Girls performed significantly less amount of physical activity than boys (girls 4,6 $\pm 1,6$ hours/week, boys 6,98 $\pm 0,2$ hours/week). Furthermore, we discovered that team sports are predominantly preferred among both, boys and girls. The research proved that the amount of physical activity decreases among the adolescents. The students prefer team sports over individual sports.

\section{P36}

\section{ASSOCIATION OF PHYSICAL ACTIVITY ON EXERCISE MOTIVATION AND BODY MASS INDEX AMONG UNIVERSITY STUDENTS}

Varghese C Antony', Kaukab Azeem ${ }^{1}$

${ }^{1}$ King Fahd University of Petroleum and Minerals, Physical Education Department, Dhahran, Saudi Arabia

Correspondence: Varghese C Antony (vcantony@kfupm.edu.sa)

Motivation as a psychological feature that arouses and energizes people to action towards physical activity and also makes them sustain to a physically active behavior. Motivation leads to increased participation in physical activity. The objective of this study was to compare and determine the association of physical activity to exercise motivation of university students at different levels of body mass index. A total of 140 undergraduate students Mage 19 \pm 0.70 years randomly categorized into underweight $<18.5 \mathrm{~kg} / \mathrm{m} 2$ [ $\mathrm{n}=37: 26.4 \%$ ]; normal-weight $18.5-24.9 \mathrm{~kg} / \mathrm{m} 2$ [ $\mathrm{n}=31: 22.1 \%]$; obese $=30.00 \mathrm{~kg} / \mathrm{m} 2[\mathrm{n}=37: 26.4 \%]$ and obese class III $=40.00 \mathrm{~kg} /$ $\mathrm{m} 2$ [n=35: 25\%]. Exercise motivation measured through BREQ-2. Analysis of variance revealed highly significant difference among BMI categories on intrinsic regulation $(\mathrm{p}=0.007<.05)$, identified regulation $(\mathrm{p}=0.006<.05)$. Obese class III students significantly differed on external regulation ( $\mathrm{p}=0.003)$ and introjected regulations $(p=0.011)$. The association of physical activity to exercise motivation revealed that students who engaged more time in physical activities had significantly higher scores on identified regulation ( $p$
$<0.05)$ and intrinsic regulation $(\mathrm{p}<0.01)$. It was concluded that university students in all weight category were internally motivated. The normal weight students had higher autonomous motivation than underweight and obese students. Obese class students exhibited higher degree of extrinsic motivation and amotivation. Students who engaged more time in physical activity had better intrinsic motivation.

\section{P37}

SCIENTIFIC SUBSTANTIATION OF THE PROGRAM OF MEDICAL REHABILITATION OF PATIENTS WITH CHRONIC HEART FAILURE BEFORE AND AFTER HEART TRANSPLANTATION IN ORDER TO PREVENT AND TREAT DISORDERS OF BONE TISSUE METABOLISM

Volha Sujayeva ${ }^{1}$

'Republican Scientific and Practical Center "Cardiology", Minsk, Republic of Belarus

Correspondence: Volha Sujayeva (sujayeva@bk.ru)

The purpose of this study is to develop a scientifically based safe effective medical rehabilitation program (RP) of patients with chronic heart failure (HF) before and after heart transplantation (HT) for the prevention and treatment of bone tissue metabolism disorders. The study included 103 recipients with HF at the age of 19 to 61 years (mean $45.2 \pm 12.1$ years). We performed 6-minute walk test for NYHA class of HF verification. Tolerance to physical loading (TPL) was estimated using spiro bicycle ergometry test (spiroBET) which was performed at Schiller AG AT-104 ErgoSpiro using Bruce protocol. RP consists of individualized according to TPL physical trainings, has started before HT and continued for one year after HT. We also performed dual-energy x-ray absorptiometry (DRA) for bone tissue metabolism estimation. There were no complications when using the developed program of RP, which required discontinuation. Under the influence of the developed PR method, the growth of TPL and aerobic physical capacity was observed according to spiroBET data. We also revealed reduction of bone mineral density loss according to DRA data. Developed RP helps to improve the functional status of the blood circulatory system and reduce the severity of metabolic disorders of bone tissue during the first year after HT.

\section{P38}

\section{THE EFFECT OF PHYSICAL EXERCISE ACCORDING TO THE PROGRAM FOR THE DEVELOPMENT OF FLEXIBILITY IN THE MOTORIC ABILITIES OF YOUNG SOCCER PLAYERS}

Sami Sermaxhaj', Fadil Luta', Jeton Havolli', Imran Isufi'

${ }^{1}$ Universi College, Faculty of Physical Culture Sport and Recreation, Prishtina, Kosovo, 2Institute of Sports Anthropology, Prishtina, Kosovo Correspondence: Sami Sermaxhaj (sermaxhajsami@live.com)

The aim of this research is to establish the effect of the flexibility exercise on the motoric abilities of young football players. The total number of sample was 68 young football players (beginners, pioneers and cadets) from Football Club "Ramiz Sadiku" from Prishtina. Samples of participants were divided into control and experimental group. The research implemented 14 variables of motoric abilities. The effect of physical exercise according to the program of flexibility on the motoric abilities of young football players was analyzed with univariate analysis. In the course of preparatory and competition period training program was conducted three times per week, for both of the groups. Only the manner of execution of experimental program was different (17 exercises of static stretching) for development of flexibility, which was conducted only with experimental group within the frame of increased duration by the 
end of the training. Acquired results show that conducted program for development of flexibility (exercised of static stretching) have statistically important effect only on flexibility variable "sit and reach test" with the experimental group of cadets, and with no statistically essential influence on motoric ability of beginners, pioneers and cadets. Therefore, it can be confirmed that static exercises have essential effect on improvement of flexibility of samples older than 15 years old, but without positive or negative effect on other variables of motoric ability of young players.

\section{P39}

\section{THROWING SPEED OF HANDBALL ACCORDING TO THE PLAYING POSITION}

Jeton Havolli', Primoz Pori², Sami Sermaxhaj', Bujar Begu'

'Universi College, Faculty of Physical Culture, Sport and Recreation, Prishtina, Kosovo, 'niversity of Ljubljana, Faculty of Sport, Ljubljana, Slovenia

Correspondence: Jeton Havolli (jeton.havolli@kolegjiuniversi.org)

The goal of this paper was to compare throwing speed of the ball without jumping, by playing position (backcourt, wing, pivot, and goalkeeper) and to compare throwing speed without jumping and throwing speed three steep jumping. In this research we measured 93 players from Kosovo's elite league $(22 \pm 4.70$ years old; training experience $8.30 \pm 4.29$ years; body height $183 \pm 7.83 \mathrm{~cm}$; weight 84 $\pm 13.74 \mathrm{~kg}$; Measurements were made with radar speed gun. The results obtained were analyzed through descriptive statistics for morphologic parameter, but throwing speed were analyzed by ANOVA and Post hoc test Kruskall-Wallis. Also difference between throwing speed without jumping and throwing with three steps jumping were analyzed by T-test. The overall average throwing speed was 85.67 $\mathrm{km}-\mathrm{h} 1$, measured by radar gun. The results proved that the differences in the throwing speed between the playing positions have relevant significance at level $(\mathrm{P}<0.01)$. Also the $\mathrm{T}$-test have showed differences in the level of significance $(\mathrm{P}<0.01)$ between throwing without jumping and throwing with three step jump, the difference is in favor of throwing without jumping. The differences in throwing speed have been established, according to the playing positions, we think the exercises should also be differentiated.

\section{P40}

\section{DIFFERENCES BETWEEN BASKETBALL PLAYERS OF SUPER AND UNIQUE LEAGUE IN SITUATIONAL AND MOTOR ABILITIES AT KOSOVO JUNIORS}

\section{Bujar Begu', Metin Dalip², Jeton Havolli', Sherif Ilazi'}

${ }^{1}$ Universi College, Prishtina, Kosovo, ${ }^{2}$ State University of Tetova, Faculty of Physical Education, Tetovo, North Macedonia

Correspondence: Bujar Begu (bujarbegu4@gmail.com)

The purpose of this research is to distinguish the differences between two leagues of Kosovo juniors in situational and motor abilities. In this research are tested 120 basketball players 18 ages of Super and Unique League with 60 players. Measuring instruments which are selected in this research are: 12 variables from motor basic and 5 from situational motor. Witty timer (Microgate) electronic sensors were used to obtain the most accurate speed and agility speed data. The T-test was used to determine the significant differences of leagues in one variable while the canonical discriminant analysis made the difference between the two leagues in the set of measured variables. With T-test is confirmed the difference in variable of explosive force of the hands at the level of significance $(\mathrm{P}<0.01)$. In the variables of repetitive force, agility and situational motor showed a level of significance $(\mathrm{P}<0.05)$. Based on the results of the discriminatory analysis shows statistically significant differences and is confirmed in favor of basketball players of super league.

\section{P41}

\section{BALANCE BEAM VS FLOOR: ANALYSIS OF DIFFERENCES IN DIFFICULTY VALUES OF ELEMENTS AMONG OLYMPIAN GYMNASTS}

Suncica Delas Kalinski', Igor Jelaska', Ana Kezic ${ }^{1}$

'University of Split, Faculty of Kinesiology, Split, Croatia

Correspondence: Suncica Delas Kalinski (suncica@kifst.hr)

To identify and explain differences in difficulty values of elements performed on balance beam and floor by elite gymnasts. From the judges records of 40 balance beam and 40 floor exercises, performed in the Apparatus Finals at last five Olympic Games (OG), using the $\varkappa 2$ test, the significance of differences in the frequencies of acrobatic and dance elements have been examined. Significant differences between the frequencies of acrobatic elements from the balance beam and floor have been identified: 1) at OG2004 and OG2008 among the D elements; 2) at OG2000 and OG2004 among the C elements; 3) on all analyzed OGs among the B elements; 4) in the period OG2004-OG2016 among the A elements. Furthermore, significant differences between the frequencies of dance elements have been found: 1) at OG2000, OG2012 and OG2016 among the D elements; 2) at OG2012 among the B elements; 3) at OG2000 among the A elements. A significant differences in the total number of acrobatic elements has been determined at OG2000, OG2004, and OG2012, while significant differences in the total number of dance elements have been determined at OG2016. Changes within the Codes of Points and of floor construction are probably responsible for determined dominance in a number and in difficulty values of performed acrobatic and dance elements on the floor compared to the balance beam.

\section{P42}

\section{THE INFLUENCE OF SOCIAL SUPPORT FROM PARENTS ON THE LEVEL OF PHYSICAL ACTIVITY IN ADOLESCENTS}

Armend Kastrati', Nazrije Gashi' ${ }^{2}$, Georgi Georgiev ${ }^{1}$

${ }^{1}$ Ss. Cyril and Methodius University, Faculty of Physical Education, Sport, and Health, Skopje, North Macedonia, ${ }^{2}$ University of Pristina "Hasan Pristina", Pristina, Kosovo

Correspondence: Armend Kastrati (armend.kastrati@uni-pr.edu)

Numerous scientific-expert studies emphasize the causal relationship between physical activity, physical fitness and the health of the individual. The basic goal of the study was to determine the influence of social support from parents on the level of physical activity in adolescents. The research was conducted on a sample of 974 randomly selected respondents from several faculties within the University "Hasan Prishtina" from Prishtina, Kosovo. The data was collected by using the method of structured survey questionnaire. The dependent variables analyzed social support for physical activity. On the basis of the IPAQ scoring recommendations and the physical activity classification criteria, the respondents are classified into three categories of physical activity. From the Mean Rank values of the items and the arithmetic means it is observable that the group of male respondents classified in the category of high physical activity shows higher values of these two items compared to the respondents classified in the moderate and low physical activity. The results of the research suggest the importance of the preparation of a national plan and program to promote physical activity in order to help young people change unhealthy lifestyle habits and increase physical activity, thereby to improve their health. 


\section{P43}

COMPARATIVE ANALYSIS OF PERIPHERAL BLOOD CIRCULATION INDICATORS IN STAYER SWIMMERS UNDER THE CONDITIONS OF THE HYPOXIC GAS ENVIRONMENT AND MIDDLE MOUNTAINS

Alexander Bolotin', Vladislav Bakayev ${ }^{1}$

${ }^{1}$ Peter the Great St. Petersburg Polytechnic University, Institute of Physical Education, Sports and Tourism, St. Petersburg, Russia

Correspondence: Alexander Bolotin (vlvbaks@gmail.com)

Competitive activity in the midlands places high demands on the state of the cardiovascular system of swimmers-styers. Modern strategies for the prevention of cardiovascular disorders in swimmers-styers for competitive activity in the midlands are based mainly on the assessment of systemic hemodynamics, excluding microcirculation. The aim of this study is to review the available literature on studies related to the state of the cardiovascular system of swimmers-styers under conditions of a hypoxic gas environment and midlands. Specific key words "exercise", "swimmers", "stayer", "hipoxia", "midlands", and "mountains" were used to search relevant electronic databases, such as PubMed, Web of Science and Scopus. The process of adaptation and change in functional indicators in swimmers-styers, characterizing their physical performance and the functioning of external respiration, occurs mainly due to the expansion of the range of application of training tools and methods. The endless expansion of the range of application of training tools and methods can lead to serious disturbances in the functioning of their cardiovascular system. Studies have shown that microcirculation in swimmers-styers during the load of different capacities in the midlands and hypoxic gas environment have a similar dynamics. This allows us to better diagnose the state of the cardiovascular system in athletes and more accurately assess the reaction of their body to a load of different power in the midlands.

\section{P44}

\section{BODY MASS INDEX MODULATES GRIP STRENGTH DEVELOPMENT}

Drazenka Macak', Danilo Radanovic', Nebojsa Trajkovic', Boris Popovic', Marko Gusic', Dejan Madic'

'University of Novi Sad, Faculty for Sport and Physical Education, Novi Sad, Serbia

\section{Correspondence: Drazenka Macak (macak.md@yahoo.com)}

Grip strength (GS) has been considered as a reliable indicator of general strength in healthy children. Notwithstanding, recent studies suggested the use of grip-to-BMI ratio, because GS approximation likely depends on BMI, and in this regard, the approximation of GS development trajectories. The study aimed to investigate the confounding effects of BMI on GS in the function of age in healthy children, and in turn potentially justify the grip-to-BMI ratio usefulness. This study included boys $(n=493)$ and girls $(n=664)$ aged from 4 to 7 years and measured their body height $(\mathrm{cm})$, weight $(\mathrm{kg})$, $\mathrm{BMI}(\mathrm{kg} / \mathrm{m} 2)$ and GS of dominant-hand using Bulb dynamometer (psi). The multilevel linear regression model tested the hypotheses. Mean-GS tended to linear increase with age $(-1.796+0.889$ AGE; $\mathrm{R}=.478 ; \mathrm{p}<.001 ; \mathrm{B}: 95 \% \mathrm{CI}$.795to.983). However, age influence was significantly lower when BMI was deemed in the model $(-4.772+0.841$ AGE $+0.2 \mathrm{BMI} ; \mathrm{R}=.543, \mathrm{p}<.001)$, because mean-GS tended to be higher with higher BMI $(-0.163+0.24 \mathrm{BMI}$; $\mathrm{R}=.303$; $\mathrm{p}<.001 ; \mathrm{B}: 95 \% \mathrm{CI}$.196to.284). When the general strength is assessed using grip strength in healthy children, the approximation of general strength and its trajectories should be made by cautions because many factors influence GS performance and development. A possible solution may be grip-to-BMI ratio, but according to previous studies, lean body mass, and fat mass also modulate GS across all ages.

\section{P45}

\section{SPORTS NUTRITION KNOWLEDGE EVALUATION CONDUCTED ON MONTENEGRIN FIRST LEAGUE OF MEN'S HANDBALL} PLAYERS

Erol Vrevic ${ }^{1}$, Mirko Mikic ${ }^{1}$, Miroslav Kezunovic ${ }^{1}$

'University of Montenegro, Faculty for Sport and Physical Education, Niksic, Montenegro

Correspondence: Erol Vrevic (vrevicerol@gmail.com)

Besides numerous factors that affect athletes' physical fitness and success in different sports branches, an adequate nutrition plays an important role. The aim of this research was evaluation of Montenegrin first league of men's handball knowledge of sports nutrition basics. This study encompassed 37 professional athletes in Montenegrin first league of men's handball, aged from 16 to 38 . The research was based on a closed-ended questionnaire consisting of 17 questions and designed per questionnaires already available in literature (Rosenbloon, Jonnalagadda \& Skinner, 2002; Zawila, Steib \& Hoogenboom, 2003; Juzwiak \& Ancona-Lopez, 2004; Ersoy, 2004; Ozdogan \& Ozcelik, 2011). As for descriptive statistical methods, the measures of central tendency, arithmetic mean and median were used. Statistical analysis was accomplished by SPSS 17.0 software. $48.33 \%$ of respondents answered the questions correctly, $39.90 \%$ answered wrongly, and $11.77 \%$ stated they did not know the answer to the question, implying thereby that $51.67 \%$ of respondents did not have a basic knowledge of sports nutrition. Based on acquired results, we can conclude that knowledge of sports nutrition is below the satisfactory level. It is necessary to work on continuous education on importance of proper sports nutrition and impact on health and performance of all athletes as well as to focus future researches in this area on a bigger sample of professional athletes so as to obtain more accurate results and provide recommendations in this area.

\section{P46}

\section{SPECIFICITY OF TESTING MAXIMAL OXYGEN CONSUMPTION IN KAYAKERS}

Djurdja Cvjetkovic', Sandra Veselinovic', Borislav Tapavicki', Andrea Zubnar', Otto Barak', Miodrag Drapsin ${ }^{1}$

'University of Novi Sad, Faculty of Medicine, Department of Physiology, Novi Sad, Serbia

Correspondence: Djurdja Cvjetkovic (dj.cvjetkovic@gmail.com)

The purpose of this study was to determine the difference in aerobic capacity in athletes (kayakers) and non-athletes, and also to determine the difference in aerobic capacity in kayakers comparing results on a bicycle ergometer and kayak ergometer. The study included 30 male subjects (15 kayakers and 15 non-athletes), for which the following parameters were measured: body weight, body height, Body Mass Index, body fat percentage, dynamometric measurements of muscle strength, spyrometric parameters and aerobic capacity. There was no statistically significant difference in body height, body weight and BMI between kayakers and non-athletes $(\mathrm{p}>0,05)$ and also no statistically significant difference in VO2 results for kayakers on bicycle and kayak ergometer $(p>0,05)$. There was a statistically significant difference in aerobic capacity on bicycle ergometers in advantage of kayakers $(p<0,01)$. The group of kayakers have showed statistically higher values of aerobic capacity in comparison to non-athletes on bicycle ergometer. In comparison of results on a bicycle and kayak ergometer for kayakers there was no statistically significant difference. 


\section{P47}

\section{ISOKINETIC STRENGTH IN FEMALE JUDOIST}

Nebojsa Janjic', Miodrag Drapsin ${ }^{1,2}$, Patrik Drid ${ }^{2}$, Andrea Zubnar', Tamara Gavrilovic ${ }^{3}$

${ }^{1}$ University of Novi Sad, Faculty of Medicine, Novi Sad, Serbia, ${ }^{2}$ University of Novi Sad, Faculty of Sports and Physical Education, Novi Sad, Serbia, ${ }^{3}$ Serbian Institute of Sport and Sports Medicine, Belgrade, Serbia Correspondence: Nebojsa Janjic (nebojsa.janjic@uns.ac.rs)

In competitions, judoists are classified into seven weight categories. The strength is influenced by judoist's weight, skill, training experience, muscle balance and neuromuscular synchronization. The purpose of the study was to compare absolute and normalized (weight-adjusted) muscle strength of judoists in different categories, and to examine if the training experience (in years) correlated with normalized strength and hamstrings-to-quadriceps (H:Q) ratio. The study included 58 female judoists in different categories. Muscle strength was assessed using the Humac norm isokinetic dynamometer. The highest concentric peak torque values $(\mathrm{Nm})$ of hamstrings and quadriceps were measured and analysed before and after normalization (Nmkg-1), while isokinetic $\mathrm{H}: \mathrm{Q}$ ratio was calculated for each leg. There were significant differences in absolute flexor and extensor strengths among different categories $(\mathrm{p}<0.01)$, which stemmed from differences between higher and lower categories (post-hoc analysis). Weight-normalized torque values did not differ significantly among categories $(\mathrm{p}>0.05)$. Normalized hamstring torque values correlated negatively with the training experience (right leg $\mathrm{r}=-0.33, \mathrm{p}=0.01$; left leg $\mathrm{r}=-0.51, \mathrm{p}<0.01$ ). There were negative correlations between training experience and $\mathrm{H}: \mathrm{Q}$ ratios of both legs (right leg $\mathrm{r}=-0.4, \mathrm{p}<0.01$; left leg $\mathrm{r}=-0.57, \mathrm{p}<0.01$ ). After weight-normalization, there was no difference in isokinetic strength among different categories of judoists. The length of training experience correlated negatively with hamstrings-to-quadriceps ratios.

\section{P48}

\section{UNDERWEIGHT: IMPACT OF COMPLEMENT PROTEIN WITH ADDITIONAL FOOD CONSUMPTION AND EXERCISE ON ACROMEGALY AND ENERGY VARIABLE AMONGST MALES} Ibrahim Syed ${ }^{1}$

${ }^{1}$ King Fahd University of Petroleum \& Minerals, Dhahran, Saudi Arabia Correspondence: Ibrahim Syed (sibrahim@kfupm.edu.sa)

To discern impact of complement protein with additional food consumption and exercise on acromegaly and energy variables among underweight males. 28 participants $19-25$ years, BMI $>18.5 \mathrm{~kg} / \mathrm{m} 2$ were allocated to complement protein cluster with additional food intake (AFI) and weight training (WT) $(\mathrm{C} 1 ; \mathrm{n}=10)$, WT with AFI $(C 2 ; n=8)$ control $(C 3 ; n=19)$. Training was for 8 weeks (2 D X 40 $\mathrm{M})$. C1 was administered with protein $2 / \mathrm{W}$ with WT for $40 \mathrm{M}$ and AFI. The tests were Body Mass, BMI, percentage Body Fat, FFM, 1 $\mathrm{R} \mathrm{M}$ in Leg press, Chest press and FI. ANOVA was applied for age, height and ER and repeated measures for other variables. Significance level was 0.05 . ANOVA revealed no significant change for age, height, BMI \& ER $(\mathrm{P}<0.05)$. When repeated measures were applied, there were significant main effect for group and time $(\mathrm{P}>$ 0.05 ) and interaction of group by time for FI and Body mass. FFM showed significant main effect of time and group $(\mathrm{P}>0.05)$ but no interaction of group by time. Percent Body fat showed no effect whereas Leg press and chest press showed significant main effect for time, group and interaction of group by time $(\mathrm{P}>0.002)$. The study indicated that underweight can improve their body mass and strength with above training protocol.
P49

\section{AMBIDEXTERITY DEVELOPMENT IN AESTHETIC SPORTS: RHYTHMIC GYMNASTICS VS. MAJORETTE DANCE}

Ana Kezic', Ina Lalic', Iva Macan'1

'University of Split, Faculty of Kinesiology, Split, Croatia

Correspondence: Ana Kezic (anakezic@kifst.hr)

The aesthetic appearance of the performance of elements in Rhythmic gymnastics and Majorette dance greatly depends on ambidexterity. The aim of this study was to determine which of the two sports better develops the relationship between the right and left side of the body (ambidexterity) using a 5-month standard training process. Sample consisted of 40 participants (7-12 years old); 20 of them were Rhythmic gymnastics practitioners and 20 were Majorette dance practitioners. New measuring instruments were designed to assess the degree of acquisition of specific techniques in one and in the other sport (10 for each sport). Three experienced judges made an assessment based on the videotaped material and coefficients of asymmetry were calculated. The obtained objectivity parameters have shown that the analyzed tests with the corresponding criteria are an objective measuring instrument and can be used to evaluate the ambidexterity in the beginner's exercise. The 5-month standard training process significantly improved the ambidexterity both in Rhythmic gymnastics and Majorette dance. Although numerically visible, the difference between training asymmetry coefficients of the two different sports were insignificant, both in the initial and final measurement point. Rhythmic gymnastics and Majorette dance trainings are largely aimed at the equal development of both sides of the body / arms / legs and in these terms have a positive effect on the overall health of the trainee.

\section{P50}

THE INFLUENCE OF BASIC - MOTOR POTENTIALS ON THE ACCURACY OF SPIKE IN ELITE FEMALE VOLLEYBALL PLAYERS Danilo Bojanic', Milovan Ljubojevic', Dragan Krivokapic', Pavle Malovic ${ }^{1}$, Ivan Vasiljevic ${ }^{1}$

'University of Montenegro, Faculty for Sport and Physical Education, Niksic, Montenegro

Correspondence: Danilo Bojanic (danilo.bo@ucg.ac.me)

Contemporary volleyball is showing increasing conditionality and an unbreakable connection to science, which allows new methods, principles of training, paths and regularities in the training process of volleyball players. Selected respondents represent the population of top volleyball players competing in the First Volleyball League of Montenegro. This research was conducted on a sample of 75 female volleyball respondents who were in the active training process: VBC "Buducnost" - Podgorica, VBC "Moraca" - Podgorica, VBC "Rudar" - Pljevlja, VBC "Galeb" - Bar, and VBC "Luka" - Bar. Situation-motor space was estimated with the variable spike with ball against the wall. Individual impact on a statistically significant level is reduced to four variables of basic motor potentials participating in the manifestation of spike with ball against the wall, namely two variables of the lower limb explosive power of the horizontal component: standing long jump and triple long jump, then one variable of repetitive power upper extremities: push ups, and one variable of segmental velocity: foot taping against the wall. The results confirm to what extent is actually important tested space of situational motor skills for effective realization of the actions and achievement of points in top volleyball.

\section{P51}

\section{QUADRICEPS MUSCLE OXYGENATION IN OLDER ATHLETES DURING A MAXIMAL EXERCISE TESTING}

Ignacio Martínez-González-Moro', María José Paredes-Ruiz', María Jó- 
dar-Reverte', Vicente Ferrer López ${ }^{1}$

'University of Murcia, University Institute for Researching in Aging, Research Group: Physical Exercise and Human Performance, Murcia, Spain

Correspondence: Ignacio Martinez-Gonzalez-Moro (ignaciomgm@ um.es)

Determining oxygen muscle saturation $(\mathrm{SmO} 2)$ using near-infrared spectroscopy (NIRS) is an emerging technique that is increasing its use in sports science. Therefore it is necessary to know its results in different population groups. We have analysed it in a group of Nordic Walking. Analysing the $\mathrm{SmO} 2$ values obtained at various times from an exercise testing in a group of athletes over 45.30 athletes (18 males), average age 51.3 years performed a maximal exercise testing in treadmill according to modified Bruce protocol in ramp. The electrocardiogram was continuously monitored. We measured VO2max (Metalyzer 3B) and calculated the ventilatory thresholds. In addition, we placed a Humon Hex device on the right thigh to measure quadriceps oxygenation. Heart rate, $\mathrm{VO} 2$ and $\mathrm{SmO} 2$ ratios are obtained based on the exercise intensity. $\mathrm{SmO} 2$ at start-up $63.3 \%$, standard deviation (SD) 9.2\%; $\mathrm{SmO} 2$ declined $61.8 \%$, SD $11.4 \%$; $\mathrm{SmO} 2$ in VO2max $57.4 \%$ SD $10.2 \%$ and SmO2 5 minutes after starting recovery $72.5 \% \mathrm{SD} 7.9 \%$. There is a relationship between ventilatory thresholds and variations in $\mathrm{SmO}$. There are no significant differences between the sexes. The minimum values of $\mathrm{SmO} 2$ are related to the $\mathrm{VO} 2$ max. During recovery there are higher values than at rest. The information obtained could be used to control and plan the training.

\section{P52}

\section{COMPARISON OF A HITTING RATE IN SOFTBALL WHILE USING THE VIRTUAL REALITY AND SOFTBALL PITCHING MACHINE}

Stefan Balko', Lenka Barcalova', Iva Balko', Josef Heidler', Jan Hnizdil ${ }^{1}$ ${ }^{1}$ Jan Evangelista Purkyne University, Faculty of Education, Usti nad Labem, Czech Republic

Correspondence: Stefan Balko (stefan.balko@ujep.cz)

The research aimed to determine, whether a hitting rate of a softball in virtual reality will correlate with the hitting rate while using a softball pitching machine. A group of 18 amateur students of Sports (12 males, 6 females, $22.7 \pm 1.9$ years old) participated in this research. The HTC Vive glasses and virtual softball simulator were used to analyze the hitting rate in virtual reality. There were two ways how to hit the virtual ball (with the knowledge of the trajectory of the ball - VR1 and without the knowledge of the trajectory of the ball - VR2). The pitching machine with the pitching speed of $25 \mathrm{~km} / \mathrm{h}(\mathrm{S} 25)$ and $40 \mathrm{~km} / \mathrm{h}$ (S40) was used to monitor the hitting rate in the real environment. Participants had 10 measured pitches in each condition. Simple (one stimulus) - and choice (two stimuli) - reaction times were also monitored in the present study. By Spearman's rank correlation coefficient, we determined relationship between VR1 vs. VR2 and S25 vs. S40. The hitting rate was not related to any of the four conditions with simple and choice reaction time. This issue may be further extended and used in problematics of the individual needs of the athletes.

\section{P53}

EFFECTS OF STATIC AND DYNAMIC STRETCHING EXERCISE ON UNILATERAL RATIO OF THIGH MUSCLES (HQR)

Nikolina Gerdijan', Dusan Peric ${ }^{2}$, Adriana Ljubojevic', Vladimir Jakovljevic ${ }^{1}$

'University of Banja Luka, Faculty of Physical Education and Sports, Banjaluka, Bosnia and Herzegovina, ${ }^{2}$ University of Educons, Faculty of
Sports and Tourism, Novi Sad, Serbia

Correspondence: Nikolina Gerdijan (ngerdijan@gmail.com)

The screened sample consisted of ten students (Faculty of PE and Sports). The aim of this study was to observe the influence of dynamic and static stretching on the unilateral ratio of extensor and flexor muscles around the knee joint in dominant leg. Actions were recorded on isokinetic dynamometer for both muscle groups, and the variable of hamstring/quadriceps ratio was singled out. Measurements were recorded at low $\left(60^{\circ} / \mathrm{s}\right)$ and high $(240 \%)$ contraction velocities. The same measurement protocols were applied to the three selected experimental situations: without pre-exercise stretching, after dynamic stretching, and after static stretching. The obtained results of statistical analysis showed that hamstring/ quadriceps ratio (HQR) significantly changed under the influence of both types of stretching at low contraction velocity $(60 \%)$. HQR improved (values approach the expected ones) when dynamic and static stretching exercises were followed by low muscle contraction velocities. In case of high contraction velocity $(240 \%)$, deficit of particular muscle group (established at initial testing) increased relative to the initial values. The results thus indicated that static and dynamic stretching had positive acute effects when performed prior to low velocity isokinetic strains in thigh muscles. In case of muscle deficit occurrence in one or both muscle groups, the intermuscular coordination should be improved prior to any activities with high contraction velocity, i.e. the HQR values should approach the expected values.

\section{P54}

\section{ASSESSMENT OF BODY FAT WITH ANTHROPOMETRIC METHODS AND BIOELECTRIC IMPEDANCE IN PROFESSIONAL ACROBATIC SKYDIVERS}

Vicente Ferrer-Lopez', Ignacio Martínez-González-Moro', María-José Paredes-Ruiz', María Jódar-Reverte', José-Luis Lomas-Albaladejo² 'University of Murcia, University Institute for Researching in Aging, Research Group: Physical Exercise and Human Performance, Murcia, Spain, ${ }^{2}$ Acrobatic Parachutist Patrol of Air Force, Murcia, Spain Correspondence: Vicente Ferrer-Lopez (ferrerlopezv@gmail.com)

The Acrobatic Patrol Parachutist of the Air Force (PAPEA) of Spain is an international elite team in sportive parachuting. Assessing their body composition is important for planning their workout, but there are several ways to measure it. To assess the body fat measurement by anthropometric equations and bioelectrical impedance (BI) methods of PAPEA. Cross sectional study. The 11 members of the masculine team of the PAPEA have participated; means age: $33.7 \pm 4.3$ years; experience $3225 \pm 3000,8$ jumps and $6,9 \pm 5,7$ years in the team. Device OMRON BF-306 has been used to quantify the fat mass. We have calculated the body fat percentage, anthropometrically (ABF), from the equation of Yuhasz and the relative fat mass (RFM) obtained by the equation of Woolcott and Bergman for men [ $64 \mathrm{x}$ (20 $\mathrm{s}$ (height/waist)]. The percentage of body fat average with bioelectrical impedance is $20.4 \pm 3.6 \%$. Anthropometrically, BFA is $12.2 \pm 2.7 \%$, $\mathrm{RFM}=20,9 \pm 3,4 \%$. The correlation coefficient between $\mathrm{BI}$ and $\mathrm{ABF}$ is $r=0,759$; between $B I$ and RFM is $r=0,734$ and between $A B F$ and RFM is $0,678(p<0,05)$. The values of three measurements are different but with a relation among them. Measurements are not interchangeable but have a good correlation.

\section{P55}

\section{RELATIONSHIP BETWEEN MUSCLE STRENGTH OF KNEE STABILIZERS AND QUALITY OF VERTICAL JUMP} PERFORMANCE IN PHYSICALLY ACTIVE FEMALE POPULATION Izet Bajramovic', Denis Causevic', Ivor Doder', Erol Kovacevic', Haris 
Alic', Slavenko Likic

'University of Sarajevo, Faculty of Sport and Physical Education, Sarajevo, Bosnia and Herzegovina

Correspondence: Izet Bajramovic (izet.bajramovic@fasto.unsa.ba)

It is known from practice that for the injuries may be different: insufficient healing, agonist and antagonist muscle imbalance, weakness of the knee stabilizers, or a poorly designed training program. The aim of this study was to determine the relationship between isokinetic parameters of knee joint muscle strength with the efficiency of performing vertical jumps from the site. The sample represents a group of 16 healthy and physically active woman (age = $31,04 \pm 3,71)$. An isokinetic dynamometer was used to determine the muscular strength of the knee joint, while the two foot vertical jump performance was measured using the Opto Jump System. Pearson's correlation coefficient was used to determine the correlation and the magnitude of the correlation was interpreted as follow: small correlation ( $\mathrm{r}=0,10$ to 0,29$)$; middle ( $\mathrm{r}=0,30$ to 0,49$)$; high ( $\mathrm{r}=0,50$ to 1,0 ). The obtained results indicate high correlations of the peak torque of the dominant and non-dominant leg, both in flexion and extension with counter movement free arms jump (from .511 $\mathrm{p}<.05$ to $.594 \mathrm{p}<.05$ ) and the total work of dominant and non-dominant leg in flexion and extension with counter movement jump with free arms (from $.512 \mathrm{p}<.05$ to $.5 .31 \mathrm{p}<.05$ ). Given that these are physically active women, we can assume that their counter movement free arm jump type was the most natural form of expressing their explosive potential.

\section{P56}

PROFILE OF TOP CROATIAN FEMALE CADET HANDBALL PLAYERS BY PLAYING POSITION

Marijana Cavala', Nenad Rogulj', Josefina Đuzel ${ }^{1}$

'University of Split, Faculty of Kinesiology, Split, Croatia

Correspondence: Marijana Cavala (mcavala@kifst.hr)

The research was conducted with the purpose of establishing differences in motor abilities between different groups of handball players divided by their playing positions. The research was conducted on 70 handball players who were grouped according to their playing positions. Thirteen motor tests were measured. In the basic motor domain, the differences are mostly expressed between goalkeepers and wing players in flexibility, which is more developed in goalkeepers, and coordination, which is more developed in wing players. Further on, the variable to assess explosive power of sprint type is dominated by players in wing positions. It is well-known the main tasks of the players in wing positions are quick turnovers from the defence to attack phase and run over of the opponents' defences, so we may assume this is the reason their results in 20-metres sprint testing were the best. Unlike them, goalkeepers have completely different tasks in the game. The agility tests are dominated by outer players, followed by wing players, which is caused by the demands and the roles of these playing positions, overflowed with maximally fast changes of direction course in difficult dynamic conditions and the abilities to quickly restructure movement contents, therefore the obtained results were expected as well. The findings suggest that a coaches should apply specific training programs for each playing position.

\section{P57}

\section{EFFECTS OF 4 WEEKS FIFA11+ WARM-UP PROGRAM ON PHYSICAL PERFORMANCE IN U12 SOCCER PLAYERS}

Marko Gusic', Aleksandar Kosic', Slavko Molnar', Jovan Vukovic', Slobodan Andrasic ${ }^{2}$

'University of Novi Sad, Faculty of Sport and Physical Education, Novi Sad, Serbia, ${ }^{2}$ University of Novi Sad, Faculty of Economics, Novi Sad,
Serbia

Correspondence: Marko Gusic (gusicmarko@yahoo.com)

Specific warm-up program designed by the FIFA Medical and Research Centre (F-MARC) is mainly used to decrease injury risk for soccer players, targeting muscular strength, body kinaesthetic awareness and neuromuscular control during static/dynamic movements. Study reports using FIFA11+ were mostly focused in injury reduction effectiveness but reports concerning effects of physical performance are limited. The goal of this study was to examine effects of 4 weeks FIFA11+ program on physical performance in U12 soccer players. Sample was conducted of 36 U12 male soccer players randomly divided into experimental and control groups. Sit\&Reach, $20 \mathrm{~m}$ sprint, Long jump, Illinois agility test, Repeated sprint ability test (20+20 shuttle run) and 30-15 Intermittent Fitness Test were used for physical performance evaluation. Differences between pre and post tests were analysed using ANCOVA. Significant differences were found in Sit\&Reach $(\mathrm{p}=.046)$, Long jump $(\mathrm{p}=.000)$ and Ilinois agility test $(\mathrm{p}=.046)$. Results showed no significant improvements in sprint, anaerobic and aerobic endurance capacity. The findings suggest that 4 weeks of FIFA11+ warm-up program has significant role in terms of improvement of physical capacity and performance in U12 soccer players, compared to traditional warm-up protocol.

\section{P58}

\section{MEASURING PRE-PLANNED AND NON-PLANNED AGILITY IN FUTSAL; APPLICABILITY OF THE NEWLY DESIGNED SPORT SPECIFIC PROTOCOLS}

Damir Sekulic', Ivan Zeljko², Barbara Gilic ${ }^{1}$

'University of Split, Split, Croatia, ${ }^{2}$ University of Mostar, Mostar, Bosnia and Herzegovina

Correspondence: Damir Sekulic (dado@kifst.hr)

Agility components, including non-planned-agility (NPA), and pre-planned agility (PPA) are important determinants of success in futsal. This study evaluated applicability of the newly designed futsal specific agility-tests in evaluating differences between performance levels in top-level futsal players. The sample comprised male futsal players ( $n=30$; age: $23 \pm 2.1$ years), separated according to their performance level in starters and non-starters. Variables included body mass and height, sprint-10 meters, countermovement jump, and newly developed tests of PPA and NPA. The reliability of newly developed tests was evidenced by Cronbach Alpha, and analysis of variance (ANOVA). In order to identify applicability of the tests in differentiating performance levels, $t$-test for independent samples was calculated between performance-groups. Cronbach-alpha indicated appropriate reliability of the PPA and NPA (Cronback Alpha: 0.81 and 0.76 , respectively), with no significant ANOVA differences among three testing trials (F-test: 2.31 and 1.11; $p>0.05$, for PPA and NPA, respectively). Performance groups significantly differed in PPA indicating superior performance among starters ( $\mathrm{t}$-test: 2.31, $\mathrm{p}<0.05)$. No significant between-group differences were found for remaining variables. Results indicated good reliability of the newly developed tests, with appropriate reliability of the PPA in distinguishing differences between performance groups in futsal. Further analyses are needed in females and younger players.

\section{P59}

\section{SPORT'S JOURNALISM IN BUILDING OF MONTENEGRO AS BRAND}

Veselin Drljević ${ }^{1}$

'Daily Journal DAN, Podgorica, Montenegro

Correspondence: Veselin Drljevic (veselindrljevic@t-com.me)

The paper present theoretical and practical aspects of sport's jour- 
nalism in building of Montenegro as brand destination. The goal is to develop Montenegro as sport's country, as country with sport's tradition and sport's nation, open for cosmopolitan sport's approach. The goal of the paper is to analyse both theoretical and practical aspects of daily sports journalism in development of Montenegro as sport's country. Target groups for empirical research was tourists, sport's clubs, sports events, sport's players, sport's organizations, sport's institutions and sport's educational institutions. The questionnaire have made on 500 people from all target groups. The data were analysed by special method of research, Johariev window, which gives opportunities to saw strength and weaknesses of strategies of brand management in Montenegro. The theoretical improvement of daily sports journalism in development of Montenegro as sport's country brand is based on new concept of strategic management approach. The results of empirical research have shown that strategic marketing planning of Montenegro as sport brad country have to be based on sports events, daily sports journalism and improving of sports spirit as brand characteristic. The empirical research of target groups present that daily journalism has impact in development of cosmopolitan spirit in sports events, as well as, Montenegro as sport country brand. The research results showed positive perspective that is useful for further strategic planning of Montenegro as sports country brand.

\section{P60}

COMPARATIVE ANALYSIS OF MOTOR ABILITIES OF ATHLETES OF DIFFERENT SPORT DIRECTIONS

Marina Vukotic ${ }^{1}$

'University of Montenegro, Faculty for Sport and Physical Education, Niksic, Montenegro

Correspondence: Marina Vukotic (marina.vukotic82@gmail.com)

The main goal of this research is to determine if there are statistically significant differences in the motor and functional abilities in basketball, football and volleyball players, or to determine differences in quantitative and qualitative changes in motor and functional abilities in these athletes. In accordance with the set up goal, a transversal study was conducted in which the empirical and statistical methods were applied, and the research technique is testing. The research was conducted on a sample of 75 subjects, a male sex divided into three subsamples, with an age range of 13 to 15 years. The selected variables in this study hypothetically cover the space of motor skills (9). An analysis of ANOVA variance, multivariate analysis of MANOVA variance, LSD-test between all combinations and discriminatory analysis between all three subsamples was used to determine differences within groups. A statistically significant canonical discriminatory factor with a characteristic root of 0.24 . According to the values of the centroid of the groups, a statistically significant difference within the groups was observed on the discriminatory function. Based on the obtained results, it can be concluded that there are statistically significant differences in motor abilities in athletes. Trainers can use this research in order to achieve better results with athletes.

\section{P61}

\section{WHAT TYPES OF TRAINING ARE APPLIED TO IMPROVE VERTICAL JUMP? A SYSTEMATIC REVIEW}

Dusko Cvijovic', Suncica Pocek', Nebojsa Maksimovic ${ }^{1}$

${ }^{1}$ University of Novi Sad, Faculty of Sport and Physical Education, Novi Sad, Serbia

Correspondence: Dusko Cvijovic (dcvijovic@uns.ac.rs)

Leg muscle strength, and in particular vertical jump performance, are considered critical elements for successful sports performance, as well as daily activities. In order to achieve a high level of quality in volleyball, players are required not only to master task-specific techniques and tactics, but also to demonstrate good jumping ability. The aim of this study is to review the available literature on research pertaining to the types of training applied for improvement of vertical jump, possible differences and changes in vertical jump performance. Specific key words "vertical jump", "conditioning treatment", "plyometric training", "volleyball", and "practical recommendation" were used to search relevant electronic databases, such as PubMed, Web of Science and Scopus. The research was conducted according to PRISMA guidelines. Much research is focused on the development of vertical jump performance. Although various training methods, including strength training with resistance, explosive type training, electrostimulation training and vibration training, have been effectively used to improve vertical jump performance, most researchers agree that plyometric training is the most common method of choice to improve vertical jump ability and power of leg muscles. From the perspective of these results, plyometric training could also be recommended for healthy individuals who aim to improve not only their vertical jumping ability but also other sports performance.

\section{P62}

\section{PERILUNATE AND LUNATE DISLOCATIONS IN SPORTS}

Miodrag Vranjes ${ }^{1,2}$, Nikola Vukosav', Milan Majkic ${ }^{2}$

${ }^{1}$ Clinical Center of Vojvodina, Department of Orthopedic Surgery and Traumatology, Novi Sad, Serbia, ${ }^{2}$ University of Novi Sad, Faculty of Medicine, Novi Sad, Serbia

Correspondence: Miodrag Vranjes (miodragvranjes@gmail.com)

Injuries around the lunate bone are rare. Lunate and perilunate injuries are a continuum of ligamentar ruptures according to the mayfield classification. The aim of this study is to evaluate the clinical outcomes in sports related perilunate end lunate dislocations. A total of 9 patients with perilunate and lunate luxations were prospectively evaluated. The location of the scapholunate ligament tear, the presence of osteochondral fragments and of the dorsal radiocarpal ligament avulsions were recorded intraoperatively. Final clinical outcomes were evaluated in 9 patients with a minimum of 6 months of follow-up. Intraoperative examination of the 9 cases with operative treatment showed the volar carpal ligament tear to be present in all injuries. Complete avulsion of the dorsal extrinsic radiocarpal ligaments was found in $89 \%$ of cases. The scapholunate ligament was torn in 7 cases. Osteochondral fragments were found volarly one patient. Treatment of perilunate and lunate dislocations with a combined volar and dorsal approach results in reasonable and clinical results. The incidence of associated injuries with these carpal dislocations is high.

\section{Workshop presentations}

W1

\section{THEORY AND PRACTICE OF BOCCE SPORT: BOCCE AS A NEWLY TRENDING SPORT; POSSIBILITIES AND CHALLENGES Mutlu Turkmen ${ }^{1}$ \\ ${ }^{1}$ International Bocce Confederation (CBI), Ankara, Turkey \\ Correspondence: Mutlu Turkmen (turkmenm@yahoo.com)}

Millions of people on all continents are now practising Bocce and its disciplines either as a recreational game or competitive sports. With its governing body which was recognized by the International Olympic Committee since 1986, the sport had managed to be inside most of the world level muti-sports events. Finally, Bocce followed 
a very strong bid to be included in 2024 Summer Olympic Games since 2015 and had a very big chance when Paris was announced officially to be the host of 2024. However, International Olympic Committee and Paris 2024 Organizing Committee haven't followed a very transparent process and declared the Break Dancing to be included in the games with three other sports which had already been added to Tokyo 2020; Sport Climbing, Surfing, and Skateboarding. Now Bocce is trying to find new directions and gain more visibility in global sport movement through new partnerships. This theoretical and practical workshop aims to present both conceptual and definitive background of the sport and new strategies of the International Bocce Confederation.

\section{Publisher's Note:}

Montenegrin Sports Academy remains neutral with regard to jurisdictional claims in published maps and institutional affiliations. 